\title{
Composition and Chemistry of the Neutral Atmosphere of Venus
}

\author{
Emmanuel Marcq ${ }^{1}$ (D) - Franklin P. Mills ${ }^{2}$. \\ Christopher D. Parkinson ${ }^{3}$. Ann Carine Vandaele ${ }^{4}$
}

\author{
E. Marcq \\ emmanuel.marcq@1atmos.ipsl.fr \\ 1 LATMOS/Université de Versailles Saint-Quentin, Guyancourt, France \\ 2 Australian National University, Canberra, Australia \\ 3 University of Michigan, Ann Arbor, USA \\ 4 Belgian Institute for Space Aeronomy, Uccle, Belgium
}

\begin{abstract}
This paper deals with the composition and chemical processes occurring in the neutral atmosphere of Venus. Since the last synthesis, observers as well as modellers have emphasised the spatial and temporal variability of minor species, going beyond a static and uniform picture that may have prevailed in the past. The outline of this paper acknowledges this situation and follows closely the different dimensions along which variability in composition can be observed: vertical, latitudinal, longitudinal, temporal. The strong differences between the atmosphere below and above the cloud layers also dictate the structure of this paper. Observational constraints, obtained from both Earth and Venus Express, as well as 1D, 2D and 3D models results obtained since 1997 are also extensively referred and commented by the authors. An non-exhaustive list of topics included follows: modelled and observed latitudinal and vertical profiles of $\mathrm{CO}$ and OCS below the clouds of Venus; vertical profiles of $\mathrm{CO}$ and $\mathrm{SO}_{2}$ above the clouds as observed by solar occultation and modelled; temporal and spatial variability of sulphur oxides above the clouds. As a conclusion, open questions and topics of interest for further studies are discussed.
\end{abstract}

Keywords Venus atmosphere $\cdot$ Atmospheric composition $\cdot$ Spectroscopy $\cdot$ Chemical modeling 


\section{Introduction}

Venus has the largest gaseous inventory among the terrestrial planets-only the Earth surpasses them all, but most of its volatiles are condensed in its oceans. Among them, carbon dioxide $(96.5 \%)$ and nitrogen $(3.5 \%)$ make up about $99.9 \%$ of the total. This paper deals with the trace species composition and chemistry at work, mostly in the lowermost $100 \mathrm{~km}$ of Venus' atmosphere, at pressures higher than 0.1 mbar. It does not cover extensively processes that involve charged particles or airglow that become important above about $90 \mathrm{~km}$ in altitude, which are treated instead in Gérard et al. (2017). This most recent attempt to summarise all the known facts about Venus' atmospheric composition and chemistry is not the first one; the interested reader is advised to consult von Zahn et al. (1983) and Esposito et al. (1997) for earlier results and syntheses published before 1997, as well as other review papers (de Bergh et al. 2006; Bézard and de Bergh 2007; Mills et al. 2007) for results published between 1997 and 2006. Older results will sometimes be quoted for context, but we shall focus here mostly on the advances obtained during the last fifteen years, mostly thanks to the Venus Express (2006-2014) mission. Our focus is on presenting an overview of published results with some synthesis. We will identify apparent conflicts or contradictions but will not attempt to resolve them. That task is left to ongoing efforts to develop reference models (e.g. Vandaele et al. 2017).

The Venus International Reference Atmosphere (VIRA) was compiled by Kliore et al. (1985), and presents a synthesis of the knowledge of the neutral atmosphere and the ionosphere of the planet. This was the first attempt to summarise all that was known about Venus, providing through tables and averages, a common standard reference. Chapter $\mathrm{V}$ of the VIRA compilation gave an overview of the known composition of the Venus atmosphere below $100 \mathrm{~km}$ altitude (von Zahn and Moroz 1985). Since then many missions have yielded new and valuable information. A first attempt to update the VIRA model was put forward by Moroz and Zasova (1997). They considered new data provided by the Vega 1 and 2 UV spectrometers (Linkin et al. 1986; Bertaux et al. 1996), Venera 15 and 16 infrared spectrometers (Oertel et al. 1985; Moroz et al. 1986; Zasova 1995; Zasova et al. 1996) and radio occultation experiment (Iakovlev et al. 1991), as well as NIMS observations obtained during the Galileo fly-by of Venus in 1990 (Collard et al. 1993; Carlson et al. 1993; Grinspoon 1993; Roos et al. 1993; Taylor 1995). They also included re-analysis of previous data (from previous Venera missions and Pioneer Venus) and some ground-based observations for trace gases abundances (Bézard et al. 1990; Pollack et al. 1993; de Bergh et al. 1995). However most of the efforts on improving the VIRA model were concentrated on updating the temperature and structure data (Zasova et al. 2006). Except for an updated version of the initial Table 5-1 of Seiff et al. (1985) given in Moroz and Zasova (1997), no similar update was ever done for the composition of the Venusian atmosphere.

Furthermore, most of these early efforts were focused on reporting and standardising the mean state of the Venusian atmosphere, considered as a unidimensional atmospheric medium. Such a choice made sense when the available data set was quite modest, and is scientifically validated a posteriori by the fact that horizontal contrasts are in fact very small, at least in the lower atmosphere, compared to other terrestrial atmospheres such as Earth's and Mars'. The absence of any noticeable seasonal cycle also contributed to this static vision of the Venusian atmosphere. Nevertheless, the emphasis moved slowly, but steadily towards a more dynamic vision of Venus' atmospheric composition. Results from the Pioneer Venus mission, supplemented by Earth-based observations, evidenced noticeable variability in the atmospheric composition in the photochemical region located above the clouds. Horizontal 
variability became also easier to study, thanks to technological progress in both spectrometers and spectral imagers technology as well as in computers used in spectroscopic signal processing.

This paper therefore wants to acknowledge this shift towards the study of Venus' atmospheric composition variability on all four possible dimensions: temporal, latitudinal, longitudinal or solar local time, and vertical. The chosen outline reflects this line of thought: in Sect. 2, we shall discuss the vertical profiles of minor species; in Sect. 3, horizontal variability of minor species (with respect to latitude or local solar time) will be detailed; in Sect. 4, temporal variations will be dealt with, with a special focus on sulphur-bearing species such as $\mathrm{SO}_{2}$ and $\mathrm{SO}$ that exhibit the most spectacular variability. Results will be synthesised in form of a synthetic table in Sect. 5. Finally, we shall open the discussion in Sect. 6, where we detail what are, in our opinion, the most striking issues and/or open questions whose answers are necessary for further progress.

\section{Vertical Profiles of Minor Species}

The chemistry in Venus' neutral atmosphere ranges from photochemistry to thermodynamic equilibrium chemistry. The former dominates within and above the global cloud layers while the latter is believed to prevail near the surface. This transition is driven both by the increase in atmospheric temperature as one goes deeper in the atmosphere and by the increasing scarcity of photons, particularly higher energy UV photons. However, work by Fegley et al. (1997) suggests gas-phase thermodynamic equilibrium may be reached only, if at all, below $0.7 \mathrm{~km}(730 \mathrm{~K})$ and suggests the remainder of the lower atmosphere is more oxidising than would be predicted on the basis of thermodynamical equilibrium.

An example of the evolving state of knowledge about the chemistry and composition of Venus' atmosphere is that early work (Lewis 1970; Prinn 1975, 1978, 1979) suggested OCS was the dominant form of sulphur, while observations (Bézard and de Bergh 2007; Marcq et al. 2008) and modern thermochemical calculations (Fegley et al. 1997) indicate $\mathrm{SO}_{2}$ is dominant, at least for temperatures below $730 \mathrm{~K}$. Likewise, the three sulphur chemical cycles (fast atmospheric, slow atmospheric, and geologic) that summarised earlier work on Venus' sulphur chemistry (von Zahn et al. 1983; Prinn 1985) have been revised (Krasnopolsky 2007, 2013b, 2016; Mills et al. 2007; Yung et al. 2009).

The original fast atmospheric sulphur cycle (von Zahn et al. 1983; Prinn 1985) comprised, within and above the clouds, oxidation of $\mathrm{SO}_{2}$ using $\mathrm{O}$ derived from photolysis of $\mathrm{CO}_{2}$ followed by reaction with $\mathrm{H}_{2} \mathrm{O}$ to form $\mathrm{H}_{2} \mathrm{SO}_{4}$. This was balanced, within and below the clouds, by decomposition of $\mathrm{H}_{2} \mathrm{SO}_{4}$ and reduction of $\mathrm{SO}_{3}$ to produce $\mathrm{SO}_{2}$ and oxidise $\mathrm{CO}$. A new variation includes oxidation of $\mathrm{OCS}$ to $\mathrm{SO}_{3}$ using $\mathrm{O}$ derived from photolysis of $\mathrm{CO}_{2}$ within and above the clouds (Krasnopolsky 2013b). The $\mathrm{O}$ needed to oxidise $\mathrm{SO}_{2}$ also can be obtained via disproportionation of $\mathrm{SO}_{2}$ within and above the clouds to form $\mathrm{S}_{x}$ and $\mathrm{SO}_{3}$ (Mills and Allen 2007). This is balanced below the clouds by conversion of $\mathrm{SO}_{3}, \mathrm{CO}$, and $\mathrm{S}_{x}$ to $\mathrm{SO}_{2}, \mathrm{CO}_{2}$, and OCS. Recent work (Parkinson et al. 2015a) suggests a bifurcation surface exists in the $\mathrm{SO}_{2}-\mathrm{H}_{2} \mathrm{O}-\mathrm{H}_{2} \mathrm{SO}_{4}$ system so that the composition of air convected upward through the cloud layers may change dramatically depending on the local abundances of $\mathrm{SO}_{2}$ and $\mathrm{H}_{2} \mathrm{O}$.

The original slow atmospheric sulphur cycle (von Zahn et al. 1983; Prinn 1985) comprised, within and above the clouds, oxidation of $\mathrm{H}_{2}$ and $\mathrm{OCS}$ using $\mathrm{O}$ from $\mathrm{CO}_{2}$ photolysis to produce $\mathrm{SO}_{3}$ and $\mathrm{H}_{2} \mathrm{SO}_{4}$ in parallel with production of $\mathrm{S}_{x}$ from $\mathrm{H}_{2} \mathrm{~S}$ and OCS. This was balanced below the clouds by reduction of $\mathrm{SO}_{3}$ and $\mathrm{H}_{2} \mathrm{SO}_{4}$ to oxidise $\mathrm{CO}$ and produce $\mathrm{H}_{2} \mathrm{~S}$ 
and OCS in parallel with net reactions of $\mathrm{S}_{x}$ with $\mathrm{H}_{2}$ and CO to form $\mathrm{H}_{2} \mathrm{~S}$ and OCS. A more recent version comprises cycling within the $\mathrm{S}_{x}$ + OCS reduced sulphur system (Krasnopolsky 2013b, 2016). This version would occur almost entirely within the lower atmosphere but includes some leakage of $S_{x}+$ OCS into the upper atmosphere and some reduction in the lower atmosphere of $\mathrm{SO}_{3}$ that was produced in the upper atmosphere (Krasnopolsky 2013b, 2016).

Observations and model interpretations of the vertical profiles of species in the lower atmosphere and clouds (Sect. 2.1) and above the cloud top (Sect. 2.3) are presented in the remainder of this section. Since they straddle the cloud layer boundary, observations and modelling of nitrogen oxides and lightning are discussed separately in Sect. 2.2. Updates to the geologic sulphur cycle are briefly summarised in Sect. 6.4.

\subsection{Lower Atmosphere and Clouds $(0-70 \mathrm{~km})$}

Besides in-situ measurements obtained by descent probes and already extensively discussed by von Zahn et al. (1983) and Esposito et al. (1997), most of our knowledge about the vertical profiles of minor species in Venus' atmosphere below the clouds comes from the serendipitous discovery (Allen and Crawford 1984) of several near-infrared spectral windows, that enable some thermal radiation to reach outer space after being (almost) conservatively scattered in the optically thick cloud layers. However, since these spectral windows are located between 1.02 and $2.5 \mu \mathrm{m}$, the analysis of this thermal radiation is possible only on the night side since solar radiation, wherever present, dominates in these short wavelengths by a factor of at least $10^{4}$. A first review of these spectral windows and the compositional information that they carry can be found in Taylor et al. (1997). Here we shall focus on newer constraints, obtained both from Venus Express instruments (mostly SPICAV-IR and VIRTIS) and ground-based observations.

\subsubsection{Water Vapour}

$\mathrm{H}_{2} \mathrm{O}$ spectral lines feature in most of these NIR windows probing at different altitudes, so that its vertical profile is probably the best constrained of most minor species below the clouds. However, the still poorly known $\mathrm{CO}_{2}$ continuum opacity makes horizontal variations (or lack thereof) of water better constrained than its horizontally-averaged value. Numerical values are given in Table 1 below.

With this caveat in mind, measurements in the 30-40 km region near $2.4 \mu \mathrm{m}$ performed since 1997 mostly confirm previous determinations: ground-based IRTF/SpeX observations from Marcq et al. (2006); more recent (Arney et al. 2014) data from Apache Point Observatory/TripleSpec; space-borne observations near $2.4 \mu \mathrm{m}$ conducted using Venus Express/VIRTIS by Marcq et al. (2008) using the -H channel, and Tsang et al. (2010) using the -M channel. Tsang et al. (2010) found that the horizontal variations were correlated with lower cloud opacity. However, they also pointed out the fact that these observations are compatible with a constant $\mathrm{H}_{2} \mathrm{O}$ mixing ratio of about $30 \mathrm{ppmv}$, provided the lower cloud opacity variations correlate with changes of their refractive index instead of $\mathrm{H}_{2} \mathrm{O}$ vapor mixing ratio.

At lower altitudes between 15 and $30 \mathrm{~km}$, measurements in the $1.74 \mu \mathrm{m}$ window have also been performed by Arney et al. (2014). Measurements in the $1.18 \mu \mathrm{m}$ window were performed by both VIRTIS and SPICAV on-board Venus Express. They probed the lowermost atmosphere, between the surface and an altitude of $15 \mathrm{~km}$. The first VIRTIS-M measurements from Bézard et al. (2009) found a somewhat larger value, with an upper limit of $1.5 \%$ on any horizontal variations. However, using data at a higher spectral resolution 
Table 1 Summary of Venus Express-era NIR measurements of tropospheric $\mathrm{H}_{2} \mathrm{O}$ on the night side of Venus

\begin{tabular}{|c|c|c|c|c|}
\hline Altitude & Wavelength & $\mathrm{vmr}(\mathrm{ppmv})$ & Reference & Comment \\
\hline \multirow[t]{6}{*}{$30-40 \mathrm{~km}$} & \multirow[t]{6}{*}{$2.4 \mu \mathrm{m}$} & $26 \pm 4$ & Marcq et al. (2006) & \\
\hline & & $31 \pm 2$ & Marcq et al. (2008) & \\
\hline & & $22-35$ & Tsang et al. (2008) & Accuracy 4 ppmv \\
\hline & & $30 \pm 4$ & Tsang et al. (2008) & See main text \\
\hline & & $34 \pm 2$ & Arney et al. (2014) & 2009 observations \\
\hline & & $33 \pm 3$ & Arney et al. (2014) & 2010 observations \\
\hline \multirow[t]{2}{*}{$15-30 \mathrm{~km}$} & \multirow[t]{2}{*}{$1.74 \mu \mathrm{m}$} & $33 \pm 2$ & Arney et al. (2014) & 2009 observations \\
\hline & & $32 \pm 2$ & Arney et al. (2014) & 2010 observations \\
\hline \multirow[t]{7}{*}{$0-15 \mathrm{~km}$} & \multirow[t]{7}{*}{$1.18 \mu \mathrm{m}$} & $44 \pm 9$ & Bézard et al. (2009) & Variability $<1.5 \%$ \\
\hline & & $30_{-5}^{+10}$ & Bézard et al. (2011) & \\
\hline & & $31_{-6}^{+9}$ & Chamberlain et al. (2013) & \\
\hline & & $29 \pm 2$ & Arney et al. (2014) & 2009 observations \\
\hline & & $27 \pm 2$ & Arney et al. (2014) & 2010 observations \\
\hline & & $25.7_{-1.2}^{+1.4}$ & Fedorova et al. (2015) & Surf.emis. $=0.95$ \\
\hline & & $29.4_{-1.4}^{+1.6}$ & Fedorova et al. (2015) & Surf.emis. $=0.6$ \\
\hline
\end{tabular}

from SPICAV-IR, and an updated high-temperature line list as well as a better estimation of $\mathrm{CO}_{2}$ continuum opacity between 1.10 and $1.18 \mu \mathrm{m}$, Bézard et al. (2011) revised their estimation, and it is now more in line with other determinations. This value has been since refined by Fedorova et al. (2015), with $\mathrm{H}_{2} \mathrm{O}$ in this altitude range being horizontally uniform and depending on the assumed surface emissivity. Ground-based data acquired by Chamberlain et al. (2013) with IRIS2 at the Anglo-Australian Telescope and high spectral resolution ( $R \sim 2400$ ) confirmed these estimations. The need for spectral database updates in the very high pressure and temperature conditions prevailing in the lowermost Venusian atmosphere was also pointed out by Bailey (2009) regarding $\mathrm{H}_{2} \mathrm{O}$ line list. One could however note that this need is shared with hot exoplanet spectroscopic studies, and therefore high-temperature line lists for $\mathrm{H}_{2} \mathrm{O}$ have been published since (Barton et al. 2017). Other ground-based measurements from Arney et al. (2014) are in full agreement with SPICAV-IR data.

It therefore appears that a vertically uniform $\mathrm{H}_{2} \mathrm{O}$ profile of $30 \pm 3$ ppmv below the clouds matches all available observations. Interestingly, the most recent reanalysis of Venera 11 descent probe data by Ignatiev et al. (1997) is also compatible with this profile.

\section{$2.1 .2 C O \& O C S$}

Remote sensing of carbon monoxide (CO) and carbonyl sulphide (OCS) is only possible in the $2.3 \mu \mathrm{m}$ window, so they can only be measured in the $30-40 \mathrm{~km}$ altitude range. Nevertheless, as first shown by Pollack et al. (1993), part of their vertical profiles can be derived since the spectral features of $\mathrm{CO}$ - and even more so OCS — depend on their respective vertical gradients in the probed altitude range.

As far as we know, in global average, $\mathrm{CO}$ increases with increasing altitude in this 30 $40 \mathrm{~km}$ range (Bézard and de Bergh 2007)—see also Fig. 1 and Table 2. Conversely, OCS is shown to decrease over the same range by almost two orders of magnitude-see also Fig. 2 and Table 2. In order to cope with these sometimes dramatic variations, most radiative transfer models that are used to derive the abundances and vertical gradients of $\mathrm{CO}$ 


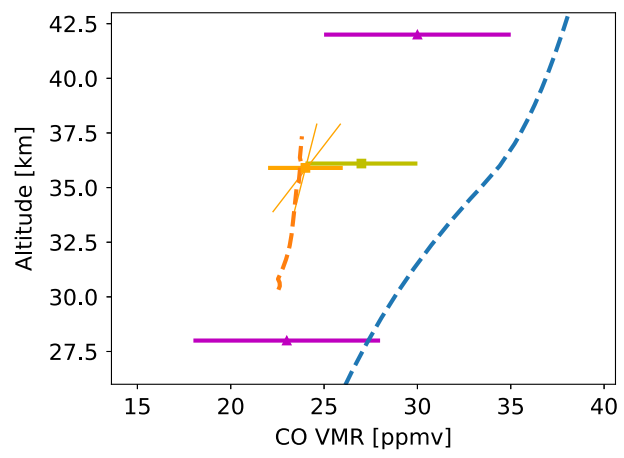

Fig. 1 Observations and model profiles for CO. In purple are plotted the VMR and vertical gradient according to Bézard and de Bergh (2007). Yellow and orange squares are more observations below the clouds (Cotton et al. (2012) in yellow, Marcq et al. (2006) in orange). The dashed blue line stands for the lower atmosphere model from Krasnopolsky (2013b), and the dashed orange line stands for the lower atmospheric model from Yung et al. (2009)

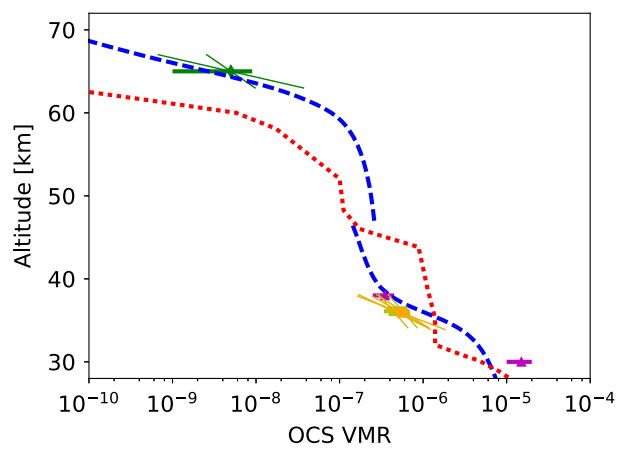

Fig. 2 Observations and model profiles for OCS. Green diamonds are observations in the upper cloud (Krasnopolsky 2010b). Solid green lines indicate the uncertainties on the inferred scale height (Krasnopolsky 2008). Magenta triangles are assessed observational ranges below the clouds (Bézard and de Bergh 2007). Yellow and orange squares are more observations below the clouds (Arney et al. 2014 in yellow, Marcq et al. 2006 in orange). Blue dashed lines stand for a lower atmosphere model (Krasnopolsky 2013b), as well as a middle atmosphere model (Krasnopolsky 2012a). Red dotted line is the global mean profile in a whole atmosphere model with Reaction (1) included (Yung et al. 2009)

and OCS introduce the dimensionless pseudo-gradient $\alpha=\frac{d \log q}{d \log P}$, where $q$ stands for the volume mixing ratio of the considered species and $P$ for the pressure vertical coordinate. These models then assume that $\alpha$ is constant within the probed altitude range. $\alpha$ is related, assuming hydrostatic equilibrium, to the vertical gradient of the mixing ratio through the formula $\alpha=-\frac{H}{q}\left(\frac{d q}{d z}\right)$, where $H$ stands for the local pressure scale height.

For $\mathrm{CO}$, whose variations span less than an order of magnitude in the $30-40 \mathrm{~km}$ range, this assumption is roughly equivalent to assuming a constant physical vertical gradient (in $\mathrm{ppm} / \mathrm{km}$ ). Using ground-based data from SpeX/IRTF, Marcq et al. (2006) derived a mixing ratio compatible with previous determinations (Pollack et al. 1993), albeit with a somewhat less steep vertical slope. Venus Express/VIRTIS studies focused more on horizontal variability (see Sect. 3.1), but all derived comparable values for the average mixing ratio typical of lower latitudes, without attempting to derive the $\mathrm{CO}$ vertical gradient. One notable exception 
Table 2 Night side ground-based retrievals for CO and OCS in the 30-40 km altitude range

\begin{tabular}{llllll}
\hline Species & $z_{0}[\mathrm{~km}]$ & $q\left(z_{0}\right)[\mathrm{ppmv}]$ & $\left(\frac{d q}{d z}\right)\left(z_{0}\right)\left[\frac{\mathrm{ppmv}}{\mathrm{km}}\right]$ & Reference & Comment \\
\hline CO & 36 & $23 \pm 5$ & $1.2 \pm 0.45$ & Pollack et al. (1993) \\
& 28 & $\sim 23$ & & Bézard and de Bergh (2007) \\
& 42 & $\sim 30$ & Bézard and de Bergh (2007) & $0-20^{\circ} \mathrm{N}$ \\
& 36 & $24 \pm 2$ & $0.6 \pm 0.3$ & Marcq et al. (2006) & Low lat. \\
OCS & 36 & $27 \pm 3$ & $1.2 \pm 0.45$ & Cotton et al. (2012) & Marcq et al. (2006) \\
& 36 & $0.52 \pm 0.05$ & $-0.26 \pm 0.05$ & Bézard and de Bergh (2007) & in 2009 \\
& 36 & $\sim 16$ & & Bézard and de Bergh (2007) & in 2009 \\
& 36 & $0.35 \pm 0.1$ & & Arney et al. (2014) & in 2010 \\
& 33 & $0.44 \pm 0.10$ & & Arney et al. (2014) & in 2010 \\
\hline
\end{tabular}

is the work of Cotton et al. (2012), who provided an alternate interpretation of the horizontal variability of $\mathrm{CO}$ through a dramatic increase above $40 \mathrm{~km}$-this would imply a very large increase of the positive vertical gradient of $\mathrm{CO}$ near $40 \mathrm{~km}$, by a factor of possibly 10 . However, they do not discuss their results in terms of vertical gradient, rather focusing on the resulting mixing ratio increase above $40 \mathrm{~km}$.

Concerning OCS, Taylor et al. (1997) recommended a value for $\alpha$ of the order of 5 in the 30 to $37 \mathrm{~km}$ altitude range; this is equivalent to a $e$-fold decrease of OCS for each $2 \mathrm{~km}$ upwards. Marcq et al. (2006) confirmed this estimate and provided error bars for $\alpha=5 \pm 1$, implying that this $e$-fold decrease occurs for each $(2 \pm 0.5) \mathrm{km}$ upwards. Venus Express/VIRTIS-H instrument was the only one capable of providing relatively high spectral resolution observations in the $2.3 \mu \mathrm{m}$ window, which are necessary to study OCS with enough accuracy, but no study has tried to constrain the OCS vertical gradient from these data; Marcq et al. (2008) focused more on latitudinal variations of OCS around its reference profile (see Sect. 3.1). Recent ground-based data from Arney et al. (2014) provided measurements of OCS mixing ratios near $36 \mathrm{~km}$ as well as OCS vertical gradient near $33 \mathrm{~km}$. The underlying pseudo-gradients (respectively $\alpha=3.4 \pm 1.4$ in 2009 and $\alpha=2.8 \pm 0.8$ in 2010) are somewhat less steep than previous estimations, albeit still confirming a strong decrease of OCS with increasing altitude between 30 and $37 \mathrm{~km}$.

\subsubsection{Other Species}

Sulphur-Bearing Species: $\mathrm{SO}_{2}, \mathrm{H}_{2} \mathrm{SO}_{4}, \mathrm{~S}_{3}$ Re-analysis of in situ scattered sunlight in the visible range obtained during Venera 11 probe descent was performed by Maiorov et al. (2005). They found new estimates of the $S_{3}$ mixing ratio in the 3 to $19 \mathrm{~km}$ altitude range, with a volume mixing ratio increasing with increasing altitude from 0.03 to $0.1 \mathrm{ppbv}$. Krasnopolsky (2013b) performed a new retrieval of $S_{3}$ and $S_{4}$ from the Venera 11 spectra. The retrieval results were $f_{S_{3}}=11 \pm 3$ pptv at $3-10 \mathrm{~km}, f_{S_{3}}=18 \pm 3 \mathrm{pptv}$ at $10-19 \mathrm{~km}$, $f_{S_{4}}=4 \pm 4$ pptv at $3-10 \mathrm{~km}$, and $f_{S_{4}}=6 \pm 2 \mathrm{pptv}$ at $10-19 \mathrm{~km}$. Both species show a rapid decrease above $19 \mathrm{~km}$ (Maiorov et al. 2005).

In absence of any new in situ measurements or re-analyses thereof, $\mathrm{SO}_{2}$ under the clouds could only be measured near $2.4 \mu \mathrm{m}$ on the night side. Due to the weak signal and narrow 
spectral signature of $\mathrm{SO}_{2}$, VIRTIS-H measurements were only able to confirm its average mixing ratio in the 30-40 $\mathrm{km}$ range, $130 \pm 50 \mathrm{ppmv}$ (Marcq et al. 2008). Ground-based measurements from Arney et al. (2014) in 2009 (140 \pm 37 ppmv) and 2010 (126 \pm 32 ppmv) brought further confirmation of this value, with no compelling evidence for any horizontal variability larger than the $\sim 25 \%$ error bars.

$\mathrm{H}_{2} \mathrm{SO}_{4}$ vapour profiles were measured by VeRa on-board Venus Express (Oschlisniok et al. 2012) within the lower cloud region. Since $\mathrm{H}_{2} \mathrm{SO}_{4}$ saturation pressure is strongly varying with temperature and concentration, sulphuric acid vapour is found to be quite abundant (typically a few ppmv) at the lower cloud boundary near $48 \mathrm{~km}$, just below the measurement altitude, and conversely below the detection threshold of about 1 ppmv higher in the atmosphere, above about $53 \mathrm{~km}$, in a general agreement with Magellan measurements (Jenkins et al. 1994).

Halides No new constraints have been provided since 1997 for gaseous hydrogen fluoride, whose mean abundance $(5 \pm 2 \mathrm{ppbv})$ can be derived in the $2.3 \mu \mathrm{m}$ window between 30 and $40 \mathrm{~km}$ (Taylor et al. 1997). Hydrogen chloride was measured by Arney et al. (2014) in 2009 $(410 \pm 40 \mathrm{ppbv})$ and $2010(420 \pm 50 \mathrm{ppbv})$ in the $1.74 \mu \mathrm{m}$ window probing in the $15-25 \mathrm{~km}$ range, with no evidence for any horizontal variability. These estimates are in full agreement with previous determinations.

\subsubsection{Lower Atmosphere Chemistry Models, Key Results and Comparisons with Observations}

Several studies since 1996 have modelled the chemistry in the lower atmosphere (Krasnopolsky 2007, 2013b; Yung et al. 2009), as well as the oxidation state of the surface and the lowest scale height of the atmosphere (Fegley et al. 1997). The latter is discussed in Sect. 6.4. Earlier modelling, e.g., by Krasnopolsky and Pollack (1994), was reviewed in Mills et al. (2007) and has largely been superseded by subsequent work.

The most recent lower atmosphere chemistry model (Krasnopolsky 2013b) updated the results presented in earlier studies (Krasnopolsky and Pollack 1994; Krasnopolsky 2007). In particular, the upper boundary fluxes of $\mathrm{H}_{2} \mathrm{SO}_{4}$ and $\mathrm{CO}$ were reduced to match those calculated with a middle atmosphere photochemistry model (Krasnopolsky 2012a) and production/loss of OCS and CO on Venus' surface were eliminated (Krasnopolsky 2013b). The calculated OCS profile, Fig. 2, is in reasonable agreement with observations at $35-40 \mathrm{~km}$ but is somewhat smaller than observed near $30 \mathrm{~km}$. Calculated CO is $15-30 \%$ higher than is observed at $25-45 \mathrm{~km}$, which is within the observational uncertainty at $28 \mathrm{~km}$ but outside the observational uncertainty at 35-43 km, Fig. 2 (Krasnopolsky 2013b).

Krasnopolsky (2013b) also modelled his retrieved number densities of $S_{3}$ and $S_{4}$ using three free parameters related to their physical properties. The preferred model agrees with both retrieved $\mathrm{S}_{3}$ number densities and one retrieved $\mathrm{S}_{4}$ number density and lies within the uncertainty on the other retrieved $\mathrm{S}_{4}$ number density (Krasnopolsky 2013b).

The 2-D chemical transport modelling by Yung et al. (2009) took a more parametric approach to the OCS-CO chemistry, introducing Reaction (1) and determining empirically the loss coefficient for OCS near $30 \mathrm{~km}$ by comparison with observations. In contrast with Krasnopolsky (2013b) who found no requirement for a significant surface source of OCS, Yung et al. (2009) found a surface source of OCS was needed. The sensitivity studies by Yung et al. (2009), incorporating both the 2-D meridional circulation and the loss coefficient for Reaction (1), indicated (1) the source for OCS is the surface at equatorial latitudes, (2) the middle atmosphere is a net sink for OCS, and (3) an additional chemical sink beyond 
direct photolysis of OCS that converts OCS to CO is required at 30-50 km. Points (2) and (3) are consistent with previous results (e.g., Krasnopolsky and Pollack 1994). Unless there is a massive volcanic source for OCS, which is not consistent with existing observations, Yung et al. (2009) proposed that surface reaction(s) produce OCS. Possible surface reactions include heterogeneous reactions, such as $\mathrm{S}_{2}+\mathrm{CO} \rightarrow \mathrm{OCS}+\mathrm{S}$, which was favoured by Hong and Fegley (1997), and reactions between surface minerals (e.g., pyrite) and $\mathrm{CO}$ or $\mathrm{CO}_{2}$ (von Zahn et al. 1983; Prinn 1985; Fegley and Treiman 1992; Mills et al. 2007). The global mean modelled vertical profile for OCS in Yung et al. (2009) is somewhat smaller than observed near $30 \mathrm{~km}$, is larger than observed at 35-40 km, and shows a more rapid decline with increasing altitude at $55-70 \mathrm{~km}$ than is implied by observations, cf. Fig. 2. Yung et al. (2009) suggest the relatively poor fit to observed OCS at 55-70 km may be due to unrealistic circulation in their GCM above the cloud tops. Yung et al. (2009) proposed several hypotheses for Reaction (1), including photosensitised dissociation of OCS, Reactions (2a)-(2c) and (3), as well as heterogeneous chemistry on aerosol particles. Reactions (2a)-(2c) had been considered not significant in Krasnopolsky (2007). Reactions (2a)-(2c) and (3) were explored further in Krasnopolsky (2013b). All of the proposed hypotheses require laboratory work and/or observational studies to assess their viability and importance (Yung et al. 2009).

$$
\begin{aligned}
& \mathrm{OCS}+\mathrm{X} \rightarrow \mathrm{CO}+\mathrm{Y} \\
& \mathrm{S}_{3}+h v \rightarrow \mathrm{S}_{2}+\mathrm{S} \\
& \mathrm{S}_{2}+\mathrm{S}+M \rightarrow \mathrm{S}_{3}+M \\
& \mathrm{OCS}+\mathrm{S} \rightarrow \mathrm{CO}+\mathrm{S}_{2} \\
& \mathrm{~S}_{3}+h v \rightarrow \mathrm{S}_{2}+\mathrm{S} \\
& \mathrm{S}_{4}+h v \rightarrow \mathrm{S}_{3}+\mathrm{S} \\
& 2 \mathrm{~S}_{2}+M \rightarrow \mathrm{S}_{4}+M \\
& \mathrm{OCS}+\mathrm{S} \rightarrow \mathrm{CO}+\mathrm{S}_{2} \\
& \mathrm{SO}_{3}+\mathrm{CO} \rightarrow \mathrm{CO}_{2}+\mathrm{SO}_{2} \\
& \mathrm{H}_{2} \mathrm{SO}_{4}+\mathrm{H}_{2} \mathrm{O} \rightarrow \mathrm{SO}_{3}+2 \mathrm{H}_{2} \mathrm{O} \\
& \mathrm{SO}_{3}+\mathrm{OCS} \rightarrow \mathrm{CO}_{2}+\left(\mathrm{SO}_{2}\right. \\
&\left(\mathrm{SO}_{2}+\mathrm{OCS} \rightarrow \mathrm{CO}_{2} \mathrm{SO}_{2}+\mathrm{S}_{2}\right.
\end{aligned}
$$

In Krasnopolsky (2013b) four sets of modelled reactions controlled the vertical profiles for OCS and CO. Reactions (4)-(5c) were originally proposed in Krasnopolsky and Pollack (1994) and updated in Krasnopolsky (2007) while Reactions (3) were proposed in Yung et al. (2009) but not explicitly used in their simulations. The model which gave the best fit to observed OCS and CO included all four sets of reactions, and the modelled sum OCS $+\mathrm{S}_{x}$ was equal to 20 ppmv below $47 \mathrm{~km}$ (Krasnopolsky 2013b). Only a few of these reactions have had their viability assessed and rate coefficients measured in laboratory studies. The rate coefficients for Reactions (4), (5b), and (5c) were adjustable free parameters in Krasnopolsky and Pollack (1994) that have been adopted for use in later studies (Krasnopolsky 2007, $2013 \mathrm{~b}$ ); the rate coefficient for Reaction (5a) was calculated from the inverse reaction using 
thermochemical data (Krasnopolsky 2007); the rate coefficient for Reaction (2c) used by Yung et al. (2009) is from Lu et al. (2006) while that used by Krasnopolsky (2013b) is from a fit to the rate coefficient at $400 \mathrm{~K}$ from Klemm and Davis (1974) and at $900 \mathrm{~K}$ from Shiina et al. (1996) as described in Krasnopolsky (2007). For altitudes below $50 \mathrm{~km}$, these rate coefficients differ by less than $15 \%$. The rate coefficients for Reactions (2b) and (3b) in Yung et al. (2009) were estimated by Mills (1998) while those used by Krasnopolsky (2013b) were from calculations by Du et al. (2008). The rate coefficients used by Krasnopolsky (2013b) are two to three orders of magnitude slower than those used by Yung et al. (2009) which will tend to increase the amount of $\mathrm{S}$ and $\mathrm{S}_{2}$ available.

The empirical loss coefficient inferred for Reaction (1), 1 to $3 \cdot 10^{-8}$ per second (Yung et al. 2009), is comparable to the loss of OCS via Reactions (5b) and (5c) at $36 \mathrm{~km}$, which is the weighted mean altitude for Reactions (5b) and (5c) (Krasnopolsky 2013b) - the mixing ratio and number density for $\mathrm{SO}_{3}$ at $36 \mathrm{~km}$ are $10^{-7}$ and $8 \cdot 10^{12}$ per $\mathrm{cm}^{3}$, respectively, and the rate coefficient for Reaction (5b) is $2 \cdot 10^{-21}$ per $\mathrm{cm}^{3}$ per second, which implies the loss coefficient for Reaction (5b) is $2 \cdot 10^{-8}$ per second. Krasnopolsky (2013b) indicates the column integrated rates for Reactions (5b) and (5c) are the same, suggesting the total loss coefficient for OCS is about 3 to $4 \cdot 10^{-8}$ per second near $36 \mathrm{~km}$ in the Krasnopolsky (2013b) model. Just below $30 \mathrm{~km}$, the loss coefficient for OCS via Reaction (2c) (Krasnopolsky 2013b) appears to be comparable to but smaller than that for Reaction (1) (Yung et al. 2009). The similar loss coefficients are not surprising as both studies used empirical fits to the vertical profile of OCS to determine the rates of their OCS loss reactions.

Krasnopolsky (2013b) found Reactions (4) and (5a)-(5c) were necessary to achieve a good fit to extant observations. Calculations without Reactions (4) and (5a)-(5c) gave OCS and $\mathrm{CO}$ abundances that exceed observations by an order of magnitude. However, that alone should not be construed as a substitute for rigorous laboratory demonstration of the reality of Reactions (4) and (5a)-(5c), and the actual mechanisms underlying Reactions (4) and (5a)-(5c) may be more complex. Laboratory data for many of the key reactions postulated in Krasnopolsky (2013b) and Yung et al. (2009) are nonexistent or highly uncertain. More detailed observations of spectrally-resolved UV-visible irradiance, as well as $(\mathrm{SO})_{2}$, $\mathrm{SO}_{3}$, and $\mathrm{S}_{x}$, in the lower atmosphere are needed, as are modelling studies of the latitudedependent vertical profiles for OCS and CO.

\subsection{Observations and Modelling of Nitrogen Oxides and Lightning}

Many spacecraft have reported radio frequency or optical evidence of lightning, and even though only one ground-based optical observation has been reported, intracloud and cloudto-ionosphere lightning are the most likely forms (Krasnopolsky 2006a; Delitsky and Baines 2015, and references therein). Venera 9 and 10 optical spectrometer data were used to infer a global flash rate of 45 per $\mathrm{km}^{2}$ per year, visible flash energy of 2 to $2.5 \cdot 10^{7} \mathrm{~J}$, and total flash energy of $8 \cdot 10^{8} \mathrm{~J}$ (Krasnopolsky 1983). The global flash rate determined from Venus Express magnetometer observations over the polar vortex, a region Krasnopolsky (1983) assumed would not contribute significantly to global lightning, was equivalent to 1.2 per km ${ }^{2}$ per year, about $20 \%$ of the terrestrial rate (Russell et al. 2008), which agrees qualitatively with the analysis of radio frequency emissions observed by Galileo (Gurnett et al. 2001). The detection of NO has been modelled to imply a lightning energy deposition rate of $(0.19 \pm$ $0.06) \cdot 10^{-7} \mathrm{~J}$ per $\mathrm{cm}^{2}$ per second, which yields a global flash rate of $6 \pm 2$ per $\mathrm{km}^{2}$ per year, assuming the total flash energy is about $10^{9} \mathrm{~J}$ (Krasnopolsky 2006a).

The detection of NO in the Venus clouds was modelled to give a mixing ratio of $5.5 \pm$ 1.5 ppbv below $65 \mathrm{~km}$ altitude and an upward flux of $\mathrm{NO}$ at $60 \mathrm{~km}$ of $(6 \pm 2) \cdot 10^{7}$ per $\mathrm{cm}^{2}$ 
per second (Krasnopolsky 2006a). Correcting for the estimated effect of cosmic rays, the required upward flux was $(7 \pm 2) \cdot 10^{7}$ per $\mathrm{cm}^{2}$ per second (Krasnopolsky 2006a). The inferred abundance is much smaller than the $30 \mathrm{ppbv}$ that was assumed in an early model that examined, primarily, the potential impact of $\mathrm{NO}_{x}$ catalytic cycles on the global-scale $\mathrm{CO}_{2}$ cycle, Reactions (6a)-(6d) (Yung and DeMore 1982, model B).

$$
\begin{aligned}
\mathrm{H}+\mathrm{O}_{2}+M & \rightarrow \mathrm{HO}_{2}+M \\
\mathrm{HO}_{2}+\mathrm{NO} & \rightarrow \mathrm{OH}+\mathrm{NO}_{2} \\
\mathrm{NO}_{2}+\mathrm{h} \nu & \rightarrow \mathrm{NO}+\mathrm{O} \\
\mathrm{CO}+\mathrm{OH} & \rightarrow \mathrm{CO}_{2}+\mathrm{H} \\
\text { net } \mathrm{CO}+\mathrm{O}_{2} & \rightarrow \mathrm{CO}_{2}+\mathrm{O}
\end{aligned}
$$

In the NO discovery paper, the most significant photochemical impacts from NO were assessed to be via Reactions (7) and (8), which occur in the mesosphere (Krasnopolsky 2006a). Subsequent work with a simplified chemistry scheme suggested gas-phase odd nitrogen chemistry could alter $\mathrm{SO}_{x}$ and $\mathrm{O}$ abundances at 80-90 km altitude and $\mathrm{O}_{2}$ and $\mathrm{CO}$ abundances at $58-68 \mathrm{~km}$ by more than $30 \%$ if the assumed NO mixing ratio at $58 \mathrm{~km}$ was larger than 7 ppbv (Shunmuga Sundaram et al. 2011). Work with a more comprehensive chemistry scheme based on models developed for Mars (Nair et al. 1994; Krasnopolsky 1995) found odd nitrogen cycles provided one-quarter of modelled $\mathrm{O}_{2}$ production, onethird of $\mathrm{Cl}_{2}$ production, and one-quarter of $\mathrm{SO}_{2}$ production (Krasnopolsky 2012a). Similarly comprehensive odd nitrogen chemistry was included in Zhang et al. (2012) but odd nitrogen chemistry received little discussion in that paper. Insufficient detail is provided to assess whether these studies agree on the broader impacts of odd nitrogen chemistry or not. NO has been assessed to be unreactive below $50 \mathrm{~km}$ (Krasnopolsky 2013b) with a lifetime (against photochemical loss after transport into the mesosphere) of about 3000 years (Delitsky and Baines 2015).

$$
\begin{gathered}
\mathrm{NO}_{2}+\mathrm{SO} \rightarrow \mathrm{NO}+\mathrm{SO}_{2} \\
\mathrm{NO}_{2}+\mathrm{O} \rightarrow \mathrm{NO}+\mathrm{O}_{2}
\end{gathered}
$$

Delitsky and Baines (2015) looked at potential storm-induced local effects from lightning, identifying carbon oxides and suboxides, higher oxides of sulphur, nitrogen oxides, and sulphuric acid clusters as the most likely compounds that would be produced. The amounts generated would be less than from photochemistry, but if diffusion away from storms was inhibited, then localised enhancements of a factor of $5 \cdot 10^{4}$ for a $100 \times 100 \mathrm{~km}^{2}$ storm could occur and result in potentially detectable concentrations (Delitsky and Baines 2015). Species suggested for further study or possible observation included negative ions, $\mathrm{C}_{3} \mathrm{O}_{2}, \mathrm{~S}_{n} \mathrm{O}$, and $\mathrm{CO}$ (Delitsky and Baines 2015). No simulations have assessed the potential implications of lightning-induced $\mathrm{CO}$ production for the observed, latitude-dependent distribution.

\subsection{Above the Cloud Top (70-100 km)}

The Venus Express mission has yielded a wealth of new results on the Venus atmosphere, from the surface up to highest layers of the atmosphere. In particular, two instruments on board Venus Express performed observations of the mesosphere and lower thermosphere 
of Venus. SPICAV and SOIR carried out nadir observations, as well as stellar and solar occultations which sounded the region from above the clouds up to $170 \mathrm{~km}$. Observations were performed in the infrared range (SPICAV-IR and SOIR) as well as in the UV region (SPICAV-UV). The SOIR instrument (Nevejans et al. 2006) provided high vertical resolution profiles of $\mathrm{CO}_{2}$ and temperature (Mahieux et al. 2010, 2012, 2015b) and a series of trace gases, such as $\mathrm{H}_{2} \mathrm{O}, \mathrm{HDO}, \mathrm{CO}, \mathrm{HCl}, \mathrm{HF}$ and $\mathrm{SO}_{2}$. UV observations in nadir and occultation gave access to the sulfur content ( $\mathrm{SO}$ and $\mathrm{SO}_{2}$ ). VIRTIS (Drossart et al. 2007) probed the Venus atmosphere through nadir measurements as well as limb observations in the infrared spectral range. The VIRTIS-M channel has been used to investigate the night-side atmosphere above the cloud top (Irwin et al. 2008) and VIRTIS-H limb observations provided CO vertical information (Gilli et al. 2015).

Ground-based spectroscopy, making use of sophisticated and often high-resolution instruments coupled to powerful telescopes, provides important supplementary information. Observations performed in the UV, IR, sub-mm, and $\mathrm{mm}$ ranges, are indeed a powerful tool for monitoring minor species in planetary atmospheres. They also deliver global views of their evolution with latitude and longitude, season and local time. Daily maps provided by ground-based instruments give a unique chance of studying short-term and short-scale variations as well as transient phenomena.

\subsection{1 $\mathrm{H}_{2} \mathrm{O}$ and $\mathrm{HDO}$}

Despite the importance of water in the Venus atmosphere, it has been up to now only poorly constrained by observations, especially in the region above the clouds. Up to now, and based on observations performed from the ground or from space, only a general behaviour of the vertical distribution of water vapour has been established: a few ppm at cloud level and above and an increase up to a few tens of ppm below the clouds.

On Venus Express, the SOIR instrument observed routinely water vapour and its isotopologue: $\mathrm{H}_{2} \mathrm{O}$ between $70-110 \mathrm{~km}$ and HDO between 70-95 km altitude. Early SOIR water vapour observations (Bertaux et al. 2007a; Fedorova et al. 2008) show a depletion in the volume mixing ratio at $85 \mathrm{~km}$ in both $\mathrm{HDO}$ and $\mathrm{H}_{2} \mathrm{O}$ and an increase in $\mathrm{HDO} / \mathrm{H}_{2} \mathrm{O}$ ratio above the clouds. No noticeable temporal variability was detected. Numerous subsequent $\mathrm{H}_{2} \mathrm{O}$ and HDO SOIR observations have been obtained between 2007 and 2014 (Chamberlain et al. 2015). Fedorova et al. (2016) analysed the $1.38 \mu \mathrm{m} \mathrm{H}_{2} \mathrm{O}$ band observed by the SPICAV-IR instrument in nadir. They obtained values between 2 and 10 ppmv near the cloud top (65-74 km). Water vapour abundances near the cloud tops (at $69.5 \pm 2 \mathrm{~km}$ ) were also obtained with VIRTIS-H on the day side (Cottini et al. 2012, 2015) (see Sect. 3.2) and by ground-based spectroscopy at $74 \mathrm{~km}$ (Krasnopolsky et al. 2013).

From millimeter and sub-millimeter investigations (Sandor and Clancy 2005; Gurwell et al. 2007), the $\mathrm{H}_{2} \mathrm{O}$ mixing ratio in the mesosphere appears to be more or less constant with altitude with values ranging from 0 to $4.5 \mathrm{ppmv}$, although with strong spatial and temporal variations. Using the ALMA instrument, Encrenaz et al. (2015) obtained a $\mathrm{H}_{2} \mathrm{O}$ average mixing ratio of $2.5 \pm 0.6 \mathrm{ppmv}$. Such instruments usually observe $\mathrm{HDO}$ and assume a value for the $\mathrm{D} / \mathrm{H}$ enrichment to convert these measurements into $\mathrm{H}_{2} \mathrm{O}$ abundances.

\subsubsection{CO}

Carbon monoxide and atomic oxygen are produced by photo-dissociation of $\mathrm{CO}_{2}$ on the day side in the upper atmosphere of Venus. These are transported to the night side by the SS-AS circulation, which is active at altitudes above $120 \mathrm{~km}$. The 3-body recombination reaction of 
$\mathrm{CO}$ and $\mathrm{O}$ into $\mathrm{CO}_{2}$ is very slow and, alone, cannot explain the low $\mathrm{O}_{2}$ abundances observed in the Venus atmosphere. Faster recombination processes through catalytic cycles involving chlorine $\left(\mathrm{ClO}_{x}\right)$ or hydrogen $\left(\mathrm{HO}_{x}\right)$ oxides (Yung and DeMore 1982; Krasnopolsky and Parshev 1983; Krasnopolsky 2012a) as well as catalytic CO oxidisation reactions within the clouds (Mills et al. 2007; Mills and Allen 2007) have been proposed and will be detailed in Sect. 2.3.4. The volume mixing ratio ( $\mathrm{vmr}$ ) of $\mathrm{CO}$ is thus expected to decrease with decreasing altitudes, the CO-rich air from the higher layers being steadily diluted by COpoor air at lower altitudes. $\mathrm{CO}$ is also transported by the strong zonal winds. Thus, although $\mathrm{CO}$ is produced on the day side of the planet, it is quickly transported to the night side.

The first observations of $\mathrm{CO}$ abundance above the clouds were performed by groundbased instruments. Connes et al. (1968) deduced a disk-average mixing ratio of $45 \pm$ 10 ppmv at $64 \mathrm{~km}$. Kakar et al. (1976) were the first to deduce vertical information on the mesospheric $\mathrm{CO}$ using heterodyne millimeter spectroscopy. Using the ground-based CSHELL instrument at the NASA's Infrared Telescope Facility (IRTF), Krasnopolsky (2008) investigated the latitudinal distribution of $\mathrm{CO}$ and reported an average value of $70 \pm 10 \mathrm{ppm}$ at $60^{\circ}$ latitude and $8 \mathrm{AM}$ local solar time for altitudes between 68 and $71 \mathrm{~km}$. The $10 \%$ variability observed on the CO measurement was associated to atmospheric dynamics. However, a later investigation of the same observations showed that these data were not corrected for the solar CO lines. Krasnopolsky (2010a) investigated the latitudinal distribution of $\mathrm{CO}$ at $68 \mathrm{~km}$ and reported an average value of $51 \pm 4 \mathrm{ppmv}$ in the morning (08:00 AM) and $40 \pm 4$ ppmv in the afternoon (16:30 PM). Krasnopolsky (2014) retrieved $\mathrm{CO}$ abundances of $560 \pm 100 \mathrm{ppmv}$ near $104 \mathrm{~km}$ that vary insignificantly within $\pm 60^{\circ}$ using ground-based observations of the $\mathrm{CO}$ dayglow at $4.7 \mu \mathrm{m}$. Observations at millimetre and sub-millimetre wavelengths have shown that the $\mathrm{CO}$ abundance is very variable at high altitudes around $100 \mathrm{~km}$ (Clancy and Muhleman 1985, 1991; Gurwell et al. 1995; Clancy et al. 2008, 2012). Iwagami et al. (2010) observed nearly uniform distribution of CO above the clouds consistent with the findings of Krasnopolsky (2008). Recent observations with CSHELL/IRTF at $4.53 \mu \mathrm{m}$ (Marcq et al. 2015) reveals CO abundances ranging from $25 \mathrm{ppm}$ to $45 \mathrm{ppm}$ at $70 \mathrm{~km}$, associated to a scale height of $5 \pm 0.5 \mathrm{~km}$ between 70 and $76 \mathrm{~km}$ on the day side. Observations at millimeter and sub-millimeter wavelengths provide $\mathrm{CO}$ profiles from $80 \mathrm{~km}$ up to $105 \mathrm{~km}$. These measurements have shown that the $\mathrm{CO}$ abundance is very variable at high altitudes (around $100 \mathrm{~km}$ ) (Clancy and Muhleman 1985, 1991; Gurwell et al. 1995; Clancy et al. 2008, 2012). These short-term CO variations were not correlated with changes in the zonal and SS-AS circulations.

SOIR is also able to detect $\mathrm{CO}$ above the cloud deck. A first published study investigated the short term variation of CO in the Venus atmosphere (Vandaele et al. 2015b) based on the selection of profiles acquired on consecutive days or close together. A recent analysis taking into account all CO observations performed by the SOIR instrument (Vandaele et al. 2015a) confirmed the first results already obtained, i.e. high spatial and short-term variability.

Figure 3 illustrates the current knowledge of $\mathrm{CO}$ abundance profiles above the clouds.

\subsubsection{Other Species}

Halides Hydrogen halides play an important role in the chemistry of the Venus atmosphere, being active species involved in three of the main chemical cycles, i.e. the $\mathrm{CO}_{2}$, the sulphur oxidation and the polysulphur cycles. Reviews of these chemical reactions can be found in Prinn (1971), McElroy et al. (1973), Yung and DeMore (1982), Mills and Allen (2007), Krasnopolsky (2012a) for example.

$\mathrm{HCl}$ has first been observed in the Venus atmosphere by Connes et al. (1967), who reported volume mixing ratio values at the cloud top as being $0.6 \mathrm{ppmv}$, which was lately 


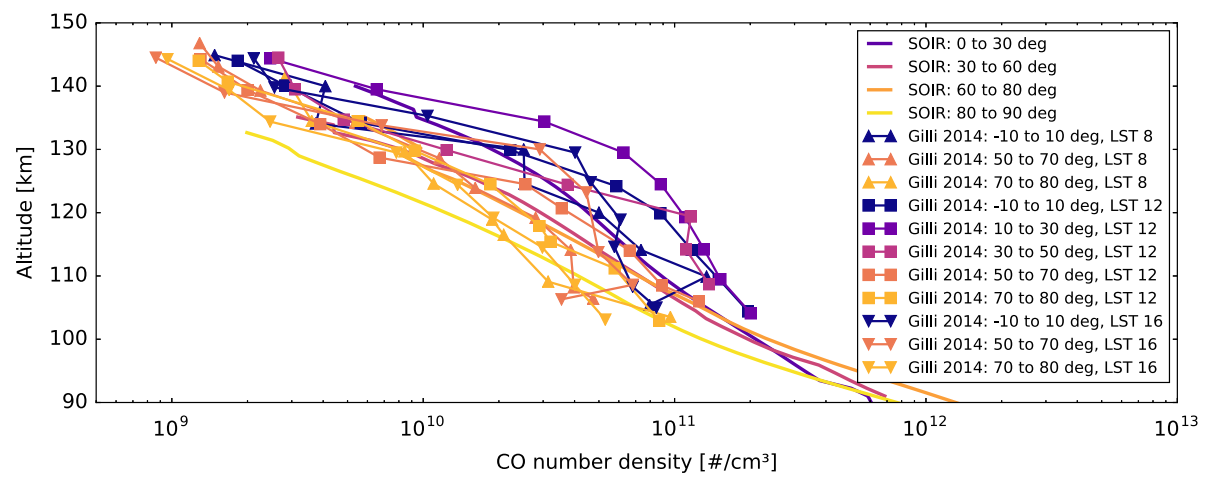

Fig. 3 CO density profiles from SOIR solar occultation and VIRTIS-H limb observations

corrected by Young (1972) as being equal to $0.42 \pm 0.07 \mathrm{ppmv}$. Since then, Iwagami et al. (2008) observed an $\mathrm{HCl}$ mixing ratio of $0.76 \pm 0.1 \mathrm{ppmv}$ at $61-67 \mathrm{~km}$ and a slightly lower value $(0.50 \pm 0.05 \mathrm{ppmv})$ below the clouds, suggesting the existence of a production mechanism of $\mathrm{HCl}$ within the clouds. Krasnopolsky (2010a) measured $\mathrm{HCl}$ abundance of $0.40 \pm 0.03 \mathrm{ppmv}$ just above the clouds $(74 \mathrm{~km})$, using the CSHELL spectrograph at NASA IRTF. Sandor and Clancy (2012) reported $\mathrm{HCl}$ vertical profiles with a mixing ratio of $0.4 \mathrm{ppmv}$ near $70 \mathrm{~km}$ decreasing to $0.2 \mathrm{ppmv}$ and less near $90 \mathrm{~km}$.

The SOIR instrument on board Venus Express is sensitive in the region where $\mathrm{HCl}$ absorbs. SOIR provides vertical profiles of both $\mathrm{H}^{35} \mathrm{Cl}$ and $\mathrm{H}^{37} \mathrm{Cl}$ isotopologues in the 70$115 \mathrm{~km}$ altitude range (Mahieux et al. 2015a). Based on a series of 180 profiles, average profiles were obtained for different latitudinal zones. Figure 4 shows a compilation of existing $\mathrm{HCl}$ profiles in the mesosphere. There seems to be a constant disagreement between the ground-based observations and those performed from space at the terminator, i.e. the SOIR profiles. The solar occultation technique used by SOIR is however a very powerful method delivering high spatial resolution (on the order of the vertical scale height). This method does not rely on any assumption made on the profile itself prior to retrieval which is not the case for the other observations. If the SOIR retrievals are confirmed to be representative of the mean vertical profiles for $\mathrm{HCl}$, this would imply profound changes in our understanding of chlorine photochemistry and other aspects of Venus' atmospheric chemistry (e.g. $\mathrm{CO}_{2}$ recycling rate or the existence of other chlorine-bearing species). Note that such $\mathrm{HCl}$ profiles could suggest the existence of a strong source of $\mathrm{HCl}$ near $100 \mathrm{~km}$ altitude and of a strong sink near $70 \mathrm{~km}$.

HF has also first been observed in the Venus atmosphere by Connes et al. (1967), with a mixing ratio at the cloud top of 5 ppbv. Krasnopolsky (2010a) reported values of the abundance of $3.5 \pm 0.2 \mathrm{ppbv}$ at $68 \mathrm{~km}$. SOIR is also able to measure HF (Mahieux et al. 2015a). Vertical HF profiles were obtained for 37 orbits, providing an average value of $5 \mathrm{ppbv}$ at $80 \mathrm{~km}$ increasing up to $36 \mathrm{ppbv}$ at $100 \mathrm{~km}$. The lower bound value is in agreement with the values found earlier.

Sulfur-Bearing Species: $\mathbf{S O}$ and $\mathbf{S O}_{2}$ Sulfur dioxide, $\mathrm{SO}_{2}$, has been detected in the Venus atmosphere, above, within and below the clouds, very early in the history of Venus exploration, using in situ, space-borne instrumentation or from Earth. The recent European Venus Express mission marked a regain in the interest of Venus and the understanding of its complex photochemistry and dynamics, in which the sulphur cycle plays a predominant role. 


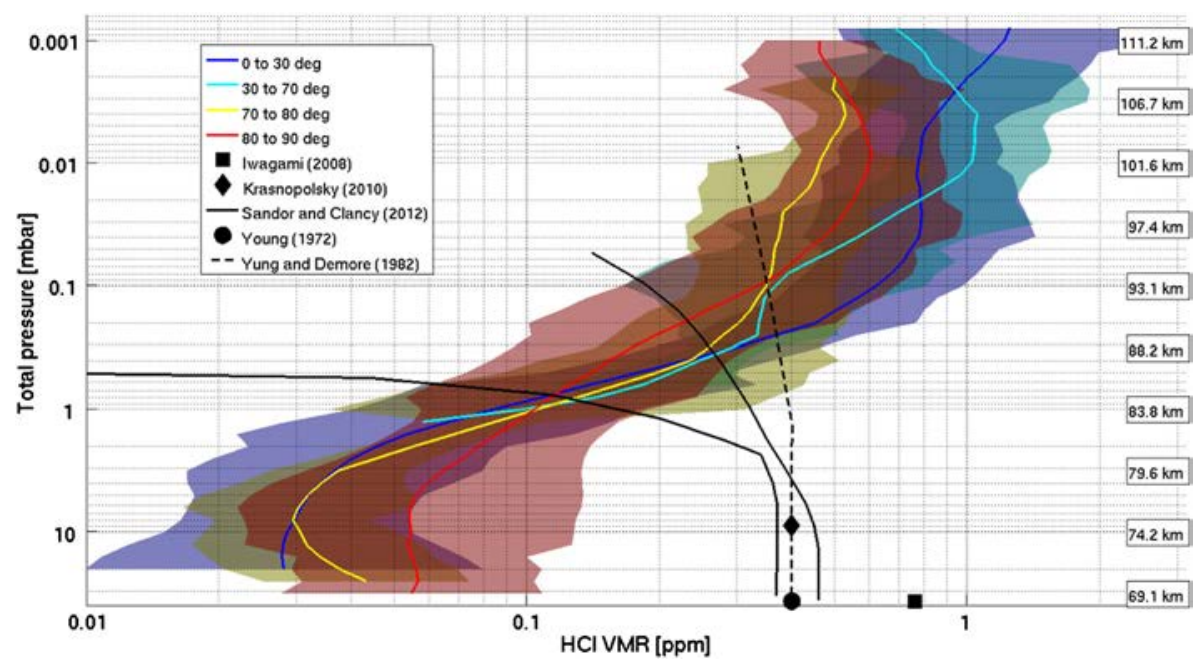

Fig. 4 Mean value of the $\mathrm{HCl}$ volume mixing ratio for different latitude bins as a function of total pressure. The altitudes are also shown. Colour shaded envelopes code for the weighted standard deviations

$\mathrm{SO}_{2}$ was first detected in the Venusian upper atmosphere from Earth-based ultraviolet observations (Barker 1979) soon followed by observations from space with the International Ultraviolet Explorer (IUE) (Conway et al. 1979) and with Pioneer Venus Orbiter (PVO) Ultraviolet Spectrometer (UVS) (Stewart et al. 1979). $\mathrm{SO}_{2}$ abundance was also monitored with the Fourier spectrometer on board the Venera 15 orbiter. A first analysis (Moroz et al. 1990; Zasova et al. 1993) reported abundance of $2 \mathrm{ppm}$ at an altitude of 60-62 km, with no apparent latitudinal variation. However, the analysis was later applied on a more consistent data set and provided new insights on the latitudinal distribution of $\mathrm{SO}_{2}$ (see Sect. 3.2).

Above the clouds, $\mathrm{SO}_{2}$ has been observed by Venus Express with SPICAV-UV (Marcq et al. 2011) and SOIR (Belyaev et al. 2008, 2012; Mahieux et al. 2015c). SPICAV-UV is able to detect $\mathrm{SO}_{2}$ either in nadir mode (Marcq et al. 2011, 2013) or in solar occultation (Belyaev et al. 2012). Cross-sections in the UV are much larger than in the infrared favouring thus UV observations. SPICAV-UV occultations indicate the presence of an enhanced layer of $\mathrm{SO}_{2}$ at $85-100 \mathrm{~km}$ altitude. $\mathrm{SO}_{2}$ absorption is weak in the spectral range of the SOIR instrument and, in some cases this would result in the determination of detection limits rather than positive abundance measurements. A critical analysis and definition of objective criteria for positive detection was described in Mahieux et al. (2015c). This analysis provides $\mathrm{SO}_{2}$ number density and volume mixing ratio vertical profiles in the 65 to $100 \mathrm{~km}$ region at the Venus terminator, covering all latitudes, in the period May 2006 to February 2013. Figure 5 summarises the different measurements of $\mathrm{SO}_{2}$ performed above the clouds using different techniques, from ground-based to space-borne observations, including detection using the STIS (Space Telescope Imaging Spectrograph) UV spectrometer on the HST (Hubble Space Telescope) (Jessup et al. 2015).

Ground-based observations were performed in the sub-mm range with the JCMT (Sandor et al. 2010, 2012) and the ALMA (Encrenaz et al. 2015) instruments, as well as in the IR with the TEXES/IRTF facility (Encrenaz et al. 2012, 2013). These observations have shown strong spatial and temporal variations both at the cloud top and in the upper mesosphere (see Sect. 3.2). Observations with ALMA and TEXES indicated that both $\mathrm{SO}$ and $\mathrm{SO}_{2}$ vertical profiles exhibit 'cut-off'-type profiles, i.e. negligible abundance below a cut-off altitude, 


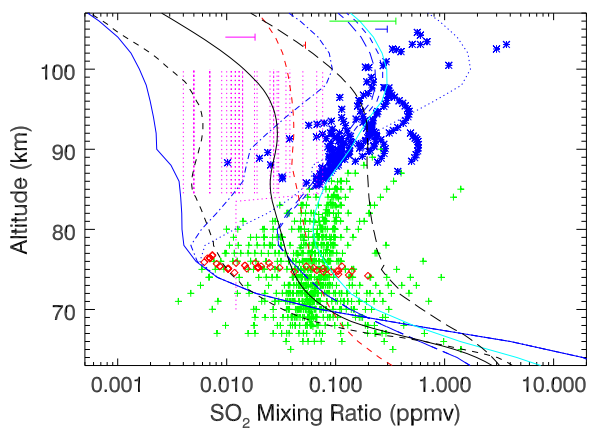

Fig. 5 Observations and model profiles for $\mathrm{SO}_{2}$. Green crosses are $\mathrm{SO}_{2}$ observations by SOIR, blue asterisks are solar occultation observations by SPICAV-UV, red diamonds are HST observations (Jessup et al. 2015), and magenta vertical dotted lines are JCMT observations above $84 \mathrm{~km}$ with an indicative upper limit below $84 \mathrm{~km}$. Typical uncertainties on the observations are indicated by the half-error bars at the top. Blue solid, dash-dot, and dotted lines are models A, B, and C, respectively (Zhang et al. 2010). Blue long-dash and short-dash lines are models A and B, respectively (Zhang et al. 2012). Red short-dash line is the nominal model from Mills and Allen (2007). Black long-dash, solid and short-dash line are models with eddy diffusion break at 55, 60 and $65 \mathrm{~km}$ respectively (Krasnopolsky 2012a). Cyan solid line is the nominal model from Parkinson et al. (2015b)

constant volume mixing ratio (vmr) above. The disk averaged profile matched cut-off altitudes of $88 \pm 2 \mathrm{~km}$ and $88 \pm 3 \mathrm{~km}$, and constant vmr of $8 \pm 2 \mathrm{ppbv}$ and $12 \pm 2.5 \mathrm{ppbv}$ for $\mathrm{SO}$ and $\mathrm{SO}_{2}$ respectively. Sandor et al. (2010, 2012), who monitored $\mathrm{SO}$ and $\mathrm{SO}_{2}$ in the Venus atmosphere since 2004, found similar cut-off profiles using JCMT. These observations are qualitatively consistent with the enhancement of $\mathrm{SO}_{2}$ seen by SPICAV (Belyaev et al. 2012) in the $85-100 \mathrm{~km}$ range, although the abundances are higher than those obtained with sub-mm instruments and the steepness of the vertical gradients differ.

The HST/STIS instrument carried out high-resolution observations of both $\mathrm{SO}$ and $\mathrm{SO}_{2}$ at cloud deck altitude during selected days in 2010 and 2011. The HST retrieved SO gas column densities (Jessup et al. 2015) were positively correlated with both the temporal and latitudinal variability of $\mathrm{SO}_{2}$; for example, the largest values of both species were observed at the terminator. This implies that the $\mathrm{SO}_{x}$ balance in the atmosphere is not purely photochemically driven, but that an additional source for $\mathrm{SO}_{2}$ is available in the $74-81 \mathrm{~km}$ region; otherwise the two species would exhibit anti-correlated densities. The $\mathrm{SO}_{2} / \mathrm{SO}$ ratio determined from the HST observations ranged between 4.4 and 15 with an unweighted mean of 8.7. SO abundances (vmr) obtained from JCMT observations (Sandor et al. 2010) are larger than the averaged values deduced from the HST observations. The $\mathrm{SO}_{2} / \mathrm{SO}$ ratio determined from the JCMT day side observations ranged between 0.6 and 4, so smaller than was determined from the lower altitude HST observations. Sulphur monoxide was also observed by SPICAV/UV at altitudes ranging from 85 to $105 \mathrm{~km}$ (Belyaev et al. 2012), showing an increase of abundance with altitude, which is in contradiction with the observations performed with the JCMT, which are best fit by a constant volume mixing ratio at $85-105 \mathrm{~km}$.

Recently, an ISSI (International Space Science Institute) International Team was set up during 2013-2014 to analyse and understand the different observations of $\mathrm{SO}_{2}$ performed from space (space missions and Hubble Space Telescope) and from ground ("Sulphur dioxide variability in the Venus atmosphere"). Its final report (Vandaele et al. 2017) states that the apparent disagreement between ground-based and space observations in the highest layers can be resolved by considering the different local time at which the measurements have 
been performed. Available vertical profiles thus evidence two distinct layers for $\mathrm{SO}_{2}$ : one below $80 \mathrm{~km}$ with $\mathrm{SO}_{2}$ decreasing with increasing altitude, most probably supplied by the lower atmosphere; and the other above $80 \mathrm{~km}$, with $\mathrm{SO}_{2}$ increasing with increasing height and consistent with a high-altitude supply yet unidentified.

Oxygen Species: $\mathbf{O}_{\mathbf{2}}$ and $\mathbf{O}_{3}$ No new attempts to detect ground-state $\mathrm{O}_{2}$ have been made since 1995 (Mills 1999), although (Krasnopolsky 2006b) proposed a new, more restrictive interpretation of the upper limit observation by Trauger and Lunine (1983). Many studies have examined the vertical, geographic, and temporal distribution of the visible and IR airglow emitted as excited states of $\mathrm{O}_{2}$ decay radiatively to the ground-state. These studies are summarised in Gérard et al. (2017).

Indirect evidence for day side ozone comes from the more intense $\mathrm{O}_{2}\left(\mathrm{a}^{1} \Delta-\mathrm{X}^{3} \Sigma\right)$ airglow observed on the day side (Connes et al. 1979). The presence of $\mathrm{O}_{3}$ near $95 \mathrm{~km}$ altitude on the night side has been inferred from observations of night side $\mathrm{OH}$ airglow as summarised in Gérard et al. (2017). Ozone was identified more directly in the atmosphere of Venus by the SPICAV/UV instrument (Montmessin et al. 2011) on board Venus Express. The SPICAV/UV detection is characterised by a vertically confined layer in the night side thermosphere at a mean altitude of $100 \mathrm{~km}$. The ozone peak concentrations are of the order of $10^{7}-10^{8}$ molecules $\mathrm{cm}^{-3}$. The observed night side ozone concentrations are consistent with the chlorine-catalysed destruction schemes included in early global-average models (Yung and Demore 1999). However, Krasnopolsky (2013a) found good agreement between the night side observations above $90 \mathrm{~km}$ and a night time model could only be achieved with a strong flux of $\mathrm{H}\left(10^{10} \mathrm{~cm}^{-2} \mathrm{~s}^{-1}\right)$ from the day side to the night side. An alternative model with strong fluxes of both $\mathrm{H}$ and $\mathrm{Cl}\left(10^{10} \mathrm{~cm}^{-2} \mathrm{~s}^{-1}\right)$ from the day side to the night side gave similar results above $90 \mathrm{~km}$ and significantly reduced ozone abundances below $90 \mathrm{~km}$, an altitude region in which ozone has not been measured yet (Krasnopolsky 2013a). Further study in multi-dimensional chemical transport models of the coupled system of $\mathrm{O}_{3}$, $\mathrm{O}_{2}\left(a^{1} \Delta\right)$, and $\mathrm{OH}$ is required.

\subsubsection{Overview of Current 1-D Photochemical Models}

The earliest photochemical models that resemble the current understanding of mesospheric chemistry on Venus were the sulphur chemistry model by Winick and Stewart (1980), the chlorine chemistry model by Krasnopolsky and Parshev (1981a,b, 1983), and the hydrogen, nitrogen, and chlorine chemistry models by Yung and DeMore (1982). All were 1-D global average models with reasonably comprehensive neutral chemistry that spanned the 60-110 km altitude range; all focused on the oxidation chemistry that dominates in the mesosphere; and all gave reasonable agreement with the then extant observations.

Of these models, the one with most relevance today is the chlorine chemistry model, model C, from Yung and DeMore (1982). The Winick and Stewart (1980) model had the most limited chemistry and key aspects do not agree with subsequent findings. The models by Krasnopolsky and Parshev (1981a,b, 1983) took the equilibrium constant for ClCO from a compilation that was incorrect due to a typographical error. This meant $\mathrm{ClCO}$ in their modeling was two orders of magnitude more stable than laboratory studies had found. Subsequent work (Pernice et al. 2004) confirmed Reaction (9c), originally proposed by Yung and DeMore (1982), is viable and dominates CO oxidation. Based on the altitude profile for $\mathrm{CO}$ oxidation and the simulated abundance of $\mathrm{Cl}_{2}$, a candidate for the unidentified UV absorber, Yung and DeMore (1982) felt their chlorine chemistry model was the most realistic. In addition, their hydrogen model required too much $\mathrm{H}_{2}$ and was based on the interpretation 
(later revised) that the mass 2 ion detected in the ionosphere was $\mathrm{H}^{+}$while their nitrogen model required too much $\mathrm{NO}$ and $\mathrm{H}_{2}$.

As mentioned in Sect. 2, reviews in the mid-1980s (von Zahn et al. 1983; Prinn 1985) summarised global sulphur chemistry on Venus in terms of three cycles: the fast atmospheric, slow atmospheric, and geologic sulphur cycles. More recent reviews (Mills et al. 2007; Mills and Allen 2007), summarised mesospheric sulphur chemistry in terms of two cycles: the sulphur oxidation and polysulphur cycles, which correspond roughly, but not exactly, to the fast and slow atmospheric cycles, respectively. One of the conceptual changes from early work has been the inclusion of oxidation of OCS to form SO as part of the sulphur oxidation and fast atmospheric sulphur cycles (Krasnopolsky 2007, 2013b; Mills et al. 2007). In addition, Mills et al. (2007) and Mills and Allen (2007) formally posited the carbon dioxide cycle, which had been studied previously but not named. The most recent comprehensive 1-D photochemical models for the Venus mesosphere are Mills and Allen (2007), Zhang et al. (2012), and Krasnopolsky (2012a). Other, more specialised recent models, include Mills et al. (2006), Zhang et al. (2010), Krasnopolsky (2010c, 2011, 2013a), Parkinson et al. (2015a,b), and Jessup et al. (2015). Detailed descriptions of these models are provided in the original publications. Discussion of key results from the more recent models is grouped below by topic. Mills et al. (2007) reviews the state of knowledge of the composition, chemistry, and clouds for Venus' neutral atmosphere prior to the Venus Express mission.

$\mathrm{CO}, \mathrm{O}_{2}, \mathrm{CICO}$, and $\mathrm{CIC}(\mathrm{O}) \mathrm{OO}$ The carbon dioxide cycle maintains the chemical stability of the primary constituent of Venus' atmosphere. Although it has received less attention during the Venus Express era, it presents one of the most important unsolved conundrums for Venus' atmosphere. Specifically, even with the introduction of fast catalytic cycles to oxidise $\mathrm{CO}$, such as Reaction (9a)-(9c), the modeled $\mathrm{O}_{2}$ mesospheric column abundance above $58 \mathrm{~km}$ altitude for models with standard chemistry is a factor of 10 larger than the most stringent upper limit on ground-state $\mathrm{O}_{2}$ (Trauger and Lunine 1983; Krasnopolsky 2006b). Model simulations of $\mathrm{O}_{2}$ column abundances above $58 \mathrm{~km}$ and observational upper limits are shown in Table 3 [corresponding references in table caption].

$$
\begin{aligned}
\mathrm{Cl}_{2}+h v & \rightarrow 2 \mathrm{Cl} \\
\mathrm{Cl}+\mathrm{CO} & \rightarrow \mathrm{ClCO} \\
\mathrm{ClCO}+\mathrm{O}_{2} & \rightarrow \mathrm{ClC}(\mathrm{O}) \mathrm{OO}
\end{aligned}
$$

The peroxychloroformyl radical, $\mathrm{ClC}(\mathrm{O}) \mathrm{OO}$, plays a central role in the modeled oxidation of CO. The experimental and ab initio work in Pernice et al. (2004) confirmed its existence and its stability at mesospheric temperatures, as well as validating the production path, Reaction (9c), that had been postulated by Yung and DeMore (1982) based on their own experimental work. Simulations with a 1-D global average model in which the thermal stability of $\mathrm{ClCO}$ was enhanced by the assessed uncertainty (Sander et al. 2003) quantified the contributions from the major CO oxidation pathways (Pernice et al. 2004).

The critical parameter determining the efficiency of Reaction (9a)-(9c) is the thermal stability of $\mathrm{ClCO}$, and model simulations of the $\mathrm{O}_{2}$ mesospheric column abundance are very sensitive to this, as discussed in Mills and Allen (2007), even though the uncertainty in the thermal stability of $\mathrm{ClCO}$, expressed as the uncertainty in its equilibrium constant, is small by laboratory standards. Enhanced thermal stability for $\mathrm{ClCO}$ was originally proposed by Mills (1998) as a way to reduce the difference between modelled and observed $\mathrm{O}_{2}$ mesospheric column abundances. The same enhanced thermal stability for $\mathrm{ClCO}$ was adopted in 
Table $3 \mathrm{O}_{2}$ column abundance from models and observational upper limits

\begin{tabular}{|c|c|c|c|c|c|c|c|}
\hline \multicolumn{2}{|c|}{ Observations } & \multicolumn{6}{|c|}{ Model Calculations } \\
\hline Year & $\operatorname{Limit}^{\dagger \alpha}$ & Model & Column $^{\dagger \dagger}$ & Model & Column ${ }^{\dagger \dagger}$ & Model & Column ${ }^{\dagger \dagger}$ \\
\hline $1972^{\mathrm{a}}$ & $<10$ & nominal $^{\mathrm{f}}$ & 3.7 & $1-\sigma(a)^{h}$ & 30.5 & $\mathrm{~A}^{\mathrm{k}}$ & 1.9 \\
\hline $1982^{b}$ & $<1.5$ & $A^{g}$ & 7.3 & $1-\sigma(b)^{\mathrm{h}}$ & $2.14^{\beta}$ & $\mathrm{B}^{\mathrm{k}}$ & 1.9 \\
\hline $1982^{c}$ & $<0.8$ & $\mathrm{~B}^{\mathrm{g}}$ & 23 & $1-\sigma(\mathrm{c})^{\mathrm{h}}$ & 2.13 & $\mathrm{C}^{\mathrm{k}}$ & 1.8 \\
\hline $1995^{\mathrm{d}}$ & $<15$ & $\mathrm{C}^{\mathrm{g}}$ & 18 & aerosol $^{\mathrm{i}}$ & 2.6 & $\mathrm{~A}^{\mathrm{l}}$ & 2.2 \\
\hline \multirow[t]{4}{*}{$1995^{\mathrm{e}}$} & $<4.8$ & & & nominal $^{j}$ & 8.6 & $\mathrm{~B}^{1}$ & 2.3 \\
\hline & & & & $0.5-\sigma^{\mathrm{j}}$ & 3.1 & nominal $^{\mathrm{m}}$ & 7.6 \\
\hline & & & & $1-\sigma^{\mathrm{j}}$ & 2.4 & & \\
\hline & & & & $2-\sigma^{\mathrm{j}}$ & 2.0 & & \\
\hline
\end{tabular}

$\dagger 10^{18}$ per $\mathrm{cm}^{2}$.

$\alpha_{2-\sigma}$ upper limits.

¥ Integrated from $58 \mathrm{~km}$ altitude to top of atmosphere.

$\beta$ Absorption is equivalent to that from an $\mathrm{O}_{2}$ column abundance of $0.75 \cdot 10^{18}$ per $\mathrm{cm}^{2}$ with a uniform mixing ratio (Mills 1999) for that viewing geometry.

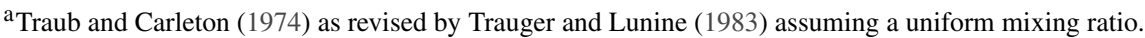

${ }^{\mathrm{b}}$ Trauger and Lunine (1983) assuming a uniform mixing ratio.

${ }^{\mathrm{c}}$ Trauger and Lunine (1983) as interpreted by Krasnopolsky (2006b).

${ }^{\mathrm{d}}$ Mills (1999) assuming a uniform mixing ratio.

${ }^{\mathrm{e}}$ Mills (1999) as interpreted by Krasnopolsky (2006b).

${ }^{f}$ Krasnopolsky and Parshev (1981b) as reported by Krasnopolsky (1986, p. 267).

g Yung and DeMore (1982) with (A) high $\mathrm{H}_{2}$, (B) $\mathrm{NO}_{x}$, and (C) $\mathrm{ClC}(\mathrm{O}) \mathrm{OO}$.

${ }^{h}$ Pernice et al. (2004) with thermal stability of $\mathrm{ClCO}$ increased by the assessed uncertainty in the equilibrium constant (Sander et al. 2003)** (a) without $\mathrm{ClC}(\mathrm{O}) \mathrm{OO}$, (b) with $\mathrm{ClC}(\mathrm{O}) \mathrm{OO}$ kinetic reactions, and (c) with $\mathrm{ClC}(\mathrm{O}) \mathrm{OO}$ photolysis and kinetic reactions.

${ }^{\mathrm{i}}$ Mills et al. (2006) with postulated heterogeneous reaction, $\mathrm{CO}+\mathrm{O}+$ aerosol $\rightarrow \mathrm{CO}_{2}+$ aerosol, and assumed reactive uptake coefficient of $10^{-5}$.

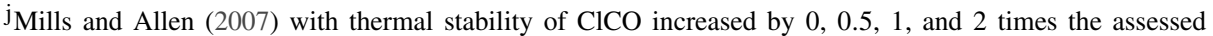
uncertainty in the equilibrium constant (Sander et al. 2003)** and model atmosphere temperatures (Seiff $1983)$ at $84-90 \mathrm{~km}$ decreased by $6 \mathrm{~K}$.

${ }^{\mathrm{k}}$ Zhang et al. (2010) with (A) standard chemistry, (B) the $\mathrm{H}_{2} \mathrm{SO}_{4}$ visible wavelength cross section increased by a factor of 100 and an $\mathrm{H}_{2} \mathrm{SO}_{4}$ saturation ratio of 0.5 , and (C) the $\mathrm{H}_{2} \mathrm{SO}_{4}$ visible wavelength cross section increased by a factor of 100 and an $\mathrm{H}_{2} \mathrm{SO}_{4}$ saturation ratio of 10 .

${ }^{\mathrm{l}}$ Zhang et al. (2012) with thermal stability of $\mathrm{ClCO}$ increased by the assessed uncertainty in the equilibrium constant from Sander et al. (2003)** and enhanced (A) $\mathrm{H}_{2} \mathrm{SO}_{4}$ and (B) $\mathrm{S}_{8}$ above $90 \mathrm{~km}$.

${ }^{\mathrm{m}}$ Krasnopolsky (2012a).

** The assessed uncertainty from Sander et al. (2003) has subsequently been reduced by a factor of 5-15 (Burkholder et al. 2015) (over the 170-260 K temperature range found in Venus' middle atmosphere), so the $1-\sigma$ model above has now become a $10-\sigma$ model.

Mills et al. (2006), Mills and Allen (2007), Zhang et al. (2010, 2012), and Parkinson et al. (2015a,b). The nominal assessed equilibrium constant from Sander et al. (2003) is the same as that from the laboratory study by Nicovich et al. (1990), but the assessed uncertainty in Sander et al. (2003) was significantly larger than in Nicovich et al. (1990). The old 1- $\sigma$ 
(Sander et al. 2003) enhancement that was introduced by Mills (1998) in the thermal stability for $\mathrm{ClCO}$ was equivalent to a factor of 11 change in the $\mathrm{ClCO}$ equilibrium constant at $200 \mathrm{~K}$. Krasnopolsky (2012a) assumed a factor of 1.5 uncertainty at $200 \mathrm{~K}$ in the $\mathrm{ClCO}$ equilibrium constant, while the revised assessed $1-\sigma$ uncertainty in the $\mathrm{ClCO}$ equilibrium constant is a factor of 1.2 at $200 \mathrm{~K}$ (Burkholder et al. 2015). The change in the assessed uncertainty does not necessarily invalidate the assumption used in the models noted above but suggests $\mathrm{ClCO}$ is much less likely to have the degree of stability assumed in those models. This will reduce the effectiveness of chlorine-catalysed oxidation of $\mathrm{CO}$ and significantly increase the simulated $\mathrm{O}_{2}$ mesospheric column abundance.

Mills et al. (2006) explored several alternative pathways for oxidation of CO. One of these, Reaction (10), was found to reduce the $\mathrm{O}_{2}$ mesospheric column abundance to within a factor of two of the Trauger and Lunine (1983) upper limit on $\mathrm{O}_{2}$. However, as discussed by Mills and Allen (2007), the enhanced oxidation of CO from Reaction (10) reduces the CO abundance in the lower mesosphere to a level that is significantly smaller than is observed. No further work has examined either the carbon dioxide cycle or the discrepancy between simulated and observed ground-state $\mathrm{O}_{2}$.

$$
\mathrm{CO}+\mathrm{O}+\text { aerosol } \rightarrow \mathrm{CO}_{2}+\text { aerosol }
$$

HCl All published model profiles for $\mathrm{HCl}$ show similar behaviour: a nearly constant mixing ratio from 60 to $80 \mathrm{~km}$, a gradual decrease from 80 to $95 \mathrm{~km}$, and then a more rapid decrease above $95 \mathrm{~km}$ to $112 \mathrm{~km}$. In Krasnopolsky (2012a), for example, the mixing ratio of $\mathrm{HCl}$ decreased from $400 \mathrm{ppb}$ at $60 \mathrm{~km}$ to $310 \mathrm{ppb}$ at $112 \mathrm{~km}$, while in Mills and Allen (2007) the mixing ratio of $\mathrm{HCl}$ decreased from $400 \mathrm{ppb}$ at $60 \mathrm{~km}$ to $120 \mathrm{ppb}$ at $112 \mathrm{~km}$. Observations during the Venus Express mission disagree with these model profiles but the observations from different instruments are not consistent with each other, as discussed in Sect. 2.3.3. Further work is needed to reconcile the differences amongst the observations and models.

SO $_{x}$ Sulfur species are central to understanding chemistry and climate on Venus. Within and above the clouds, OCS and $\mathrm{SO}_{2}$ are transported upward and disproportionated into $\mathrm{SO}_{3}$ and $\mathrm{S}_{x}$, polysulfur. In the sulphur oxidation cycle, $\mathrm{SO}_{3}$ reacts with $\mathrm{H}_{2} \mathrm{O}$ to form $\mathrm{H}_{2} \mathrm{SO}_{4}$ which condenses to form the global cloud and haze layers. In the polysulphur cycle, $\mathrm{S}_{x}$ builds up to $S_{8}$. This may, for example, be initiated via Reactions (11) or (12) (Krasnopolsky and Parshev 1981a; Prinn 1975) and may proceed via through association reactions and/or reactions involving chlorosulfanes (Mills and Allen 2007). $\mathrm{S}_{8}$ condenses and may form condensation nuclei for growing sulphuric acid droplets. A portion of the condensed particles grow until they settle into the lower atmosphere where they evaporate to produce $\mathrm{SO}_{2}$ and OCS. The observations described in Sect. 2.3.3 have provided information on the vertical profiles of $\mathrm{SO}$ and $\mathrm{SO}_{2}$ and the geographical and temporal variability of these vertical profiles. The observational feature that has been the focus for most modeling during the Venus Express mission is the inversion layer in the upper mesosphere where $\mathrm{SO}$ and $\mathrm{SO}_{2}$ mixing ratios increase with increasing altitude at about $84-100 \mathrm{~km}$.

$$
\begin{aligned}
& \mathrm{SO}+\mathrm{SO} \rightarrow \mathrm{SO}_{2}+\mathrm{S} \\
& \mathrm{S}+\mathrm{OCS} \rightarrow \mathrm{S}_{2}+\mathrm{CO}
\end{aligned}
$$

No 1-D photochemical model with standard chemistry has reproduced the upper mesosphere inversion layer for $\mathrm{SO}_{2}$. As shown in Fig. 5, models with standard photochemistry 
(Mills and Allen 2007; Krasnopolsky 2012a; Parkinson et al. 2015b) calculate a volume mixing ratio profile for $\mathrm{SO}_{2}$ that is constant or decreases slowly with increasing altitude at $80-100 \mathrm{~km}$. None of these models included photolysis of gas-phase $\mathrm{H}_{2} \mathrm{SO}_{4}$. All found a narrow layer near $65 \mathrm{~km}$ where $\mathrm{SO}_{2}$ is rapidly oxidised to $\mathrm{H}_{2} \mathrm{SO}_{4}$. Because of its low vapour pressure, the $\mathrm{H}_{2} \mathrm{SO}_{4}$ is presumed to condense readily in this same layer, thereby maintaining the upper cloud and effectively sequestering a significant fraction of Venus' sulphur oxide in a relatively non-reactive form. Variable transport of $\mathrm{SO}_{2}$ and $\mathrm{H}_{2} \mathrm{O}$ through this layer, for example via small variations in eddy diffusion (Krasnopolsky 2012a), may produce large variations in $\mathrm{SO}, \mathrm{SO}_{2}$, and OCS above $70 \mathrm{~km}$. Factor of 30 variations in $\mathrm{SO}_{2}$ at $70-100 \mathrm{~km}$ altitude were produced by changing the transition altitude in the adopted eddy diffusion profile from $60 \mathrm{~km}$ to 55 and $65 \mathrm{~km}$ (Krasnopolsky 2012a). Krasnopolsky (2012a) reported similar sensitivity to the model's lower boundary condition for $\mathrm{SO}_{2}$ using a boundary condition of $21 \mathrm{ppm}$ of $\mathrm{H}_{2} \mathrm{O}$ at $47 \mathrm{~km}$. The sensitivity of the coupled $\mathrm{SO}_{2}-\mathrm{H}_{2} \mathrm{O}-\mathrm{H}_{2} \mathrm{SO}_{4}$ system to assumed boundary conditions below $60 \mathrm{~km}$ (Parkinson et al. 2015b) is reviewed in the next section below.

Two sets of models have produced an upper mesosphere inversion layer for $\mathrm{SO}_{2}$ (Zhang et al. 2010, 2012). In both studies, the source for upper mesospheric sulphur is evaporation above $90 \mathrm{~km}$ of condensed sulphur, either sulphuric acid or polysulphur, that was transported upward in the condensed phase from the upper cloud. In all simulations, photolysis of sulphuric acid and polysulphur was included, and the vertical profile of condensed sulphur was specified a priori so that the calculations produced an $\mathrm{SO}_{2}$ vertical profile which agreed with the observed upper mesosphere $\mathrm{SO}_{2}$ inversion layer. However, the $\mathrm{H}_{2} \mathrm{SO}_{4}$ profiles calculated by Krasnopolsky (2011) are smaller by 6-9 orders of magnitude, largely due to the differing temperature profile used. Furthermore, the observational upper limit of 3 ppbv on gas-phase $\mathrm{H}_{2} \mathrm{SO}_{4}$ at $85-100 \mathrm{~km}$ (Sandor et al. 2012) rules out both the proposed $\sim 1000$ ppbv gasphase $\mathrm{H}_{2} \mathrm{SO}_{4}$ simulations of Zhang et al. (2010) and the lower, but still enhanced, sulphuric acid abundances of Zhang et al. (2012) (Belyaev et al. 2012).

No satisfactory upper mesosphere source of $\mathrm{SO}_{2}$ has been identified in models to date, but all observations require that one must exist, both to explain the upper mesosphere $\mathrm{SO}_{2}$ inversion layer and to balance the sulphur budget (Vandaele et al. 2017). Temporal and geographic variations in observed $\mathrm{SO}_{2}$ and $\mathrm{SO}$ have shown that at least one more photochemically active sulphur reservoir (besides $\mathrm{SO}_{2}, \mathrm{SO}$, and OCS) must exist throughout the mesosphere (Sandor et al. 2010; Jessup et al. 2015). Observations of $\mathrm{SO}_{3}$ in the upper mesosphere (Zhang et al. 2012; Belyaev et al. 2012) may help elucidate the identity of this additional sulphur reservoir, while further research that links photochemistry and dynamics is needed to identify the physical mechanisms driving these variations.

Further modeling also is required for conditions that more closely simulate the mesospheric observations made across the terminator. Almost all simulations to date have considered global average or diurnal average conditions (Mills and Allen 2007; Zhang et al. 2010, 2012; Krasnopolsky 2012a; Parkinson et al. 2015b). Simulations of the solar zenith angle dependence for the steady-state $\mathrm{SO}_{2}$ and $\mathrm{SO}$ vertical profile, however, suggest there may be significant differences between the averaged vertical profile of $\mathrm{SO}_{2}$ and its profile near the terminator (Jessup et al. 2015).

$\mathbf{S}_{x}$ Polysulfur, $\mathrm{S}_{x}$, species may help explain the upper mesosphere inversion layer (above), may be condensation nuclei for sulphuric acid in the cloud and haze layers, and may be the unidentified UV absorber. Production in early models proceeded via association reactions, like

$$
2 \mathrm{~S}_{2}+\mathrm{M} \rightarrow \mathrm{S}_{4}+\mathrm{M}
$$


but Mills and Allen (2007) showed chlorosulphanes, $\mathrm{Cl}_{n} \mathrm{~S}_{m}$, may catalyse enhanced production of $S_{x}$. Some of their work was adopted by Zhang et al. (2012), while other elements of Zhang et al. (2012) were drawn from the contemporaneously-developed chlorosulphane chemistry in Moses et al. (2002). In contrast, Krasnopolsky (2016) argues that production of sulphur aerosol $\left(S_{x}, x \geq 4\right)$ in middle atmosphere photochemical models is too small by at least two orders of magnitude for sulphur aerosol to be an important component of the upper cloud. One problem with this assessment is that all middle atmosphere photochemical models overestimate oxygen abundances in the upper cloud by at least one order of magnitude and production of polysulphur is sensitive to the oxidation state of the upper cloud (Mills and Allen 2007). Further, the results in Krasnopolsky (2016) do not necessarily preclude sulphur aerosol having a significant role as condensation nuclei. Further laboratory and photochemical and microphysical modeling work is needed to elucidate the roles of polysulphur in Venus' atmosphere.

$\mathbf{S O}_{2}$ and $\mathrm{H}_{2} \mathrm{O}$ Regulation via Formation of $\mathrm{H}_{2} \mathbf{S O}_{4} \quad$ Krasnopolsky (2011) calculated a profile of $\mathrm{H}_{2} \mathrm{SO}_{4}$ vapor by solving the continuity equations that account for condensation and sublimation of $\mathrm{H}_{2} \mathrm{O}$ and $\mathrm{H}_{2} \mathrm{SO}_{4}$ vapors, their photolyses, and vertical transport by eddy diffusion. He argued that the temperatures of $250 \mathrm{~K}$ near $96 \mathrm{~km}$ disagree with rotational temperature of the $\mathrm{O}_{2}$ nightglow at $1.27 \mu \mathrm{m}$ that is equal to $187 \pm 3 \mathrm{~K}$ in observations by five independent teams. A radiative lifetime is $1.2 \mathrm{~h}$ for this nightglow, and its peak is at 95$100 \mathrm{~km}$, so that the rotational temperature should be similar to the kinetic temperature near $96 \mathrm{~km}$. The temperatures of $250 \mathrm{~K}$ disagree with the radio-occultation and infrared observations at 15 and $4.3 \mu \mathrm{m}$ as well. Furthermore, the nighttime conditions are not applicable to the $\mathrm{H}_{2} \mathrm{SO}_{4}$ photolysis that occurs on the day side. The calculated abundances and photolysis rates of $\mathrm{H}_{2} \mathrm{SO}_{4}$ vapor in Krasnopolsky (2011) are smaller than those adopted in Zhang et al. (2010, 2012) by many orders of magnitude.

Observations indicate there is significant variability in the abundances of $\mathrm{SO}_{2}$ and $\mathrm{H}_{2} \mathrm{O}$ in the mesosphere, but there is no observational evidence to date for significant variability of either species in the troposphere. This suggests the mesospheric variability arises from variations in (a) vertical transport, (b) temperature, (c) local solar flux intensity, and/or (d) interaction with cloud particles and aerosols via evaporation and condensation. In addition (or alternatively), mesospheric chemistry may have a strong sensitivity to small variations in the abundances or relative abundances of $\mathrm{SO}_{2}$ and $\mathrm{H}_{2} \mathrm{O}$. These potential causes for the observed mesospheric variability are the focus for this section, which explores the couplings amongst the components of the $\mathrm{SO}_{2}-\mathrm{H}_{2} \mathrm{O}-\mathrm{H}_{2} \mathrm{SO}_{4}$-aerosol system. The consequences for microphysical cloud modelling are discussed in Section VI.B. Three salient points to note: (1) the abundances of $\mathrm{H}_{2} \mathrm{O}$ and $\mathrm{SO}_{2}$ below the lower clouds at $\sim 40 \mathrm{~km}$ are similar ( $\sim 30$ ppmv for water and $\sim 130-140$ ppmv for $\mathrm{SO}_{2}$, Sect. 2.1); (2) the abundances of both $\mathrm{H}_{2} \mathrm{O}$ and $\mathrm{SO}_{2}$ decrease rapidly with increasing altitude within the upper cloud at $\sim 65 \mathrm{~km}$; and (3) the primary mechanism for removing $\mathrm{H}_{2} \mathrm{O}$ and $\mathrm{SO}_{2}$ is formation of $\mathrm{H}_{2} \mathrm{SO}_{4}$ aerosols.

A study by Parkinson et al. (2015b) examines the photochemical control of the distribution of Venusian water using the updated Caltech/JPL kinetics model. They show that $\mathrm{SO}_{2}$ and $\mathrm{H}_{2} \mathrm{O}$ can regulate each other via formation of $\mathrm{H}_{2} \mathrm{SO}_{4}$. In regions of high mixing ratios of $\mathrm{SO}_{2}$ there exists a runaway effect such that $\mathrm{SO}_{2}$ gets oxidised to $\mathrm{SO}_{3}$, which quickly soaks up $\mathrm{H}_{2} \mathrm{O}$ causing a major depletion of water between 70 and $100 \mathrm{~km} . \mathrm{SO}_{2}$ exchanges rapidly with $\mathrm{SO}$ and $\mathrm{SO}_{3}$. However, formation of $\mathrm{H}_{2} \mathrm{SO}_{4}$ followed by condensation sequesters $\mathrm{SO}_{2}$ in aerosol particles and removes it from active chemistry. The reaction that forms $\mathrm{H}_{2} \mathrm{SO}_{4}$ 
appears to involve a complex with $\mathrm{H}_{2} \mathrm{O}$, viz.:

$$
\begin{gathered}
\mathrm{SO}_{3}+\mathrm{H}_{2} \mathrm{O} \rightarrow \mathrm{SO}_{3} \cdot \mathrm{H}_{2} \mathrm{O} \\
\mathrm{SO}_{3} \cdot \mathrm{H}_{2} \mathrm{O} \rightarrow \mathrm{H}_{2} \mathrm{SO}_{4}
\end{gathered}
$$

$\mathrm{H}_{2} \mathrm{O}$ is removed above the cloud tops by formation of $\mathrm{H}_{2} \mathrm{SO}_{4}$. Parkinson et al. (2015b) show the vertical profile of $\mathrm{H}_{2} \mathrm{O}$ is relatively constant, falling off slightly with height where $\mathrm{H}_{2} \mathrm{O}$ at the lower boundary is 35 ppmv. As the $\mathrm{H}_{2} \mathrm{O}$ decreases from 30 to $18 \mathrm{ppmv}$ at the lower boundary, there is corresponding decrease in the $\mathrm{H}_{2} \mathrm{O}$ higher up due to $\mathrm{H}_{2} \mathrm{O}$ removal. As $\mathrm{H}_{2} \mathrm{O}$ concentration at the lower boundary is further lowered to 17,15 and $10 \mathrm{ppmv}$, there is a sudden falloff of $\mathrm{H}_{2} \mathrm{O}$ above $\sim 65 \mathrm{~km}$. The reason is the complete sequestration of $\mathrm{H}_{2} \mathrm{O}$ by $\mathrm{H}_{2} \mathrm{SO}_{4}$ aerosols. Thus, $\mathrm{H}_{2} \mathrm{O}$ could exhibit a chemical bifurcation as its value falls below a critical value.

Parkinson et al. (2010) and Krasnopolsky (2012a) find that the abundances of sulphur species are very sensitive to small variations of eddy diffusion and the adopted $\mathrm{SO}_{2}$ mixing ratio at the lower boundary. Eddy diffusion sensitivity studies performed by Parkinson et al. (2015b) characterising variability due to mixing show less of an effect than varying the lower boundary mixing ratio value. However, calculations using their nominal eddy diffusion profile multiplied and divided by a factor of four can give an order of magnitude maximum difference in the $\mathrm{SO}_{2}$ mixing ratio and a factor of a few difference in the $\mathrm{H}_{2} \mathrm{O}$ mixing ratio when compared with the respective nominal mixing ratio for these two species. In addition to explaining some of the observed variability in $\mathrm{SO}_{2}$ and $\mathrm{H}_{2} \mathrm{O}$ on Venus, their work can also shed light on the observations of dark and bright contrasts at the Venus cloud tops observed in the ultraviolet spectrum. Parkinson et al. (2015b) calculations produce results in agreement with the Venus Express/SOIR results of 1 ppmv at 70-90 km (Bertaux et al. 2007a) by using a $\mathrm{SO}_{2}$ mixing ratio of $25 \mathrm{ppm}$ and $18 \mathrm{ppm}$ water as the nominal reference values. Plots showing the mixing ratio for water and $\mathrm{SO}_{2}$ at $80 \mathrm{~km}$ for paired values of $\mathrm{SO}_{2}$ and $\mathrm{H}_{2} \mathrm{O}$ mixing ratios at $58 \mathrm{~km}$ are shown in Fig. 6. Timescales for a chemical bifurcation causing a collapse of water concentrations above the cloud tops $(>64 \mathrm{~km})$ are relatively short and on the order of less than a few months, decreasing with altitude to less than a few days.

The modelled range of lower boundary values considered in Fig. 6 are $10 \mathrm{ppmv} \leq$ $q\left(\mathrm{H}_{2} \mathrm{O}\right) \leq 35 \mathrm{ppmv}$ and $5 \mathrm{ppmv} \leq q\left(\mathrm{SO}_{2}\right) \leq 75 \mathrm{ppmv}$ at $58 \mathrm{~km}$, with calculated values plotted for $80 \mathrm{~km}$ indicating what range of values at $58 \mathrm{~km}$ are implied by the observations at $80 \mathrm{~km}$ if the proposed mechanism is correct. Overlaid on the plot are the net bracketed range (approximated by diagonal lines) of observed values at $80 \mathrm{~km}$ corresponding to $q\left(\mathrm{SO}_{2}\right)$ and $q\left(\mathrm{H}_{2} \mathrm{O}\right)$ on Fig. 6 (for $\mathrm{SO}_{2}$ measurements, see also Fig. 5: $q\left(\mathrm{SO}_{2}\right) \sim 0.01$ to $0.2 \mathrm{ppmv}$; from Cottini et al. (2015) and references contained therein, $f\left(\mathrm{H}_{2} \mathrm{O}\right) \sim 2$ to 7 ppmv using combined lower and upper latitude values). Using the observed values in a simple comparison with the modelled results, we can predict the range of values of $q\left(\mathrm{SO}_{2}\right)$ with corresponding $q\left(\mathrm{H}_{2} \mathrm{O}\right)$ values (or conversely) at $58 \mathrm{~km}$ for any colour contour in the valid bracketed region. Given the lack of actual measurements at $58 \mathrm{~km}$ - except maybe those from TEXES (Encrenaz et al. 2012, 2013) near $19 \mu \mathrm{m}$, but there is a large uncertainty of their effective sounding altitude- "observational constraints" at this altitude aren't possible for a direct comparison with the model, although, if the proposed mechanism is correct, they should overlap with the estimates predicted above. The dearth of direct observations at $58 \mathrm{~km}$ strongly indicates some measurements need to be made inside the poorly known cloud region (see also Sect. 6.2). 

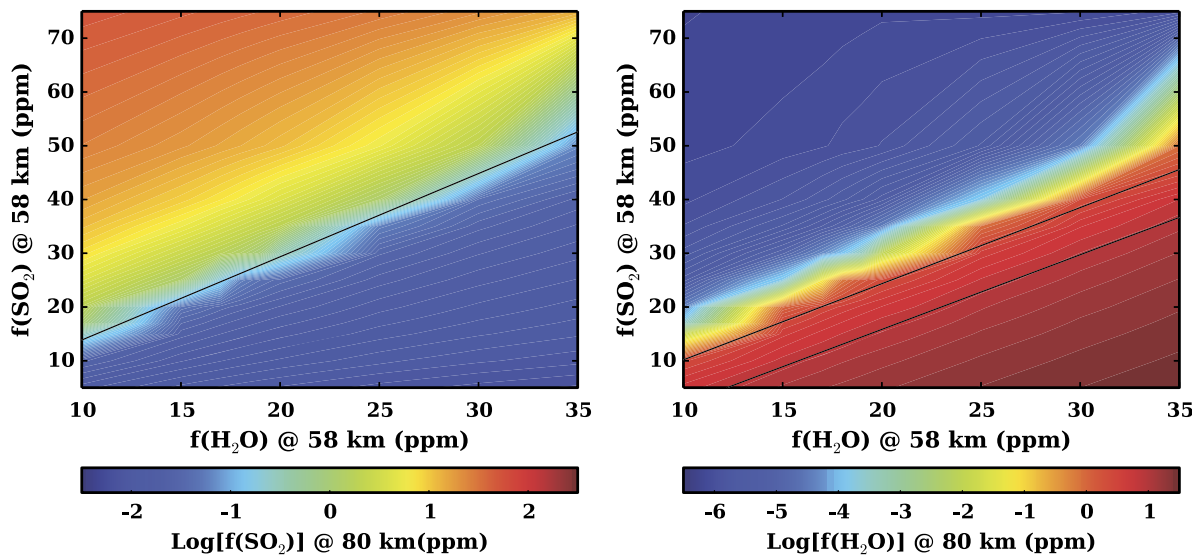

Fig. 6 Left: Water sensitivity study: mixing ratio of $\mathrm{SO}_{2}$ at $80 \mathrm{~km}$ for paired values of $\mathrm{SO}_{2}$ and $\mathrm{H}_{2} \mathrm{O}$ mixing ratios at $58 \mathrm{~km}$ over the range of values from Figs. 7 and 8 in Parkinson et al. (2015b). Right: $\mathrm{SO}_{2}$ sensitivity study: mixing ratio of $\mathrm{H}_{2} \mathrm{O}$ at $80 \mathrm{~km}$ for paired values of $\mathrm{SO}_{2}$ and $\mathrm{H}_{2} \mathrm{O}$ mixing ratios at $58 \mathrm{~km}$ over the range of values from Figs. 7 and 8 in Parkinson et al. (2015b)

$\mathrm{H}_{2} \mathrm{O}, \mathrm{H}_{2} \mathrm{SO}_{4}$ Vapour, and Sulphuric Acid Concentration in the Clouds The coupled problem of diffusion and gas exchange between the gaseous and aerosol phases in the binary mixture of $\mathrm{H}_{2} \mathrm{O}$ and $\mathrm{H}_{2} \mathrm{SO}_{4}$ in the clouds of Venus was studied by Krasnopolsky (2015). The calculated $\mathrm{H}_{2} \mathrm{O}$ mixing ratio decreases from $22 \mathrm{ppm}$ at the cloud bottom, $47 \mathrm{~km}$, to $3 \mathrm{ppm}$ at $65-75 \mathrm{~km}$, while $\mathrm{H}_{2} \mathrm{SO}_{4}$ vapour peaks at $7 \mathrm{ppm}$ near the cloud bottom and decreases to $\approx 1 \mathrm{ppm}$ at $52 \mathrm{~km}$, in accord with Magellan (Kolodner and Steffes 1998) and Venus Express (Oschlisniok et al. 2012) observations. Sulphuric acid concentration decreases in the clouds from $98 \%$ at $50 \mathrm{~km}$ to $80 \%$ at $60 \mathrm{~km}$ and then is almost constant up to $75 \mathrm{~km}$. Latitudinal variations of these values up to $60^{\circ}$ were calculated as well. The calculated concentration near $50 \mathrm{~km}$ is significantly higher than the $\approx 90 \%$ and $\approx 80 \%$ reported based on VEx/VIRTIS-M (Barstow et al. 2012) and ground-based (Arney et al. 2014) observations, respectively.

\section{Horizontal Variability of Minor Species}

\subsection{Lower Atmosphere and Clouds (0-70 km)}

\subsubsection{Latitudinal Variability}

Latitudinal variability of minor species in the deep atmosphere of Venus is thought to arise from two physical phenomena: (1) that these minor species exhibit non-uniform vertical profiles (see Sect. 2); and (2) that vertical transport in the atmosphere is coupled to planetaryscale meridional transport through global convection cells ${ }^{1}$ The observation of such latitudinal contrasts below the clouds is therefore a telltale sign that these large convection cells are not restricted to the cloud layers where most of solar energy is deposited, but rather extend deeply into the troposphere and reach the altitude range where the latitudinal contrasts are observed.

\footnotetext{
${ }^{1}$ Often named Hadley-cell circulation by analogy with Earth's general circulation in the tropics.
} 
According to this rationale, $\mathrm{CO}$ and $\mathrm{OCS}$, which are both known to exhibit vertical gradients in the altitude range that we can probe on the night side in the $2.3 \mu \mathrm{m}$ window (see Sect. 2.1), are also expected to display some latitudinal variability: $\mathrm{CO}$, which increases with increasing altitudes, should be more abundant in high latitude, downwelling regions (and conversely for OCS). On the other hand, water vapour is not expected to vary with latitude, since the vertical profile of water vapour is remarkably uniform below the clouds (see Sect. 2.1). All available observations (on the night side) are fully compatible with this interpretation.

CO Carbon monoxide was already suspected to increase with increasing latitude in the northern hemisphere (from $30 \pm 5 \mathrm{ppmv}$ at $30 \mathrm{~km}$ below $30^{\circ} \mathrm{N}$ to $40 \pm 5$ ppmv past $47^{\circ} \mathrm{N}$ ) according to Collard et al. (1993) using moderate resolution spectral data from Galileo/NIMS in the night side $2.3 \mu \mathrm{m}$ window.

Before the beginning of the Venus Express mission, ground-based observations acquired at the Infrared Telescope Facility (IRTF) located at Mauna Kea, Hawaii, used the SpeX echelle spectrometer at a higher spectral resolution $(R \sim 2000)$. These observations, acquired during the maximal elongations of Venus in February 2003 and August 2004, were analysed by Marcq et al. $(2005,2006)$ in a search for spatial variations. Their results for $\mathrm{CO}$ can be summarised as follows: (1) CO near $35 \mathrm{~km}$ exhibits an increase with increasing latitude in both hemispheres; (2) the magnitude of this enhancement is about $30 \pm 15 \%$ between the equator and $40^{\circ} \mathrm{S}$ (from $23 \pm 1 \mathrm{ppmv}$ up to $31 \pm 1 \mathrm{ppmv}$ at $36 \mathrm{~km}$ ); (3) its vertical gradient between 30 and $40 \mathrm{~km}$ is also increasing with increasing latitude, from $0.4 \pm 0.2 \mathrm{ppmv} / \mathrm{km}$ at lower latitudes up to $0.8 \pm 0.2 \mathrm{ppmv} / \mathrm{km}$ near $30^{\circ} \mathrm{S}$.

More recently, Cotton et al. (2012) also used ground-based data acquired between 2004 and 2007 with the IRIS2 instrument at the Anglo-Australian Telescope (AAT) in the $2.3 \mu \mathrm{m}$ window and a slightly higher spectral resolution $(R \sim 2400)$. They reported the same general trend as previous observers until the polar collar near $\pm 60^{\circ}$, and numerical values also consistent with previous observers assuming that the variability occurs at the peak of altitude sensitivity (between 30 and $40 \mathrm{~km}$ ). However, they also provided another interpretation that improves their fit accuracy, namely that the actual variations are much larger in amplitude (about $+100 \%$ between the low latitudes and the maximum near $60^{\circ}$ ), but restricted to altitudes above $40 \mathrm{~km}$, well above the sensitivity peak. It is interesting to note that the extra required $\mathrm{CO}$ at higher latitudes lies at the higher end of the probed altitude range, which is at least qualitatively consistent with the findings of Marcq et al. (2006) that an increasing vertical gradient of CO is observed towards higher latitudes. Cotton et al. (2012) also notice that $\mathrm{CO}$ tends to decrease past $60^{\circ} \mathrm{N} / \mathrm{S}$, a trend also seen by Venus Express, whose quasi-polar orbit favours detailed observations of the polar collar region beyond $60^{\circ}$. Also, ground-based mapping acquired with the $3.5 \mathrm{~m}$ telescope at Apache Point Observatory using the TripleSpec spectrograph $(R \sim 3500)$ in all night side IR windows in early 2009 and late 2010 were acquired by Arney et al. (2014). They could confirm this average trend: minimal values near $10^{\circ} \mathrm{S}$, ranging around $20 \mathrm{ppmv}$ at $35 \mathrm{~km}$, and a 30 to $60 \%$ relative increase towards $50^{\circ} \mathrm{N}$ and $\mathrm{S}$. Significant and previously unreported hemispheric asymmetry and interannual variability are especially noteworthy in this most recent data set.

Venus Express observations in the $2.3 \mu \mathrm{m}$ region could have been performed by VIRTIS (Coradini et al. 1998) and PFS (Formisano et al. 2006), but due to the malfunction of the latter, only VIRTIS IR -H and -M channels could be used to monitor CO under the clouds. VIRTIS-M is a true spectral imager, with a moderate spectral resolution but a good spatial resolution on its relatively large FOV, whereas VIRTIS-H trades off a much better spectral resolution against a loss in spatial coverage, resulting in a more classic spectroscopic channel. Night side VIRTIS-M data in the $2.3 \mu \mathrm{m}$ window were first processed by Tsang et al. 
(2008), whereas the corresponding VIRTIS-H data set was processed by Marcq et al. (2008). Both studies encompass the first two years of operation of Venus Express. Their results bring extra precision and extend the spatial validity of the aforementioned ground-based measurements. Tsang et al. (2008) maps of CO on the whole southern hemisphere point to an increase between the equatorial region and $60^{\circ} \mathrm{S}$ (from $23 \pm 2$ up to $32 \pm 2 \mathrm{ppmv}$ ), with evidence for a small decline polewards. Marcq et al. (2008) dealt primarily with near nadir latitudinal swaths, and confirms this increase (from $24 \pm 3$ up to $31 \pm 2 \mathrm{ppmv}$ at $36 \mathrm{~km}$ and $60^{\circ} \mathrm{N}$ and $\mathrm{S}$ ). Unfortunately, the much thicker lower clouds polewards of $60^{\circ}$ cause a decrease in the signal-to-noise ratio that prevents VIRTIS-H data yielding useful estimates of CO past $60^{\circ}$-VIRTIS-M's lower spectral resolution makes CO estimation more robust from this point of view. More recent analysis of the whole VIRTIS-M data set until 2012 has been conducted by Haus et al. (2015), and confirms the previous trends observed during the first two years of Venus Express, with $\mathrm{CO}$ estimates near $35 \mathrm{~km}$ increasing from $23 \pm 1 \mathrm{ppmv}$ near $10^{\circ} \mathrm{S}$ up to a maximum in the $65-70^{\circ} \mathrm{S}$ interval of $31 \pm 2 \mathrm{ppmv}$ and then a modest decrease to $29.5 \pm 2.5 \mathrm{ppmv}$ until $80^{\circ} \mathrm{S}$.

OCS The OCS spectral signature in the $2.3 \mu \mathrm{m}$ region is harder to analyse compared to $\mathrm{CO}$, due to its smaller spectral extent and contamination with neighbouring water lines, so that a spectral resolution of at least a few thousands is required to measure it with enough accuracy. Another difficulty that arises whenever comparing different studies or interpreting the spectral variations in terms of local mixing ratios lies in the fact that OCS vertical profile decreases by two orders of magnitude between 30 and $40 \mathrm{~km}$-actually this steep decrease is well constrained from spectroscopic data, as discussed in Sect. 2.1-so that the problems of choosing a reference altitude and cross-comparing available OCS measurements are intertwined with its assumed or measured vertical gradient.

The first study of OCS horizontal variations was performed by Marcq et al. $(2005,2006)$ from ground-based data acquired by SpeX/IRTF. They evidenced a possible anti-correlation with $\mathrm{CO}$ variations: whereas $\mathrm{CO}$ is generally increasing with increasing latitude, OCS is generally decreasing. Assuming that OCS variations are caused by vertical translations of the standard OCS vertical profile (e.g. due to vertical motions in the lower atmosphere), they found a relative decrease between $0^{\circ}-20^{\circ} \mathrm{S}(0.5 \pm 0.02 \mathrm{ppmv})$ and $20^{\circ} \mathrm{S}-40^{\circ} \mathrm{S}(0.46 \pm$ $0.01 \mathrm{ppmv}$ ) at an altitude of $36 \mathrm{~km}$. However, Marcq et al. (2006) provide an alternate interpretation of these variations in terms of variation of the OCS vertical gradient in the 30 to $37 \mathrm{~km}$ altitude range, more accurately its pseudo-gradient $\frac{d \log \text { OCS }}{d \log P}$ assumed to be constant in this altitude range. With this assumption, the OCS mixing ratio is more or less latitudinally uniform at $36 \mathrm{~km}(0.55 \pm 0.15 \mathrm{ppmv})$, but its vertical gradient is steeper at higher latitudes (as was also noticed for $\mathrm{CO}$, further strengthening the case for a common dynamical origin of these variations). This makes OCS anti-correlated with $\mathrm{CO}$ above $36 \mathrm{~km}$, but positively correlated below $33 \mathrm{~km}$. As noticed by Bézard and de Bergh (2007), this larger abundance of OCS south of $20^{\circ} \mathrm{S}$ and at lower altitudes may result from the larger abundance of CO, leading to an enhanced production of OCS.

More recent ground-based studies by Arney et al. (2014) confirmed these results: within $20^{\circ}$ of the equator, maximal value are reached between $0.54 \pm 0.13 \mathrm{ppmv}$ at $36 \mathrm{~km}$ in 2009 and $0.61 \pm 0.12 \mathrm{ppmv}$ in 2010. Their estimates for OCS vertical gradient are significantly smaller than what Pollack et al. (1993) found, but is fully consistent with Marcq et al. (2006) determinations. Like for $\mathrm{CO}$, previously unreported temporal variability and hemispheric dichotomy are visible in their data set. Local and transitory depletions in OCS also appear to be correlated with transient enhancements in $\mathrm{CO}$, strengthening the case for the previously known CO-OCS anti-correlation. 

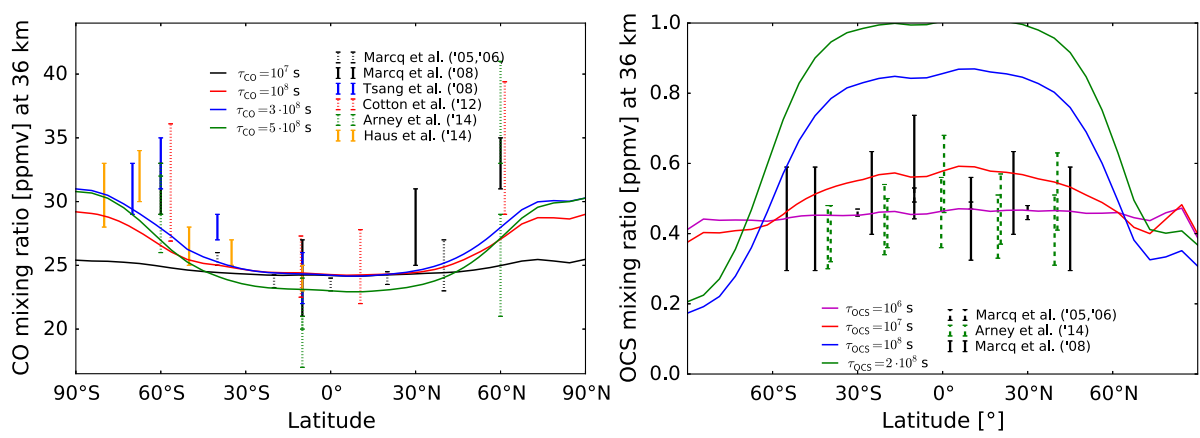

Fig. 7 Latitudinal variations of CO (left) and OCS (right) at $36 \mathrm{~km}$ according to various recent measurements. Dashed error bars stand for ground-based measurements, solid error bars for VEx/VIRTIS measurements. Wherever necessary, measurements were scaled in order to comply with the reference altitude of $36 \mathrm{~km}$

Unfortunately, the relatively poor signal-to-noise ratio of VIRTIS-H spectra prevented a thorough analysis of the OCS vertical gradient variability, so that the study by Marcq et al. (2008) is restricted to mixing ratios retrievals. Their results are consistent with the previous results about its anti-correlation with $\mathrm{CO}$, with maximal values near the equator (between $0^{\circ}$ and $20^{\circ} \mathrm{S}$ ) of $4 \pm 1.5 \mathrm{ppmv}$ at $33 \mathrm{~km}$, decreasing towards $60^{\circ} \mathrm{S}$ at $3 \pm 1 \mathrm{ppmv}$.

$\mathrm{H}_{2} \mathrm{SO}_{4}$ Previously mentioned radio occultation measurements in the 50-52 km altitude range from VeRa on-board Venus Express (Oschlisniok et al. 2012) also found a symmetrical latitudinal variation pattern consistent with a Hadley-cell driven circulation, with more abundant $\mathrm{H}_{2} \mathrm{SO}_{4}$ in upwelling regions between 2 and 3 ppmv below $50^{\circ}$, falling between 1 and 2 ppmv in the $50^{\circ}$ to $70^{\circ}$ and ultimately below 1 ppmv above $70^{\circ}$ within the downwelling regions, in full agreement with its vertical profile, strongly decreasing with increasing altitude between 50 and $55 \mathrm{~km}$.

\subsubsection{Local Time Variability}

Compositional variability with local time (or longitude) under the clouds is harder to constrain for two main reasons: (1) remote sensing measurements are restricted to the night hemisphere and may not be representative of the situation on the day hemisphere and (2) the influence of solar radiation below the clouds is at best indirect, through the coupling between the vertical transport from the upper layers (where solar radiation can influence chemistry) and the zonal circulation; such a coupling is not as well known as the more familiar one between meridional circulation and vertical transport, responsible for the already discussed (see Sect. 3.1.1) latitudinal variability.

There are nevertheless some conflicting evidence for local time variability of $\mathrm{CO}$ below the clouds, from both ground-based and Venus Express observations. VIRTIS-M analysis by Tsang et al. (2008) and Haus et al. (2015) both found a moderate increase (5 to $10 \%$ ) from West to East (i.e. dawn to dusk), especially near the latitudinal maximum of $60^{\circ}$. However, ground-based maps from Cotton et al. (2012) show an opposite trend at high latitudes, and a increase before $21 \mathrm{~h} \mathrm{LT}$ at lower latitudes, followed by a sharp decrease between 21 and $18 \mathrm{~h} \mathrm{LT}$. Other studies do not report any significant local time variability. If it is genuine, it is probably dominated by its short-term and small scale variability, in a stark contrast with latitudinal increase which is a persistent feature of the lower atmosphere. 


\subsubsection{Chemical Transport Models and Comparisons with Observations}

No modelling study has reported on longitudinal or local time variations in tropospheric chemistry, and only two (Yung et al. 2009; Marcq and Lebonnois 2013) have reported simulations of the observed latitudinal variations in tropospheric CO and OCS. The two studies took significantly different approaches. Yung et al. (2009) used a general circulation model (GCM) (Lee et al. 2007) to determine the transport description that was input to a 2-D Chemical Transport Model (CTM) (Morgan et al. 2004; Liang et al. 2005; Liang and Yung 2007), and the CTM simulated the transient chemistry occurring during meridional transport. Marcq and Lebonnois (2013) introduced passive tracers with vertically uniform time scales for relaxation to chemical equilibrium designed to simulate the latitudinal variability of OCS and CO.

Photolysis of OCS alone could not explain the observed vertical gradient in OCS (Fig. 2), so an additional loss for OCS, parametrised as Reaction (1) with loss coefficient for OCS of about $10^{-8}$ per second in the region around $30 \mathrm{~km}$, was included (Yung et al. 2009). After including Reaction (1), the simulated OCS latitudinal variation at $33 \mathrm{~km}$ altitude was in reasonable agreement with observations (Yung et al. 2009). The simulated CO latitudinal variation at $33 \mathrm{~km}$ also was in reasonable agreement with equatorial and mid-latitude observations, but there were significant differences from the few observations that had been made at that time polewards of about $40^{\circ}$ (Yung et al. 2009). A somewhat better agreement (i.e., larger equator-to-pole gradients) was found if the horizontal diffusivity was reduced, the tropical stream function was enhanced, the Hadley cell was narrowed, and the loss coefficient for Reaction (1) in the region around $30 \mathrm{~km}$ was enhanced to $3 \cdot 10^{-8}$ per second (Yung et al. 2009).

Comparing their passive tracer simulations with observations, Marcq and Lebonnois (2013) concluded there was satisfactory agreement when the relaxation timescale for CO was between $10^{8}$ and $5 \cdot 10^{8} \mathrm{~s}$ and the relaxation timescale for OCS was between $10^{7}$ and $10^{8} \mathrm{~s}$ (see Fig. 7). The inferred relaxation timescale for $\mathrm{CO}$ was extrapolated from the model's asymptotic behaviour, as steady state could not be achieved in simulations with relaxation times greater than about $10^{8} \mathrm{~s}$ (Marcq and Lebonnois 2013). Marcq and Lebonnois (2013) concluded that $\mathrm{CO}$ behaves like a passive tracer in the $30-40 \mathrm{~km}$ altitude region with its distribution controlled by the downward flux of $\mathrm{CO}$ from higher altitudes because the inferred relaxation timescale for $\mathrm{CO}$ was close to the passive transport time scale $\left(10^{8}\right.$ to $10^{9} \mathrm{~s}$ ) along a Hadley cell.

The already mentioned tropospheric CO retrieval study by Cotton et al. (2012) is consistent with this qualitative picture-namely that a downward flux of $\mathrm{CO}$ from the mesosphere produces the observed increase in CO towards the poles. Quantitatively, however, a different picture potentially emerges because their results suggest most of the high latitude increase in $\mathrm{CO}$ occurs at $40-50 \mathrm{~km}$ altitude (Cotton et al. 2012). This may imply CO is more constant with latitude near 33-36 km and may be better fit by a smaller loss coefficient (Yung et al. 2009) or shorter relaxation timescale (Marcq and Lebonnois 2013). CTM and GCM simulations assessing the Cotton et al. (2012) interpretation are needed. Also needed is a comparative evaluation of the retrieved vertical distribution and gradient of $\mathrm{CO}$ as a function of latitude across multiple data sets using a radiative transfer model.

Marcq and Lebonnois (2013) noted the similarity between their inferred relaxation time scale for OCS and the loss rate in Krasnopolsky (2007) for OCS via Reaction (5b). However, the rate coefficient for Reaction (5b) was an adjustable free parameter in Krasnopolsky and Pollack (1994) that was set based on the retrieved vertical gradient in OCS, the same basis used by Marcq and Lebonnois (2013) to infer the OCS relaxation timescale. Consequently, 
it is not surprising the two studies arrived at similar values, and this similarity does not imply the mechanism postulated in Reaction (5b) is correct. Laboratory studies are needed to assess the viability of Reaction (5b).

Both modelling studies (Yung et al. 2009; Marcq and Lebonnois 2013) are qualitatively consistent with a Hadley-cell-type circulation that extends up into the lower mesosphere with OCS being transformed into $\mathrm{CO}$ in the rising equatorial branch and $\mathrm{CO}$-rich air being transported down into the troposphere at higher latitudes. Furthermore, the loss timescales from both studies are in reasonable qualitative agreement even though quantitative comparisons between the two models are complicated because the circulations in the two GCMs used for these studies differed (Marcq and Lebonnois 2013) and the CTM allowed the loss coefficient of OCS to vary with altitude while the passive tracer simulation did not. However, the chemical mechanisms underlying these simulations cannot be known without laboratory work and further observations, particularly at mid- to high-latitudes.

\subsection{Above the Cloud Tops (70-100 km)}

\subsection{1 $\mathrm{HCl} \& \mathrm{HF}$}

In general, the spatial variability of many of the species observed on Venus is lower than the short time scale variability. It is therefore highly difficult to separate both contributions. This is the case for $\mathrm{HCl}$ and $\mathrm{HF}$ as observed by SOIR (Mahieux et al. 2015a), except maybe for $\mathrm{HCl}$ at higher altitudes (above $90 \mathrm{~km}$ ), where abundances at the equator and mid-latitudes are definitely higher than at the poles. Sub-millimeter observations of $\mathrm{H}^{35} \mathrm{Cl}$ at $625.9 \mathrm{GHz}$ by Sandor and Clancy (2012) between October and December 2010 have also failed to evidence any clear pattern of variation with respect to local solar time.

Ground-based high-resolution spectroscopy using IRTF/CSHELL (Krasnopolsky 2010a) revealed the $\mathrm{HCl}$ mixing ratio of $400 \pm 30 \mathrm{ppbv}$ at $74 \mathrm{~km}$ with no significant latitudinal variations within $\pm 60^{\circ}$, while local variations could reach $\pm 10 \%$. The simultaneous measurements of $\mathrm{HF}$ demonstrated the similar behavior was observed for the HF mixing ratio of $3.5 \pm 0.2 \mathrm{ppbv}$ at $68 \mathrm{~km}$. The observations of HF in the morning and near sunset showed similar results.

\subsection{2 $\mathrm{SO}_{2}$ and $\mathrm{SO}$}

$\mathrm{SO}_{2}$ column density above the cloud top level was also regularly measured through spectroscopic analysis of scattered UV sunlight by the SPICAV-UV instrument on-board Venus Express from 2006 until 2014 (Marcq et al. 2011, 2013). Spatial variability was very strong, spanning more than one order of magnitude, and intertwined with temporal variability (see also Sect. 4.1). Short scale variability over a few hundreds of $\mathrm{km}$ is readily visible in most SPICAV-UV observations, as well as from volume mixing ratios measured by ground-based observers through high resolution thermal IR spectroscopy (Encrenaz et al. 2012, 2013). This random "patchy" $\mathrm{SO}_{2}$ distribution pattern varies within timescales as short as several hours, with maximal values ranging between $75 \pm 25$ ppbv on $2012 / 01 / 10$ and $125 \pm 50 \mathrm{ppbv}$ on 2012/01/12 (Encrenaz et al. 2012) near $70 \mathrm{~km}$.

But Venus Express' quasi-polar orbit was especially suited to latitudinal scans of the northern hemisphere, so that an extensive data set has been acquired to study the latitudinal distribution of $\mathrm{SO}_{2}$. Subsequently, Marcq et al. (2013) found that $\mathrm{SO}_{2}$ latitudinal distribution statistically followed one of two regimes: (1) when $\mathrm{SO}_{2}$ is relatively abundant, it is more prevalent at lower latitudes by about one order of magnitude, resulting in a decreasing 
Fig. 8 Range of observed column densities from Marcq et al. (2013) during $\mathrm{SO}_{2}$-rich epochs (orange) and $\mathrm{SO}_{2}$-poor epochs (cyan). Red and blue lines correspond to simulations obtained by the 1D-box model from Marcq et al. (2013) with a typical lifetime of $2 \cdot 10^{5} \mathrm{~s}$ for $\mathrm{SO}_{2}$

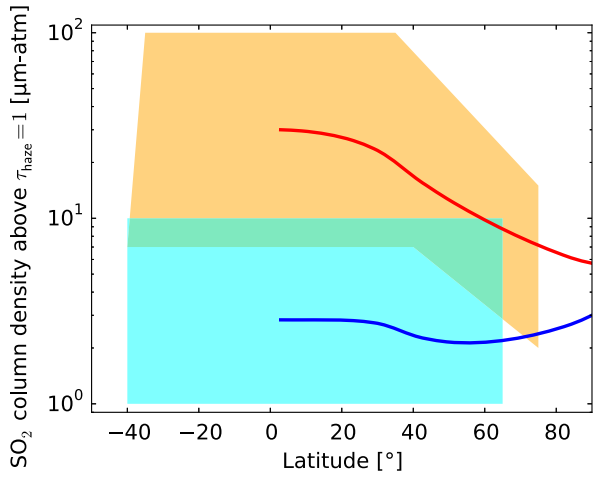

$\mathrm{SO}_{2}$ column density with increasing latitude past $40^{\circ} \mathrm{N}$; (2) when $\mathrm{SO}_{2}$ is relatively scarce, the latitudinal gradient is suppressed, or even reversed, with little $\mathrm{SO}_{2}$ seen near the poles and only transient detections of $\mathrm{SO}_{2}$ towards lower latitudes. Such a behaviour is qualitatively consistent with a simple $1 \mathrm{D}$ box model described in Marcq et al. (2013), where $\mathrm{SO}_{2}$ transport from the lower atmosphere by the Hadley-cell circulation competes with a photochemical sink acting in a characteristic time on the order of $10^{5} \mathrm{~s}$ [Fig. 8]. Abundant supply results in the decrease of $\mathrm{SO}_{2}$ with increasing latitude, whereas transient shutdowns of the circulation result within a few Earth days in a uniformly low $\mathrm{SO}_{2}$ distribution with latitude. This alternating latitudinal patterns may help in reconciling these results with the negative latitudinal gradients found in the 1990s (Zasova et al. 1993): at the $40 \mathrm{mbar}$ level $(69 \mathrm{~km})$, the $\mathrm{SO}_{2}$ mixing ratio was a few tens of ppbv at low latitudes (below $45^{\circ}$ ), 1-10 ppbv in the cold collar region, and 100-200 ppbv near the poles. It could even reach values up to $1000 \mathrm{ppbv}$ locally. The same analysis provided also similar results at the $150 \mathrm{mbar}$ level (62 km): $0.3-0.5 \mathrm{ppmv}$ at low latitudes and 1-2 ppmv in polar regions.

Unfortunately, this quasi-polar orbit also made global studies of the local solar time variability of $\mathrm{SO}_{2}$ much harder to assess, since different longitudes cannot be scanned simultaneously, but rather several months apart. Due to the aforementioned high temporal variability, it is difficult to monitor any global trend with local solar time. This may explain why the analysis of the SPICAV-UV data set could not evidence any significant variability in this

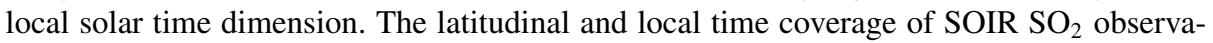
tions (Mahieux et al. 2015c) is unfortunately too sparse to support any conclusive horizontal trend, considering the huge temporal variability of $\mathrm{SO}_{2}$ that is discussed in Sect. 4.1.

Other observations include Hubble Space Telescope observations using the UV spectrometer STIS (Jessup et al. 2015) performed in Dec. 2010 and Jan. 2011. They confirmed the strong local and temporal variability, as well as the two latitudinal patterns evidenced by Marcq et al. (2013) (Jessup et al. 2015, their Fig. 12). Jessup et al. (2015) were also able to evidence a decrease with increasing local solar time on the morning quadrant, with more $\mathrm{SO}_{2}$ near the morning terminator compared with local noon at similar latitudes-which is fully consistent with the combined effects of zonal super-rotation and photochemical destruction of $\mathrm{SO}_{2}$ on the day side. The spectral resolution of STIS also allowed Jessup et al. (2015) to measure SO, which appears to be more or less correlated with $\mathrm{SO}_{2}$. The Pearson correlation coefficient between $\mathrm{SO}_{2}$ and $\mathrm{SO}$, ignoring uncertainties in the HST data, is 0.97 and a least-squares linear regression on the fit column abundances gives relation (14) where $N_{\mathrm{SO}}$ and $N_{\mathrm{SO}_{2}}$ are the retrieved column abundances of $\mathrm{SO}$ and $\mathrm{SO}_{2}$ from the HST observations. As noted in Sect. 6, this suggests $\mathrm{SO}_{2}+\mathrm{SO}$ is not constant and implies interaction on short timescales with a third, as yet unidentified, sulphur reservoir, as had previously been 
suggested by sub-mm observations at higher altitudes (Sandor et al. 2010).

$$
N_{\mathrm{SO}}=(0.04 \pm 0.02)+(0.08 \pm 0.02) N_{\mathrm{SO}_{2}}
$$

Higher up in the mesosphere (above $80 \mathrm{~km}$ ), $\mathrm{SO}$ and $\mathrm{SO}_{2}$ can be measured thanks to sub-millimeter observations. Thus, Sandor et al. (2010) using JCMT have measured $\mathrm{SO}_{2}$ (near $346.652 \mathrm{GHz}$ ) and SO (near $346.528 \mathrm{GHz}$ ) above $85 \mathrm{~km}$ since 2004 onwards. They found that, although short-term variability is dominant, both species exhibit significant diurnal variability: $\mathrm{SO}_{2}$ peaks by a factor of about 2 (about $60 \pm 20$ ppbv) during early night (18-24 LT) when it is sheltered from UV dissociation; and SO peaks by one order of magnitude (roughly $10 \mathrm{ppbv}$ ) during the afternoon (12-16 LT). Interestingly, the authors point out that the total number density of $\mathrm{SO}_{2}+\mathrm{SO}$ is not constant with respect to local solar time, hinting once again to the existence of a yet unknown sulphur reservoir in the mesosphere of Venus.

More recently, Encrenaz et al. (2015) using ALMA mapped $\mathrm{SO}$ and $\mathrm{SO}_{2}$ horizontal variability at the same frequencies during November 2011. Using a full array of dishes instead of a single dish enables a dramatic increase of the spatial resolution, comparable to the seeing of optical or infrared Earth-based telescopes. Their $\mathrm{SO}_{2}$ maps exhibit a distinctly "patchy" structure, very reminiscent of the situation at the cloud top level, with a mean abundance of $12 \pm 3.5 \mathrm{ppbv}$ above $88 \pm 3 \mathrm{~km}$. One of their two maps of $\mathrm{SO}_{2}$ also feature a clear maximum in the morning side at lower latitudes. On the other hand, their SO map also exhibits a strong horizontal variability (like $\mathrm{SO}_{2}$ by as much as a factor 4) although less patchy than $\mathrm{SO}_{2}$. The mean abundance of SO above $88 \pm 2 \mathrm{~km}$ is $8 \pm 2 \mathrm{ppbv}$. Diurnal variations are consistent with those found by Sandor et al. (2010), with a clear spatial maximum of their two maps located in the north-western part of the disk and no SO above the detection threshold on the night side. More quantitative conclusions about $\mathrm{SO}$ and $\mathrm{SO}_{2}$ will require a more thorough processing of the temperature profile derived from their simultaneous $\mathrm{CO}$ observations near 345.795 GHz.

\subsection{3 $\mathrm{H}_{2} \mathrm{O}$}

Water vapour at cloud top level can be measured using near IR scattered sunlight on the day side. Venus Express/VIRTIS-H spectra near $2.56 \mu \mathrm{m}$ were analysed by Cottini et al. (2012, 2015). They observed hemispherically symmetric variations, with lower values at lower latitudes $(3 \pm 1 \mathrm{ppmv})$ gradually increasing to $5 \pm 2 \mathrm{ppm}$ from 70 to $80^{\circ}$ latitude, followed by a sharp drop to low latitude level close to both poles. This pattern is consistent with a large scale dynamic control of water vapour abundance above the clouds. Using Venus Express/SPICAV-IR near $1.38 \mu \mathrm{m}$, Fedorova et al. (2016) found a similar distribution pattern, albeit with larger resulting abundances (5 to $10 \mathrm{ppmv}$ ). According to Fedorova et al. (2016), the discrepancy between SPICAV and VIRTIS could be due to a difference in the effective cloud top altitude between 2.56 and $1.38 \mu \mathrm{m}$, so that this would be consistent with $\mathrm{H}_{2} \mathrm{O}$ abundance increasing with increasing depth within the upper cloud: $\mathrm{H}_{2} \mathrm{SO}_{4}$ absorption is larger at longer wavelengths, which limits the penetration of scattered sunlight.

Recent ground-based data yielded conflicting results regarding the latitudinal variability of water vapour. Krasnopolsky (2010b) also found $\mathrm{HDO}$ - used as a proxy for $\mathrm{H}_{2} \mathrm{O}$, assuming a D/H ratio of 200 Standard Mean Ocean Water (SMOW) - to be increasing with increasing latitude, with a mean low latitude value of $2.9 \pm 0.3 \mathrm{ppmv}$ near $74 \mathrm{~km}$ in the morning ( $7 \mathrm{AM})$. The observation near sunset $(5 \mathrm{PM}$ ) revealed smaller abundances of $\approx 1.3 \mathrm{ppmv}$ at low latitudes increasing to $\approx 2.3 \mathrm{ppm}$ at $\pm 60^{\circ}$. The larger abundances in the morning were explained by the nighttime lack of photochemical loss of $\mathrm{H}_{2} \mathrm{O}$ to produce sulfuric acid. 
Yet, Krasnopolsky et al. (2013) did not evidence any latitudinal variability, with direct measurements of $\mathrm{H}_{2} \mathrm{O}$ near $3.2 \mathrm{ppmv}$ and a measured $\mathrm{D} / \mathrm{H}$ ratio of $95 \pm 15 \mathrm{SMOW}$, comparable to its value below the clouds but substantially lower than previous determinations (see Sect. 6.3). Matsui et al. (2012) also evidenced no clear horizontal structure for mesospheric HDO. Also, based on available $\mathrm{H}_{2} \mathrm{O}$ measurements, they inferred that the $\mathrm{D} / \mathrm{H}$ ratio of water vapour above the clouds lies between 120 and 160 .

These lower $\mathrm{D} / \mathrm{H}$ ratio measurements also help in bringing $\mathrm{H}_{2} \mathrm{O}$ indirect measurements of Encrenaz et al. $(2012,2013)$ more in line with the aforementioned determinations: the 1 to $1.5 \mathrm{ppmv}$ of water vapour that they derived near $7 \mu \mathrm{m}$ at cloud top level was based on the sole HDO measurement and assuming a D/H value of 200 SMOW following Fedorova et al. (2008). Halving this $\mathrm{D} / \mathrm{H}$ ratio would therefore cause a doubling of $\mathrm{H}_{2} \mathrm{O}$ abundance to about 3 ppmv. Note that these studies do not evidence any horizontal $\mathrm{H}_{2} \mathrm{O}$ variability larger than $20 \%$, probably because this variability is restricted to very high latitudes out of reach for Earth-based observers.

Sub-millimeter observations of $\mathrm{H}_{2} \mathrm{O}$ near 556.9 GHz (Gurwell et al. 2007) or HDO near 335.395 GHz (Sandor and Clancy 2005; Encrenaz et al. 2015) and 225.9 GHz (Sandor and Clancy 2005) as a proxy for $\mathrm{H}_{2} \mathrm{O}$ give access to water vapor variability in the $70-100 \mathrm{~km}$ range. Sandor and Clancy (2005) observations at Kitt Peak Observatory and JCMT from 1998 to 2004 were spatially integrated over the whole Earth-facing hemisphere, so that they only could evidence an hemispheric maximum of about 4 to 5 ppmv for $f=0.6$ to 0.8 , where $f$ stands for the illuminated fraction of the Venus disk and assuming a $\mathrm{D} / \mathrm{H}$ ratio of 157 SMOW. This points to an overall abundance of water that is higher during the day than at night, but this diurnal signature is weak compared to the stronger temporal variability on both short and long time scales (see Sect. 4.2). Observations from the SWAS satellite acquired between 2002 and 2004 by Gurwell et al. (2007) confirm that temporal variability of mesospheric water vapor is dominant over the diurnal variability, but nevertheless point in their Fig. 12 to a comparable maximum of $4.5 \pm 1.5$ ppmv instead of the usual $<2$ ppmv near the morning terminator (6 LT), in a good agreement with previous measurements. More recently, Encrenaz et al. (2015) measurements of HDO assuming a D/H ratio of $200 \mathrm{SMOW}$ yielded a vertically uniform mixing ratio of $2.5 \pm 0.6 \mathrm{ppmv}$ for water vapor, with a possible maximum in the northern hemisphere and in the late afternoon by a factor of 2 to 3 , meaning that unlike sulphur oxides, water vapor is always found above the detection threshold on both day and night sides. Interestingly, the north/south asymmetry for HDO is also seen in their SO retrievals, and neither was predicted by photochemical or dynamical models.

\subsubsection{CO}

Recent, spatially resolved IRTF/CSHELL observations by Krasnopolsky (2010a) on the day side near $2.25 \mu \mathrm{m}$ hinted at a possible increase of CO above Venus' cloud top with increasing latitude by about $10 \mathrm{ppmv}$ above their derived low latitude average of $45 \pm 10 \mathrm{ppmv}$. Excess of $\approx 10$ ppmv in the morning (08:00) relative to the afternoon (16:30) was observed as well. This has been confirmed by Marcq et al. (2015) using the same instrument in the (1-0) rovibrational transition system near $4.55 \mu \mathrm{m}$, which extended the coverage to both day and night side thanks to the study of both scattered sunlight and thermal emission. They found comparable values at low latitudes $(35 \pm 10 \mathrm{ppmv})$, with a $+10 \mathrm{ppmv}$ increase past $30^{\circ} \mathrm{N}$, on both day and night sides of the planet with no discernible diurnal pattern.

Venus Express/VIRTIS-M was also able to measure CO near $4.7 \mu \mathrm{m}$ on the night side. Grassi et al. (2014) found that $\mathrm{CO}$ experienced a similar increase in the southern hemisphere between $40^{\circ} \mathrm{S}$ and $60^{\circ} \mathrm{S}$, peaking near $70 \pm 10 \mathrm{ppmv}$. It then decreases to about 
$60 \pm 5 \mathrm{ppmv}$ at $70^{\circ} \mathrm{S}$. Previously, Irwin et al. (2008) reported latitudinal distribution of CO above the night side's cloud top using VIRTIS-M observations. They found an average value of $40 \pm 10 \mathrm{ppmv}$ at $65-70 \mathrm{~km}$ with little variation in the middle latitudes. IRTF/CSHELL observations of the CO dayglow at $4.7 \mu \mathrm{m}$ Krasnopolsky (2014) revealed a constant CO mixing ratio of $560 \pm 100 \mathrm{ppm}$ at $104 \mathrm{~km}$ at low and middle latitudes $\pm 50^{\circ}$. CO densities at higher altitudes (100-150 km) were obtained by Gilli et al. (2015) and Gilli (2012) using the $4.7 \mu \mathrm{m}$ non-LTE emission band of CO observed by VIRTIS-H (see Fig. 3). Although data had to be averaged on large latitudinal bins, they nevertheless showed maximum abundances on the day side at the sub-solar point and a decrease of a factor of 2 towards higher latitudes, also confirmed by SOIR (Vandaele et al. 2015a) and plotted on Fig. 3. They also observed a clear gradient from noon to the morning and evening sides of the terminator, more pronounced at the equator than at the higher latitudes. Since they could not observe any differences between the morning and evening abundances, the authors argued that the $\mathrm{CO}$ distribution is mainly controlled by dynamics with a dominant sub-solar to anti-solar gradient. However, below $90 \mathrm{~km}$, a reverse latitudinal trend is observed, with a clear maximum value corresponding to the 60 to $80^{\circ}$ latitude band, in agreement with Grassi et al. (2014) or even Tsang et al. $(2008,2009)$ below the clouds-but little spatial variability has been observed at about $70 \mathrm{~km}$ either by several ground-based observations (Krasnopolsky 2010a; Marcq et al. 2015) or by VIRTIS-M (Irwin et al. 2008).

This horizontal distribution is in agreement with the current accepted scheme: $\mathrm{CO}$ abundance at high altitudes increases during the day because $\mathrm{CO}$ is produced on the day side from the photolysis of $\mathrm{CO}_{2}$ at high altitude. This results in a peak of high altitude $\mathrm{CO}$ near the sub-solar point. No CO is produced on the night side, since photolysis stops during the night. The meridional circulation however continues to pump CO-rich air from the mesosphere down to the troposphere, and SS-AS circulation carries CO to the night side. In early evening, high abundances of $\mathrm{CO}$ are observed in the lower atmosphere in the regions where downwelling by the Hadley cell occurs (at a latitude of $60^{\circ}$ ). During the night, $\mathrm{CO}$ decays because only sink reactions happen.

Sub-millimeter observations of ${ }^{12} \mathrm{CO}$ (near $346 \mathrm{GHz}$ ) and ${ }^{13} \mathrm{CO}$ (near $330 \mathrm{GHz}$ ) were also acquired by Clancy et al. (2008, 2012), probing between 1 and $100 \mathrm{~Pa}$ (equivalent to $85-100 \mathrm{~km}$ ). Clancy et al. (2008) found no latitudinal variations along the central meridian, but evidenced a twofold peak in CO between 18:30 and 22:30 in June 2007. The same team (Clancy et al. 2012), using better spatially resolved observations acquired from 2001 to 2009 with the same instrument (JCMT), later found a maximum (100 to 200\%) near 2-3 AM in local time and between 0 and $40^{\circ}$ in latitude in 2006 and 2007. This maximum was much more modest in 2004 and 2009 (30 to 60\%) but followed the same horizontal pattern (night side and low latitude maximum) consistent with a non-zero subsolar-antisolar component of the general circulation at these altitudes, since $\mathrm{CO}$ photochemical source is located near the subsolar point. It should also be noted that recent observations of ${ }^{12} \mathrm{CO}$ by Encrenaz et al. (2015) with ALMA did not evidence any local solar time variability, indicating that these variations are much more modest than those of sulfur oxides.

\subsubsection{OCS}

Day side measurements at $2.44 \mu \mathrm{m}$ using IRTF/CSHELL by Krasnopolsky (2010b) detected and measured carbonyl sulphide above the cloud tops near $65 \mathrm{~km}$. More OCS was found in the northern hemisphere compared with the southern, along with a decreasing mixing ratio with increasing latitude in 3 out of 4 shown observations. Typical mixing ratios near $50^{\circ}$ are below 4 ppbv (decreasing also with increasing local time), and reach $5 \pm 3$ ppbv near the 
equator. Here also, this latitudinal pattern is strongly reminiscent of the situation for OCS below the clouds (Sect. 3.1.1), so that a dynamical origin is also suspected here.

\subsubsection{D/3D Dynamical and Chemical Modelling}

D/H Fractionation With its highly enhanced $\mathrm{D} / \mathrm{H}$ ratio, Venus provides a window of opportunity in the solar system for studying the end-member of water evolution. Current estimates suggest that about one Earth ocean might have been lost (e.g., Kasting and Pollack 1983; Donahue 1999) via non-thermal escape of hydrogen (such as hydrodynamic escape, charge exchange, and collisionally induced escape). Hydrogen is produced by the photolysis of water and hydrochloric acid, a process that is known to preferentially destroy the light isotopologues, resulting in the enrichment of the heavy parent molecule in the atmosphere (Cheng et al. 1999). The process of enhancing the abundance of parent molecules is similar in non-thermal escape of hydrogen, and hence over the course of Venusian history, the $\mathrm{D} / \mathrm{H}$ ratio is enriched as compared with the primordial value. Vertical profiles of trace species obtained from observation by the Venus Express mission, such as $\mathrm{HCl}, \mathrm{H}_{2} \mathrm{O}$, and HDO, provided new information to constrain chemical and dynamical process. Liang and Yung (2009) simulate these profiles, using the model developed and described in a related paper by Yung et al. (2009), with special emphasis on the modelling of $\mathrm{H}_{2} \mathrm{O}$ and HDO. The 2-D version (Liang et al. 2005) of the Caltech/JPL photochemical mode is employed to simulate the meridional distribution of $\mathrm{H}_{2} \mathrm{O} / \mathrm{HDO}$ and $\mathrm{HCl} / \mathrm{DCl}$ in the upper atmosphere of Venus. The model and the adopted transport are described in a companion paper (Yung et al. 2009). They solve the model at latitudes from pole to pole and altitudes from 56 to $112 \mathrm{~km}$. The chemical species and reactions are taken from the 1-D model described in Sect. 2.3.4. The boundary conditions are the same as the 1-D case with hydrogen escape. They found that the observed profiles of $\mathrm{HDO}$ and $\mathrm{H}_{2} \mathrm{O}$ cannot be explained satisfactorily by current knowledge of chemical and dynamical processes in this region of the atmosphere, and offer several conjectures to help resolving the problems. For instance, they suggest laboratory measurements of temperature-dependent cross sections for $\mathrm{H}_{2} \mathrm{O}$ over $\mathrm{HDO}$ are needed. Also, the correct simulation of the distribution of $\mathrm{HCl}, \mathrm{H}_{2} \mathrm{O}$, and $\mathrm{HDO}$ ultimately requires a 3-D model. They identify the most important physical and chemical processes that such a model must incorporate. Also, they consider the region of the atmosphere above $70 \mathrm{~km}$ where the $\mathrm{H}_{2} \mathrm{O}$ abundance is $\simeq 1 \mathrm{ppm}$. As the abundance of $\mathrm{H}_{2} \mathrm{O}$ in the deep atmosphere is 100 ppm, Liang and Yung (2009) point out that there should be another removal mechanism that is not related to photolysis. It is known that $\mathrm{H}_{2} \mathrm{SO}_{4}$ aerosols are formed above the cloud tops representing a net sink of $\mathrm{SO}_{2}$ and $\mathrm{H}_{2} \mathrm{O}$, thereby explaining their rapid decrease with altitude above the cloud tops (cf. Sect. 2.3.4: $\mathrm{SO}_{2}$ and $\mathrm{H}_{2} \mathrm{O}$ regulation via formation of $\mathrm{H}_{2} \mathrm{SO}_{4}$ ). It is not known whether this process can cause fractionation and hence laboratory studies are needed to determine the fractionation associated with this chemical dehydration, if any occurs.

Venus Thermospheric General Circulation Model (VTGCM) Recent VTGCM modifications involve updates of the night airglow chemistry with recent reaction rates and yields (cf. Gérard et al. 2017). Figures 2 and 3 of Brecht et al. (2011) show simplified day side odd oxygen and odd nitrogen chemical schemes derived from Bougher et al. (1990). There are two altitude regions where $\mathrm{O}$ is produced. The production peaks are near $110 \mathrm{~km}$ and $140 \mathrm{~km}$. The two different altitude source regions are important for the production of the $\mathrm{O}_{2}$ IR night airglow and the NO UV nightglow, respectively. The main sources of atomic nitrogen come from photodissociation and photoelectron impact of molecular nitrogen. The 
dissociative recombination of $\mathrm{NO}^{+}$also supplies ground state and excited atomic nitrogen species. The day side atomic nitrogen production peak is located near the ionospheric peak at $140 \mathrm{~km}$. The day side atomic nitrogen production peak is located near the ionospheric peak at $140 \mathrm{~km}$. The main chemical reaction for $\mathrm{O}_{2} \mathrm{IR}$ night airglow production and the main chemical loss of atomic oxygen on the night side (above $\sim 90 \mathrm{~km}$ ) is:

$$
\mathrm{O}+\mathrm{O}+\mathrm{M} \rightarrow \mathrm{O}_{2}^{*}+\mathrm{M}
$$

The main chemical loss on the night side for $\mathrm{N}^{\left({ }^{4} \mathrm{~S}\right)}$ and the main chemical reaction for production of the NO UV night airglow is:

$$
\mathrm{N}\left({ }^{4} \mathrm{~S}\right)+\mathrm{O}+\mathrm{M} \rightarrow \mathrm{NO}^{*}+\mathrm{M}
$$

Currently, single density profiles of trace species $\left(\mathrm{Cl}, \mathrm{Cl}_{2}, \mathrm{ClCO}, \mathrm{ClO}, \mathrm{H}_{2}, \mathrm{HCl}, \mathrm{HO}_{2}\right.$, $\mathrm{O}_{3}, \mathrm{OH}$ ) from an altitude of $\sim 70 \mathrm{~km}$ to $130 \mathrm{~km}$ for the night side have been extracted from Krasnopolsky (2010c, Fig. 8) and incorporated into the night side of the VTGCM. The model results are within observational ranges for the $\mathrm{O}_{2}$ IR, NO UV, and $\mathrm{OH}$ IR nightglow emissions and peak altitudes. Brecht et al. (2011) state that it is appropriate not to carry these trace species dynamically in the VTGCM, which is justified because in the region where the trace species greatly impact the atmospheric chemistry, they have very short chemical lifetimes with respect to the dynamics. When these trace species were added to the VTGCM, they made a noticeable difference in the nightglow layers providing additional loss terms for the $\mathrm{O}$ chemistry at the lower altitudes (below $90 \mathrm{~km}$ ) and help define a narrower $\mathrm{O}$ density layer. This directly impacts the $\mathrm{O}_{2}$ IR nightglow and indirectly impacts the NO UV nightglow. Without these trace species, the chemistry is incomplete in the VTGCM and the varying nightglow emission layers cannot be properly simulated for comparison to available data sets.

The VTGCM model is currently able to provide a self consistent view of Venus' time averaged global dynamics and horizontal variation in the middle and upper atmosphere.

\section{Temporal Variability}

\subsection{Sulphur Compounds $\left(\mathrm{SO}, \mathrm{SO}_{2}\right)$}

Sulphur compounds above the cloud top, among all minor species, exhibit probably the most spectacular temporal and spatial variabilities, spanning several orders of magnitude on various horizontal and temporal scales.

\subsubsection{Short Scale Variability}

Under this umbrella term "short scale", we mean to discuss the unorganised pattern of variations that do not encompass the whole planet. This kind of variability is best studied from Earth-based observations that can provide snapshots of the whole Earth-facing hemisphere of Venus at intervals shorter than the typical orbital periods around Venus. Encrenaz et al. (2012) using the high-resolution $\left(R \simeq 8 \cdot 10^{4}\right)$ TEXES spectrometer around $7.35 \mu \mathrm{m}$ could map $\mathrm{SO}_{2} / \mathrm{CO}_{2}$ line depth ratios for weak neighbouring transitions (see Fig. 9). Such a method directly yields volume mixing ratio maps of $\mathrm{SO}_{2}$ at cloud top level between 60 and $80 \mathrm{~km}$, which exhibits a distinctive patchy appearance, with variations spanning at least 
one order of magnitude across the whole Venusian disk, with maximal mixing ratios on the order of 100 ppbv. The spatial distribution and shape of $\mathrm{SO}_{2}$ "hot spots" (more prevalent at lower latitudes) was different every night of the acquisition campaign. Using a similar methodology, Encrenaz et al. (2013) mapped $\mathrm{SO}_{2}$ volume mixing ratio near $7 \mu \mathrm{m}$ as they previously did, but also near $19 \mu \mathrm{m}$ which probes a few kilometres below. Their main conclusions are that (1) $\mathrm{SO}_{2}$ distribution is far less patchy as seen near $19 \mu \mathrm{m}$, which is expected since the photochemical sink is less active and the large supply from the lower atmosphere easier to access, and (2) that significant variability occurs within a time frame of a few hours (between individual snapshots), consistent with a very fast photochemical or microphysical sink able to act in less than $10^{5} \mathrm{~s} .10^{5} \mathrm{~s}$ is roughly the modeled photochemical loss timescale for $\mathrm{SO}_{2}$ (defined as $\left[\mathrm{SO}_{2}\right] /$ loss rate of $\mathrm{SO}_{2}$ ) at optical depth unity (Jessup et al. 2015). STIS observations from Jessup et al. (2015) support these conclusions, with a drop of $\mathrm{SO}_{2}$ (and $\mathrm{SO}$ ) abundance at cloud top by one order of magnitude in less than an Earth month, between Dec. 2010 and Jan. 2011. Encrenaz et al. (2016) investigated the short and long term variations of $\mathrm{SO}_{2}$ at cloud top level using observations performed by TEXES. Observations took place during six runs between January 2012 and January 2016. The $\mathrm{SO}_{2}$ maps obtained show a strong short-term variability with features usually following the fourday rotation of the clouds over a timescale of two hours. This corresponds to a rotation of $7.5^{\circ}$ over the planetary disk. However, the morphology of this feature changes on short time scales, which suggests that the lifetime of this structure is not more than a few hours. Recent observations performed with the ALMA instrument (Encrenaz et al. 2015) showed that the $\mathrm{SO}_{2}$ short scale variations were decorrelated from day/night or latitude variations. Moreover, their observations seemed to exhibit a different behavior between $\mathrm{SO}$ and $\mathrm{SO}_{2}, \mathrm{SO}_{2}$ patchy variations being more pronounced.

Sub-mm observations of Venus with the JCMT have provided $\mathrm{SO}$ and $\mathrm{SO}_{2}$ abundances in the $85-100 \mathrm{~km}$ altitude range since 2004 and allowed the analysis of their temporal variation over the averaged disk (Sandor et al. 2010, 2012). Both sulphur species were found to exhibit strong temporal variation. Their main conclusions were that (1) SO is strongly depleted during the night, and (2) the total abundance of $\left(\mathrm{SO}+\mathrm{SO}_{2}\right)$ strongly varies with time. These observations imply the presence of an extra source of sulphur possibly in the form of sulphur aerosol (Sandor et al. 2012).

SOIR measurements (Mahieux et al. 2015c) are also well suited to investigate temporal variability on a scale of 1 Earth day. Figure 10 presents the variations at four pressure levels. The colour code is the absolute latitude, from blue (Equator) to red (Poles). The $\mathrm{SO}_{2}$ volume mixing ratio is calculated at different altitude levels corresponding to $2 \mathrm{mbar}(\sim 80 \mathrm{~km})$, 10 mbar $(\sim 76 \mathrm{~km}), 15.8 \mathrm{mbar}(\sim 73 \mathrm{~km})$ and $25.1 \mathrm{mbar}(\sim 69 \mathrm{~km})$. Most of the data points are from the polar regions, which removes the small latitudinal variations observed above the 30 mbar pressure level. The short term variations are predominant, reaching more than one order of magnitude.

\subsubsection{Long Scale Variability}

On the contrary, "long scale" variability deals with planetary-scale variability in space, and takes place on longer time spans (at least longer than one Venusian day). Orbital measurements are best suited for these kind of studies, since Earth-based observations are restricted to either near inferior conjunction or near the maximal elongations of Venus as seen from Earth - this being true up to a point only, long-term Earth monitoring being essential to assess decadal-scale variability. Such measurements were routinely performed by the SPICAVSOIR instrumental suite (Bertaux et al. 2007b) on-board Venus Express. The previous comparable campaign, extensively discussed in Esposito et al. (1997), dates from the Pioneer 

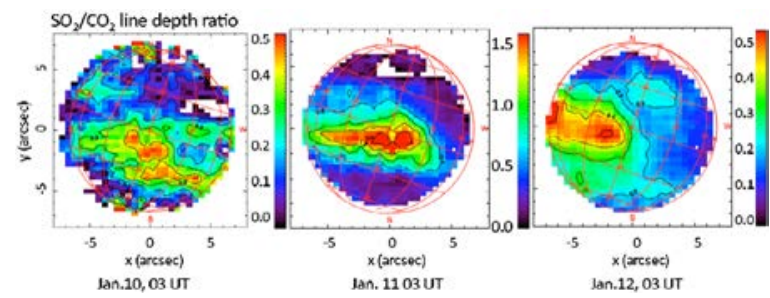

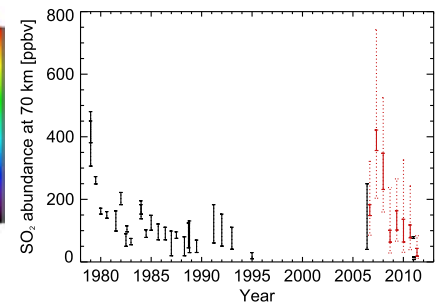

Fig. 9 Left: $7 \mu \mathrm{m}$ maps of cloud top $\mathrm{SO}_{2} / \mathrm{CO}_{2}$ line depth ratios from Encrenaz et al. (2012) on three consecutive nights, the North-South orientation has been corrected from the original as described in Encrenaz et al. (2013); Right: Secular evolution of low latitude $\mathrm{SO}_{2}$ mixing ratio at cloud top level. Black lines represent other measurements, from PVO (Esposito et al. 1988) in the earliest part, SOIR (Belyaev et al. 2008) and HST (Jessup et al. 2015) for the latest part. Red lines stand for moving average $\mathrm{SO}_{2}$ SPICAV-UV retrievals from Marcq et al. (2013) with their average $1 \cdot \sigma$ uncertainty-dotted red lines represent the much larger statistical dispersion within temporal bins

Venus mission (1978-1992) using the UV spectrometer PVOUVS with updates to include later observations in Mills et al. (2007). It showed a steady decline of the cloud top $\mathrm{SO}_{2}$ content from $100 \mathrm{ppbv}$ down to $10 \mathrm{ppbv}$ about 10 years later (see Fig. 9). The decline of the $\mathrm{SO}_{2}$ amount was rather fast over the first year, and much slower later on. This behaviour was interpreted as a massive "injection of $\mathrm{SO}_{2}$ into the Venus middle atmosphere by a volcanic explosion" (Esposito et al. 1988). Alternatively, changes in vertical mixing proposed by Krasnopolsky (1986) and/or atmospheric dynamics (Clancy and Muhleman 1991) could explain this phenomenon. This steep decline of the $\mathrm{SO}_{2}$ abundance was also confirmed by IUE observations, which showed a decrease of the abundance from $380 \pm 70 \mathrm{ppbv}$ in 1979 down to $50 \pm 20$ ppbv in 1988 ( $\mathrm{Na}$ et al. 1990). In 1995 a first measurement from the Hubble Space Telescope was performed and yielded a value of $20 \pm 10 \mathrm{ppbv}$ ( $\mathrm{Na}$ and Esposito 1995) again confirming a decrease in the $\mathrm{SO}_{2}$ abundance with time. All these observations concurred to the general vision that $\mathrm{SO}_{2}$ abundance decreased from the 1970's to the 1990's.

UV spectroscopic observations of scattered sunlight in order to measure $\mathrm{SO}_{2}$ column densities on the day side were routinely performed by SPICAV-UV. As previously determined (Esposito et al. 1997), $\mathrm{SO}_{2}$ at cloud top level not only experiences the aforementioned short-scale variability from one orbit to the next, but also that the low-pass average value over a few weeks showed large variations spanning about one order of magnitude, at least for the low latitudes. Marcq et al. (2013), using the methodology from Marcq et al. (2011), thus monitored an increase of $\mathrm{SO}_{2}$ column density above the cloud top from April 2006 to the first quarter of 2007 by a factor of about 2, followed by a slower decrease by a factor of 5 to 10 until 2012, as can be seen on Fig. 9. However, one must be cautious about inferred mixing ratios, since (1) $\mathrm{SO}$ was assumed to be $10 \%$ of $\mathrm{SO}_{2}$ mixing ratio, in a good agreement with the mean of recent measurements from Jessup et al. (2015). Were $\mathrm{SO} / \mathrm{SO}_{2}$ ratio higher than $10 \%$, retrieved $\mathrm{SO}_{2}$ column densities would likely be lower since $\mathrm{SO}$ and $\mathrm{SO}_{2}$ share a common absorption band near $220 \mathrm{~nm}-\mathrm{SPICAV-UV}$ spectral resolution cannot unfortunately distinguish individual $\mathrm{SO}_{2}$ and $\mathrm{SO}$ spectral lines; and (2) $\mathrm{SO}_{2}$ column density above the cloud top is the observable parameter that can be retrieved, not local volume mixing ratios. In order to convert the former to the latter, one must assume a vertical scale height for $\mathrm{SO}_{2}$, as well as an aerosol extinction vertical profile. With these caveats in mind, the order of magnitude for conversion between total column densities and local mixing ratio at cloud top level is close to $1 \mu \mathrm{m}$ atm $\leftrightarrow 10 \mathrm{ppbv}$. Typical $\mathrm{SO}_{2}$ mixing ratios at low latitudes near cloud top level thus vary between 0.1 and $1 \mathrm{ppmv}$, more than two orders of magnitude below the 130 ppmv value typical of the lower atmosphere. 
Long-term variations of $\mathrm{SO}_{2}$ obtained by TEXES (Encrenaz et al. 2016) show that the disk-integrated $\mathrm{SO}_{2}$ mixing ratio varies between 2012 and 2016 by a factor as high as 10, with a minimum value of $30 \pm 5$ ppbv on February 26, 2014 an a maximum value of $300 \pm 50$ ppbv on January 14, 2016. Interestingly enough, large-scale horizontal variations previously discussed in Sect. 3.2 are linked to these long-term variations. The decreasing latitudinal gradient of $\mathrm{SO}_{2}$ from equator to the northern pole is only evident during epochs where $\mathrm{SO}_{2}$ is relatively abundant, and suppressed during epochs of scarce $\mathrm{SO}_{2}$. In other words, and contrary to the short scale variations, $\mathrm{SO}_{2}$ large scale variations are a more of a low latitude phenomenon. This highlights the probable role of solar and/or dynamical driven $\mathrm{SO}_{2}$ fluctuations in $\mathrm{SO}_{2}$ supply from the lower atmosphere as the likely cause for $\mathrm{SO}_{2}$ variability at Venus' cloud tops, as Marcq et al. (2013) simple model suggests (only a few Earth days are required to transition between latitudinally uniform low $\mathrm{SO}_{2}$ and the latitudinal gradient typical of high $\mathrm{SO}_{2}$ periods).

The available SOIR database as of 2015 also covers about 11 Venus years, so that long term variations have also been investigated (see Fig. 10). It is hard to conclude on any kind of long term variations of the $\mathrm{SO}_{2} \mathrm{VMR}$ at the 2 mbar and 10 mbar levels. At lower altitude, 15.8 mbar and 25.1 mbar pressure levels, $\mathrm{SO}_{2}$ seems to be slightly increasing in the polar regions from $30 \mathrm{ppbv}$ around orbit \#400 (26/05/2007) to $100 \mathrm{ppbv}$ around orbit \#1250 (22/09/2009), followed by a decrease to $40 \mathrm{ppbv}$ at orbit \#2500 (23/02/2013). But the amplitude of these trends is smaller than those of aforementioned short term variations. The long term decay, first observed by Esposito et al. (1988) at cloud top level from PVO measurements (from 1979 till 1992), and recently reported by Marcq et al. (2013) (from 2007 till 2012) from instrument VEx/SPICAV-UV analysis, is not observed in the current SOIR data set covering the same period of time. However, the SOIR measurements are probably too sparse to support or contradict such a tendency, since the short term variability of $\mathrm{SO}_{2}$ above the cloud deck is known from this study and others (Marcq et al. 2011, 2013; Encrenaz et al. 2012) to span over more than one order of magnitude, and most of them were acquired at higher latitudes, which do not seem to be as affected by the same long-term trend as at the lower latitudes. Interestingly, recent Earth-based IR observations by Encrenaz et al. (2016) have measured a tenfold increase (from $30 \pm 5$ to $300 \pm 50 \mathrm{ppmv}$ ) between 2014 and 2016, highlighting the need for a long-term monitoring of $\mathrm{SO}_{2}$ as extensive as possible (considering the observational constraints).

\subsection{Other Species}

Although Venus Express was operational from 2006 up to the end of 2014, thus providing for almost 8 Earth years of a wealth of data, it is not always easy to derive long term trends from the different instruments. SOIR has been measuring different trace species quite regularly over the complete duration of the mission and is therefore one of the main sources of knowledge. In general, the same behaviour is observed: no noticeable long term trends, but a very large short term variability. Such short term variability has been observed for CO (Vandaele et al. 2014, 2015a), $\mathrm{HCl}$ and HF (Mahieux et al. 2015a). Typical variability of one order of magnitude occurs on time scales of 1 to 2 months.

\subsection{1 $\mathrm{H}_{2} \mathrm{O}$ and $\mathrm{HDO}$}

Similar time scales have also been reported for $\mathrm{HDO}$ and $\mathrm{H}_{2} \mathrm{O}$ by Sandor and Clancy (2005) who found water abundances varying from 0 to 3.5 ppmv between 65 and $100 \mathrm{~km}$ over time 

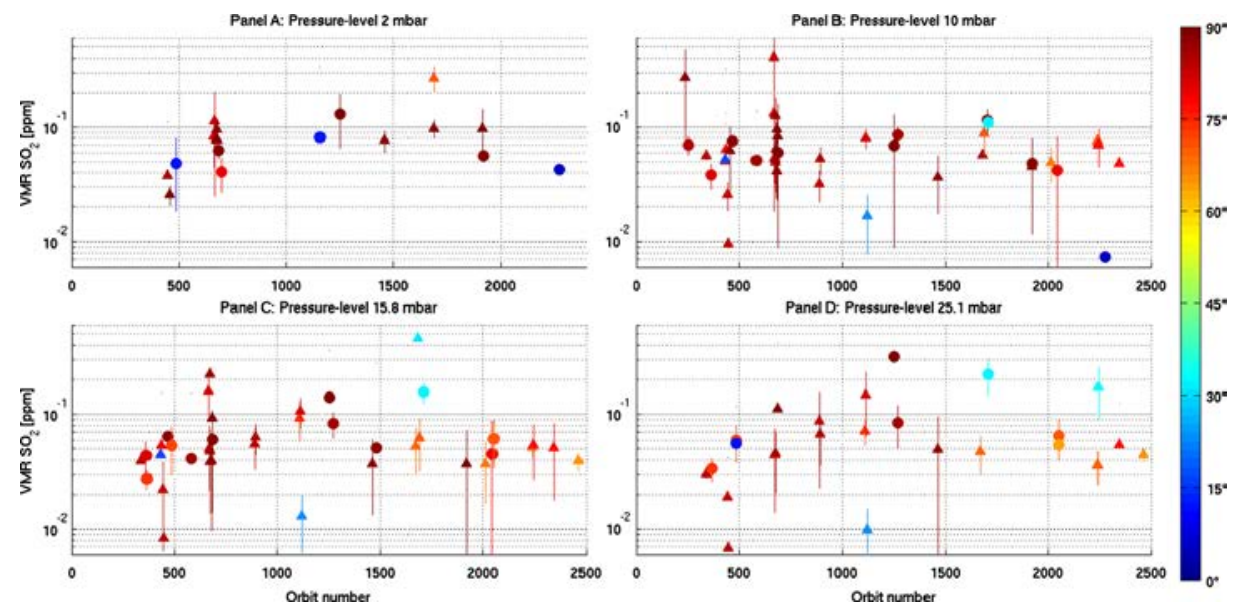

Fig. 10 Long term variations of the $\mathrm{SO}_{2} \mathrm{VMR}$ at four pressure levels: 2 mbar $(\sim 80 \mathrm{~km}), 10 \mathrm{mbar}(\sim 76 \mathrm{~km})$, 15 mbar $(\sim 73 \mathrm{~km})$ and $25 \mathrm{mbar}(\sim 69 \mathrm{~km})$ as measured by SPICAV-SOIR. Colour codes for latitude according to the colour bar. Figure from Mahieux et al. (2015c)

scales of 1-2 months. This variability manifests itself as rapid changes in the lower mesosphere which are then propagated to higher altitudes. Gurwell et al. (2007) also reported values varying between 0 and 4.5 ppmv with a strong variability (by a factor of 50) over time scales less than 2 days. They suggested that these fluctuations might be due to moderate variations of the mesospheric temperatures (by 10-15 K) leading to water condensation. Some temporal variability of $\mathrm{H}_{2} \mathrm{O}$ at cloud top level was also evidenced by Cottini et al. (2015), with a multi-year increase at higher latitudes between 2006-2008 and 2009-2011 by about 1 to $2 \mathrm{ppmv}$. Short-term variability of $\sim 1 \mathrm{ppmv}$ at lower latitudes and $\sim 2 \mathrm{ppmv}$ beyond $60^{\circ}$ is also present in VIRTIS-H data. Data at slightly lower altitudes (about $64 \mathrm{~km}$ ) acquired near $7.4 \mu \mathrm{m}$ for HDO also indicates moderate long ans short variability for the integrated disk average of water vapor, no more than a factor of 2 (Encrenaz et al. 2016).

\subsection{2 $\mathrm{CO}$}

Sub-mm studies (Clancy and Muhleman 1985, 1991; Clancy et al. 2008, 2012) have found strong variations of $\mathrm{CO}$ abundance and temperature in the Venus mesosphere, both diurnal and on larger time scales (several weeks). The $\mathrm{CO}$ changes occur at higher altitudes than the $\mathrm{H}_{2} \mathrm{O}$ variations implying that $\mathrm{CO}$ and $\mathrm{H}_{2} \mathrm{O}$ variations are disconnected (Sandor and Clancy 2005). The CO variations were neither connected with changes in the zonal and SSAS circulations, but rather to night circulation patterns active on smaller scales. Long-term variations were found: a decrease of a factor 2 was observed between the 2000-2002 and 2007-2009 observation periods.

\section{Graphical Summary}

Table 4 proposes to show a graphical summary about the compositional variability of the Venusian atmosphere as discussed in this paper. Rows refer to minor species and altitude ranges, whereas columns refer to the dimension along which variability may occur, respectively: latitude (assuming hemispheric symmetry), local time and temporal variability. 
Table 4 Synoptic summary of known variabilities for minor species in Venus' atmosphere. Signs stand for the signs of respective correlations, " 0 " indicate no known variability and " $\times$ " indicate variability without any clear trend. Bold signs stand for new discoveries made during Venus Express era

\begin{tabular}{|c|c|c|c|c|}
\hline & & $\mid$ Latitude $\mid$ & $6 \mathrm{~h} \bigodot_{0 \mathrm{~h}}^{12 \mathrm{~h}} 18 \mathrm{~h}$ & Temporal \\
\hline \multirow[t]{3}{*}{$\mathrm{CO}$} & $0-47 \mathrm{~km}$ & + & 0 (night) & 0 \\
\hline & $65-85 \mathrm{~km}$ & + & o or $+/-$ & $x$ \\
\hline & $85-100 \mathrm{~km}$ & - & $\mp$ & $x$ \\
\hline \multirow[t]{2}{*}{ OCS } & $0-47 \mathrm{~km}$ & $-?$ & 0 (night) & 0 \\
\hline & $65-85 \mathrm{~km}$ & $-?$ & $+/-$ & \\
\hline \multirow[t]{2}{*}{$\mathrm{H}_{2} \mathrm{O} \& \mathrm{HDO}$} & $0-47 \mathrm{~km}$ & 0 & 0 (night) & 0 \\
\hline & $65-100 \mathrm{~km}$ & + & o or $+/-$ & $\nearrow \rightarrow$ \\
\hline \multirow[t]{3}{*}{$\mathrm{SO}_{2}$} & $0-47 \mathrm{~km}$ & 0 & 0 (night) & 0 \\
\hline & $65-80 \mathrm{~km}$ & - or 0 & $+/-($ day $)$ & $\pi \searrow$ \\
\hline & $80-100 \mathrm{~km}$ & 0 ? & ? & $x$ \\
\hline $\mathrm{H}_{2} \mathrm{SO}_{4}$ & $50-55 \mathrm{~km}$ & - & 0 & 0 \\
\hline $\mathrm{HCl}$ & $>90 \mathrm{~km}$ & - & ? & $x$ \\
\hline
\end{tabular}

$+/ 0 /-$ signs stand for positive, null and negative correlation. E.g., a + (conversely, - ) sign in the latitude column indicated that a species mixing ratio is increasing (conversely, decreasing) with increasing latitude. For the local time column, $+/-$ and $-/+$ signs indicate a morning/evening gradient, where as \pm or $\mp$ a subsolar/antisolar gradient, according to the small picture in the header. Blue and red colors are intended to improve legibility, but convey no extra information.

\section{Open Questions and Topics of Interest}

\subsection{Upper Limits for Unobserved Gases}

Detection thresholds in the atmosphere of Venus have made substantial progress in the last two decades, thanks to (1) a huge increase of computing resources leading to better signal processing and; (2) better spectroscopic instruments (spectrographs and spectral imagers) on ground as well as space-borne. Accuracy of remote sensing trace species retrievals now range in the $10^{-8}$ regarding volumetric ratios. Recent effort was focused on chemically reduced states of already detected species. For example, Krasnopolsky (2012b) found an upper limit for $\mathrm{NH}_{3}$ above the clouds at 6 ppbv, and also Krasnopolsky (2008) put a $3 \cdot \sigma$ upper limit to $\mathrm{H}_{2} \mathrm{~S}$ at $23 \mathrm{ppbv}$ in the upper cloud and above.

Other minor species exhibit partial upper limits within specific altitude ranges. For example, although $\mathrm{O}_{2}$ nightglow emission has been routinely observed in the upper atmosphere near $115 \mathrm{~km}$, molecular oxygen has not been detected at and above 300 mbar $(\sim 58 \mathrm{~km})$, with an upper limit from Mills (1999) of 3 ppmv assuming a vertically uniform profile. This is consistent with previous upper limits of $0.3 \mathrm{ppmv}$ (Trauger and Lunine 1983) and $2 \mathrm{ppmv}$ (Traub and Carleton 1974, as reinterpreted by Trauger and Lunine 1983). 
Table 5 Upper limits for unobserved gaseous trace species derived since 1997

\begin{tabular}{llll}
\hline Species & Altitude & Upper limit & Reference \\
\hline $\mathrm{NH}_{3}$ & Cloud top & $<6 \mathrm{ppbv}$ & Krasnopolsky (2012b) \\
$\mathrm{H}_{2} \mathrm{~S}$ & Cloud top & $<23 \mathrm{ppbv}$ & Krasnopolsky (2008) \\
$\mathrm{O}_{2}$ & $\sim 58 \mathrm{~km}$ & $<3 \mathrm{ppmv}$ & Mills (1999) \\
\hline
\end{tabular}

\subsection{The Poorly Known Cloud Region (48-65 km)}

Besides the previously mentioned radio-occultation measurements of $\mathrm{H}_{2} \mathrm{SO}_{4}$ vapour in the lower cloud, NO detection and long-wave thermal IR measurements in the upper cloud, the cloud region extending from 48 to roughly $65 \mathrm{~km}$ is unreachable from remote observations. Therefore, not much progress in our understanding has been possible since the last in situ measurements from the latest Venera and Pioneer Venus missions, dating from the 1980s.

Yet this region holds the key to several outstanding questions regarding the Venusian atmospheric composition, which we detail further below. The Venus Express-era results that we discussed in the previous sections of this paper confirm that the composition of the atmospheric layers below and above the cloud region differ in many respects. Almost all minor species (with the exception of carbon monoxide) face mixing ratio changes by at least one order of magnitude, and even more than two orders of magnitude for $\mathrm{SO}_{2}$. This highlights two key problems.

\subsubsection{The Bifurcation Problem}

All water and sulphur related species are involved in chemical reactions and microphysical exchanges with the aerosol and clouds primarily composed of a sulphuric acid-water solution, which acts as a supplementary reservoir that our current understanding poorly constrains.

Parkinson et al. (2015b) show there is a strong interplay between $\mathrm{H}_{2} \mathrm{O}$ and $\mathrm{SO}_{2}$ in the middle atmosphere as described in Sect. 2.3.4. Their work illustrates what can happen to the water profile over the altitude range of 58-112 km when the $\mathrm{SO}_{2}$ mixing ratio increases or decreases at $58 \mathrm{~km}$, which is roughly the boundary between the middle and upper cloud decks (Esposito et al. 1983), and find that the collapse (or bifurcation) of water in the middle atmosphere can occur in some situations, For instance, a source pulse change in the transport rates for $\mathrm{SO}_{2}$ results in large changes in $\mathrm{SO}_{2}$ above the cloud tops from below this region. Spacecraft UV observations show such periodic $\mathrm{SO}_{2}$ injections (Esposito et al. 1988; Marcq et al. 2013). In regions of high mixing ratios of $\mathrm{SO}_{2}$ there exists a "runaway effect" such that $\mathrm{SO}_{2}$ gets oxidised to $\mathrm{SO}_{3}$, which quickly soaks up $\mathrm{H}_{2} \mathrm{O}$ causing a major depletion of water between 70 and $100 \mathrm{~km}$, thereby potentially explaining the drastic changes in water. However, the implications of this need to be studied further to quantify fully the photochemical distribution of Venusian water and the effects of this on the poorly understood cloud layer. One way to proceed is to conduct detailed dynamical and photochemical studies of the Venus middle atmosphere $(\sim 70-110 \mathrm{~km})$ to obtain a self-consistent understanding of the photochemistry, dynamics, heating, and microphysics of the Venus middle atmosphere employing existing validated models and utilising updated photochemical schemes (such as those described in this paper). This can be achieved iteratively by: (1) creating a 1-D model atmosphere that eliminates the need for saturation vapour pressure (SVP) $\mathrm{H}_{2} \mathrm{SO}_{4}$ photochemistry, relying on new chemical schemes; (2) determining a reduced chemical scheme 
for use in 3-D dynamical modelling using $\mathrm{SO}_{2}$ as a tracer; (3) using cloud microphysics to better characterise Venus' spatially and temporally highly variable upper haze, as populated by multiple particle size modes; (4) perform detailed analysis of data that may contain simultaneous $\mathrm{SO}_{2}$ and water observations (e.g. VEx/SOIR data sets).

New chemical schemes are required to address $\mathrm{SO}_{2}$ tracer species distribution for useful comparison with recent (available) ground-based and VEx data sets. Photochemical modelling can also help constrain diurnal variations in the eddy diffusion coefficient by making use of data-model comparisons of vertical profiles of species distributions. This modelling can be used in conjunction with microphysical cloud modelling in order to effectively model aerosol processes above the cloud deck in an effort to better understand the sulphur processes in the region of interest, cloud formation, and sulphuric acid precipitation in equatorial regions (Parkinson et al. 2015a). Data-model comparisons making use of simulated outputs from the 3-D modelling can subsequently be used to examine the corresponding retrograde superrotating zonal (RSZ) and subsolar-antisolar (SS-AS) wind components (or residuals) required to give rise to these middle atmosphere mean density and temperature distributions, and their variations. Performing such analyses can help make the connection of the variability of $\mathrm{SO}_{2}$ to the observed light/dark clouds observed in the Venusian atmosphere. Higher abundances of $\mathrm{SO}_{2}$ (and associated chemistry and subsequent formation of aerosols), as described by Bougher et al. (2015) and Parkinson et al. (2015a) with the relative absence of water due to a chemical bifurcation could correspond to the darker regions, while areas of depleted $\mathrm{SO}_{2}$ and moderate to high values for $\mathrm{H}_{2} \mathrm{O}$ could correspond to the lighter regions, as lower $\mathrm{SO}_{2}$ abundances could be detrimental for the formation of such a $\mathrm{UV}$ absorber. In this way, photochemistry, dynamics $\left(\mathrm{SO}_{2}\right.$ tracer) and microphysics can be employed in a self consistent way to address the problem of the unknown UV absorber (see Titov et al. 2017 for further discussion). Synoptic imaging spectroscopy with sufficient spectral, spatial, and temporal resolution and sufficient duration to track variations in $\mathrm{SO}_{2}$ and $\mathrm{SO}$ at the cloud tops across the few hours to few weeks time scales would be invaluable for sorting the relative contributions of photochemistry, dynamics and microphysics.

\subsubsection{The Sealing Problem}

Also, dynamical exchanges between the lower and upper atmosphere must be somehow limited in order to enable such dramatic changes in the vertical profiles of most minor species. The cloud region therefore acts as a barrier, whose efficiency can vary a lot, as the dramatic variations of $\mathrm{SO}_{2}$ above the clouds in a large range of temporal and spatial scales can attest - the short photochemical life of $\mathrm{SO}_{2}$ makes it particularly sensitive to any variation in the supply from the lower atmosphere. The exact causes of this sealing variability are yet to be determined and open to educated speculation. For example, the available thermal profile measurements (see Limaye et al. 2017) point out the existence of statically stable layers within the clouds. Localised and temporary alterations of the temperature profile may lower the stability of these layers, so that the exchanges between the lower and upper atmosphere may rise accordingly. Various phenomena may in turn be responsible for changes in the temperature profile: dynamical heating through various atmospheric waves (see Sánchez-Lavega et al. 2017), volcanic outgassing of very hot plumes (Esposito et al. 1988), or any other yet unidentified cause. These links between composition, atmospheric dynamics, cloud microphysics, thermal budget and interior-atmosphere coupling emphasise the need to consider Venus as a unified, highly coupled system if we want to take the next steps in our degree of understanding. 


\subsection{Isotopic Ratios (Including D/H)}

Isotopic ratios are of foremost scientific interest, especially in regard to long-term evolution of the planet and its atmosphere. Among them, noble gases isotopic ratios are very helpful in constraining the degassing history of Venus, but their chemical inertness (which makes them ideal, well-mixed atmospheric tracers) is intimately linked with their lack of spectral lines, so that they can only be measured in situ. Therefore, no new measurements have been available since the 1980s, and they have been extensively discussed (von Zahn et al. 1983; Esposito et al. 1997). Uncertainties are large, and even bulk inventory of heavier gases like Xenon and Krypton are virtually unknown (Chassefière et al. 2012). Newer generation Gas Chromatographs and Mass Spectrometers (GCMS) could substantially improve the uncertainty about these isotopic ratios, and should be a major part of any scientific payload sent within Venus atmosphere. Thus, measurements of radiogenic noble gases isotopes such as ${ }^{40} \mathrm{Ar}$ (from long lived ${ }^{40} \mathrm{~K}$ ) and ${ }^{4} \mathrm{He}$ (from heavy elements such as Uranium and Thorium) would constrain the degassing history of Venus, and would do so even better if their progenitor species could be also measured on the surface by future landers (Kaula 1999).

D/H Ratio Another especially interesting isotopic ratio is the ${ }^{2} \mathrm{H} /{ }^{1} \mathrm{H}$ (also known as $\mathrm{D} / \mathrm{H}$ ratio), since the large mass difference between these isotopes makes it very sensitive with respect to escape process, and is known to be highly variable among the major solar system reservoirs. Venus is very peculiar in this regard for two reasons. The first one is that the bulk of Venus' atmospheric water vapour exhibits a very high $\mathrm{D} / \mathrm{H}$ ratio, more than 100 times larger than VSMOW (Vienna Standard Mean Ocean Water, representative of Earth's isotopic ratio). High resolution infrared spectroscopy on Venus' night side by de Bergh et al. (1991) found $120 \pm 40$, whereas lower resolution observations near $2.4 \mu \mathrm{m}$ by Marcq (2006) yielded $135 \pm 20$ in the $30-40 \mathrm{~km}$ altitude range, below the clouds. Pioneer Venus data reanalysis by Donahue and Russell (1997) reported $157 \pm 30$. Based on the 2.59-2.65 $\mu \mathrm{m}$ dayside spectra obtained on KAO (Kuiper Air-born Observatory), Bjoraker et al. (1992) report a $\mathrm{D} / \mathrm{H}$ ratio of $157 \pm 15$ times the terrestrial value at $72 \mathrm{~km}$. Values inferred for the mesosphere by SOIR are significantly higher, as already mentioned in Sect. 2.3: $240 \pm$ 25 (Fedorova et al. 2008). Moreover these data seem to indicate a distinct increase of the $\mathrm{HDO} / \mathrm{H}_{2} \mathrm{O}$ ratio with altitude in the range from 75 to $95 \mathrm{~km}$. Krasnopolsky et al. (2013) derived the $\mathrm{D} / \mathrm{H}$ from the observation $\mathrm{HF}, \mathrm{HCl}$, and $\mathrm{H}_{2} \mathrm{O}$ at an altitude of $74 \mathrm{~km}$. They obtained diverging values, $420 \pm 200,190 \pm 50$, and $95 \pm 15$ respectively. The higher value for $\mathrm{D} / \mathrm{H}$ in $\mathrm{HCl}$ was explained by the $\mathrm{HCl}$ photochemistry in the mesosphere which tends to enrich $\mathrm{D}$ in $\mathrm{HCl}$ and deplete it in $\mathrm{H}_{2} \mathrm{O}$. The value obtained from $\mathrm{HF}$ was not confirmed by SOIR observations (Vandaele et al. 2014) which found a value close to 200 (208 \pm 155), although as for Krasnopolsky et al. (2013), the error is large due to the difficulty to observe the DF signature. Ground-based observations in the thermal infrared (Encrenaz et al. 2012 , 2013, 2016) usually observe HDO and deduce from it the abundance of $\mathrm{H}_{2} \mathrm{O}$. Further measurements are therefore needed in order to solve this problem of $\mathrm{D} / \mathrm{H}$ vertical profiling in hydrogen-bearing species; were the increase above the clouds confirmed, it would imply a substantial revision of chemical models in order to model properly this profile (Liang and Yung 2009).

These very high values for the Venus atmospheric D/H ratio are often cited as evidence for a large initial water reservoir (Donahue 1999). However, others (Grinspoon 2013) have argued that this deuterium enrichment reflects rather the balance between water escape and resupply from the interior (volcanic outgassing) and/or from space (comets) during the last $\sim 10^{9}$ years. In order to better constrain the history of water on Venus (and hence its past 
habitability), other isotopic measurements are needed, especially those of non-radiogenic noble gases (Pepin and Porcelli 2002; Gillmann et al. 2009), to distinguish between "gaspoor" scenarios where Venus' original volatile inventory is comparable with present day and "gas-rich" scenarios where Venus' current volatile inventory is the remnant of a much larger initial one. Currently, "gas-rich" scenarios are in favour since they are able to accomodate for a larger range of accretion and loss processes to account for available observations, but need more free, yet unconstrained parameters in order to do so.

${ }^{37} \mathbf{C l} /{ }^{35} \mathrm{Cl}$ Numerous concomitant density profiles of $\mathrm{H}^{35} \mathrm{Cl}$ and $\mathrm{H}^{37} \mathrm{Cl}$ observed by SOIR (Mahieux et al. 2015a) led to the determination of the ${ }^{37} \mathrm{Cl} /{ }^{35} \mathrm{Cl}$ isotopic ratio on Venus. It was found to be equal to $0.34 \pm 0.13$, which is compatible with the value found on Earth. The hemispheric distribution of the ${ }^{37} \mathrm{Cl} /{ }^{35} \mathrm{Cl}$ isotopic ratio was found by Iwagami et al. (2008) to show no significant structure on the Venus disk, with a disk-averaged value of $0.32 \pm 0.13$ which coincides with the terrestrial value of 0.3198 (Rothman et al. 2013).

Other Finally, other isotopic ratios such as ${ }^{13} \mathrm{C} /{ }^{12} \mathrm{C}$ or ${ }^{15} \mathrm{~N} /{ }^{14} \mathrm{~N}$ have not been studied extensively since the Venera and Pioneer Venus missions, and measurements (Hoffmann et al. 1980; Istomin et al. 1980) yielded values compatible with terrestrial values, therefore not constraining any peculiar atmospheric process. Here also, smaller uncertainties on their measurements could inform us about possible departures, hinting at some other process at work in Venus atmosphere.

\subsection{Interactions Between Interior/Surface and Lowermost Atmosphere}

It was long thought (Fegley and Treiman 1992; Fegley et al. 1997) that the bulk $\mathrm{CO}_{2}$ content of the Venusian atmosphere was controlled by surface-atmosphere buffering, more precisely through the reaction: $\mathrm{CaCO}_{3}+\mathrm{SiO}_{2}=\mathrm{CaSiO}_{3}+\mathrm{CO}_{2}$, which reaches thermodynamic equilibrium — provided that these minerals are indeed present on Venus surface—for pressure and temperature close to those experienced at the surface. However, this view has been challenged (Hashimoto et al. 1997; Treiman and Bullock 2012) on the grounds that such an equilibrium is unstable with respect to small changes in surface temperature (due e.g. to fluctuations in solar activity) or pressure, possibly leading to an atmospheric collapse, or conversely to a runaway disappearance of mineral buffer species on the surface. Treiman and Bullock (2012) provided a simple thermodynamic criterion based on the fact that, for any stabilising buffering reaction, $(d P / d T)_{\text {atm }}>(d P / d T)_{\text {chem. }}$. Such a criterion is very hard to satisfy for any reaction producing a radiatively active gas in an atmosphere already dominated by this gas, which is the case for the aforementioned reaction. The coincidence between the $(P, T)$ conditions at Venus surface and the aforementioned reaction must therefore be regarded only as such.

On the other hand, buffering reactions producing a trace species in Venus atmosphere are much more likely to meet the above-stated stability criterion. Thus, $\mathrm{SO}_{2}$ and $\mathrm{CO}$ abundances near the surface are compatible with a buffering through the pyrite buffer reaction:

$$
3 \mathrm{FeS}_{2}+16 \mathrm{CO}_{2}=\mathrm{Fe}_{3} \mathrm{O}_{4}+6 \mathrm{SO}_{2}+16 \mathrm{CO}
$$

as proposed by e.g. Hashimoto and Abe (2005). It is however noteworthy that Bertaux et al. (1996) in situ $\mathrm{SO}_{2}$ retrievals from VEGA-1 and 2 entry probes have yielded significantly lower values than the $150 \mathrm{ppmv}$ assumed from remote sensing below the clouds near $2.3 \mu \mathrm{m}$ (Pollack et al. 1993; Marcq et al. 2008; Arney et al. 2014), and these lower values would not 
be compatible with the pyrite buffer hypothesis. Nevertheless, other processes may also contribute to $\mathrm{SO}_{2}$ balance in Venus atmosphere, namely episodic injections that may also help in explaining its observed variability at cloud top level (Esposito et al. 1988; Zhang 2014). Actually, if these decadal variations of $\mathrm{SO}_{2}$ cannot be explained through large-scale atmospheric oscillations, then surface-atmosphere interactions would be too slow to provide such a forcing, and volcanic outgassing and associated increased buoyancy would be the only remaining explanation. The degree of interaction between the surface and the atmosphere that was assumed in lower atmosphere chemistry models has ranged from very slow interaction (significantly slower than chemistry in the lower atmosphere) in Krasnopolsky (2013b) to the surface being a significant source of OCS, at least at equatorial latitudes (Yung et al. 2009). An unmodelled extension of the latter would be surface-atmosphere buffering that varies with latitude. Thermochemical calculations suggest gas-phase thermochemical equilibrium for $\mathrm{CO}$ and $\mathrm{O}_{2}$ may be reached only, if at all, below $0.7 \mathrm{~km}(730 \mathrm{~K})$, Fegley et al. (1997) indicating surface mineralogy and surface-atmosphere buffering are likely to vary with surface elevation. Assessing which mechanisms are in control of Venus atmospheric composition (including trace species) in the lowermost scale heights should therefore be a prime scientific goal for future observations (in situ, in orbit or Earth-based).

\subsection{Laboratory Studies: What Can They Teach Us?}

Laboratory work underpins the observational and modelling results summarised here, and significant laboratory advances have been made since 1996. For example, the mechanism in Reaction (9a)-(9c) (Yung and DeMore 1982) was verified by Pernice et al. (2004); temperature-dependent spectra for $\mathrm{SO}_{2}$ (e.g., Bogumil et al. 2003; Vandaele et al. 2009; Blackie et al. 2011) have enhanced the accuracy of retrievals and photochemical modelling (Jessup et al. 2015); potential surface-atmosphere reactions have been quantified (Fegley et al. 1997); and improved high-temperature molecular spectroscopy line lists for $\mathrm{H}_{2} \mathrm{O}$ and HDO (Barber et al. 2006; Voronin et al. 2010) significantly enhanced simulations of nearsurface spectra in near-infrared windows (Chamberlain et al. 2013).

Earlier sections have identified critical areas in which further laboratory work is required. Remote sensing measurements of the lowest scale heights in Venus' troposphere require further improvements in understanding the high-temperature, high-pressure spectra at nearinfrared wavelengths of $\mathrm{H}_{2} \mathrm{O}, \mathrm{HDO}$, and $\mathrm{CO}_{2}$, including the far wing and collision-induced continuum for $\mathrm{CO}_{2}$ (Tonkov et al. 1996; Snels et al. 2014), even though recent observations of Venus by Venus Express have succeeded in yielding new constraints upon $\mathrm{CO}_{2}$ continuum opacity (Bézard et al. 2009, 2011; Fedorova et al. 2015). The mechanisms for Reactions (4) and (5a)-(5c), which potentially convert $\mathrm{SO}_{3}$ and $\mathrm{OCS}$ to $\mathrm{CO}, \mathrm{CO}_{2}$, and $\mathrm{SO}_{2}$, require laboratory demonstration of their viability and, if valid, determination of their rate coefficients. If the postulated mechanisms are valid, then laboratory spectra at wavelengths suitable for use by instruments searching for $(\mathrm{SO})_{2}$ and $\mathrm{SO}_{3}$ from a descent probe will be required.

For research in the upper troposphere and mesosphere, laboratory data in multiple areas, particularly associated with sulphur chemistry, are required. Rate coefficients are required for all of the sulphur association reactions, e.g., Reaction (2b), that build up to $S_{8}$ from sulphur atoms. Rate coefficients also are required for reactions producing and destroying chlorosulphanes, $\mathrm{ClSO}_{2}, \mathrm{ClSO}_{4}$, and $\mathrm{SO}_{2} \mathrm{Cl}_{2}$. Cross sections for these species and for $\mathrm{S}_{2} \mathrm{O}$ and $(\mathrm{SO})_{2}$ are required for photochemical modelling and to assess their potential as candidates for the unidentified UV absorber. Historically, there has been some confusion in laboratory experiments on the attribution of observed absorption to $\mathrm{S}_{2} \mathrm{O}$ or $(\mathrm{SO})_{2}$ (Mills 1998). Cross-sections, comparable in quality to the high-resolution, temperature-dependent 
ones measured for $\mathrm{SO}_{2}$, are needed for $\mathrm{SO}$ in the $\mathrm{UV}, \mathrm{H}_{2} \mathrm{SO}_{4}$ in the $\mathrm{UV}$-visible, $\mathrm{HSO}_{3}$ and $\mathrm{SO}_{3}$ at $\mathrm{S}$-band, and $\mathrm{SO}_{3}$ in the sub-millimetre. $\mathrm{SO}_{x}$ spectra at wavelengths observable from SOFIA (NASA's Stratospheric Observatory for Infrared Astronomy) are needed to make efficient use of this observing resource.

For cloud layer and lightning studies, assessment of mechanisms for producing $\mathrm{H}_{2} \mathrm{SO}_{4}$ that may be faster than Reaction (13a), (13b) in the dry conditions present above $60 \mathrm{~km}$ altitude is needed. Also needed are measurements of equilibrium vapour pressures for $\mathrm{H}_{2} \mathrm{SO}_{4}$, $\mathrm{H}_{2} \mathrm{O}, \mathrm{SO}_{3}$, and $\mathrm{SO}_{2}$ over 70 to $95 \mathrm{wt} \%$ sulphuric acid at 150 to $300 \mathrm{~K}$, the rate coefficient for $\mathrm{SO}_{2}+\mathrm{O}+\mathrm{CO}_{2} \rightarrow \mathrm{SO}_{3}+\mathrm{CO}_{2}$, and the isotopic fractionation for $\mathrm{D}$ and $\mathrm{H}$ associated with condensation onto and evaporation from sulphuric acid aerosols and cloud droplets. Temperature-dependent UV cross sections for $\mathrm{H}_{2} \mathrm{O}$ and $\mathrm{HDO}$ are needed as well for more accurate isotopic fractionation studies. Studies of the chemical effects of lightning will benefit from further laboratory work on reactions involving $\mathrm{C}_{3} \mathrm{O}_{2}, \mathrm{~S}_{n} \mathrm{O}$, and negative ions.

Acknowledgements The research program was supported in Belgium by the Belgian Federal Science Policy Office and the European Space Agency (ESA, PRODEX program, contracts C 90268, 90113, and 17645). We also recognize the support from the FP7 EuroVenus project (G.A. 606798), from the "Interuniversity Attraction Poles" program financed by the Belgian government (Planet TOPERS), and from the BRAIN research grant BR/143/A2/SCOOP of the Belgian Federal Science Policy Office.

The authors also wish to thank the International Space Science Institute (ISSI) for their fruitful support, in particular to the members of the ISSI International Team "Sulfur Dioxide variability in the Venus atmosphere" which met during 2013-2015 in the facilities of ISSI in Bern, Switzerland.

\section{References}

D.A. Allen, J.W. Crawford, Cloud structure on the dark side of Venus. Nature 307, 222-224 (1984). doi:10. 1038/307222a0

G. Arney, V. Meadows, D. Crisp, S.J. Schmidt, J. Bailey, T. Robinson, Spatially resolved measurements of $\mathrm{H}_{2} \mathrm{O}, \mathrm{HCl}, \mathrm{CO}, \mathrm{OCS}, \mathrm{SO}_{2}$, cloud opacity, and acid concentration in the Venus near-infrared spectral windows. J. Geophys. Res., Planets 119, 1860-1891 (2014). doi:10.1002/2014JE004662

J. Bailey, A comparison of water vapor line parameters for modeling the Venus deep atmosphere. Icarus 201, 444-453 (2009). doi:10.1016/j.icarus.2009.01.013

R.J. Barber, J. Tennyson, G.J. Harris, R.N. Tolchenov, A high-accuracy computed water line list. Mon. Not. R. Astron. Soc. 368, 1087-1094 (2006). doi:10.1111/j.1365-2966.2006.10184.x

E.S. Barker, Detection of $\mathrm{SO}_{2}$ in the UV spectrum of Venus. Geophys. Res. Lett. 6, 117-120 (1979). doi:10. 1029/GL006i002p00117

J.K. Barstow, C.C.C. Tsang, C.F. Wilson, P.G.J. Irwin, F.W. Taylor, K. McGouldrick, P. Drossart, G. Piccioni, S. Tellmann, Models of the global cloud structure on Venus derived from Venus Express observations. Icarus 217, 542-560 (2012). doi:10.1016/j.icarus.2011.05.018

E.J. Barton, C. Hill, S.N. Yurchenko, J. Tennyson, A.S. Dudaryonok, N.N. Lavrentieva, Pressure-dependent water absorption cross sections for exoplanets and other atmospheres. J. Quant. Spectrosc. Radiat. Transf. 187, 453-460 (2017). doi:10.1016/j.jqsrt.2016.10.024

D. Belyaev, O. Korablev, A. Fedorova, J.-L. Bertaux, A.-C. Vandaele, F. Montmessin, A. Mahieux, V. Wilquet, R. Drummond, First observations of $\mathrm{SO}_{2}$ above Venus' clouds by means of solar occultation in the infrared. J. Geophys. Res., Planets 113, E00B25 (2008). doi:10.1029/2008JE003143

D.A. Belyaev, F. Montmessin, J.-L. Bertaux, A. Mahieux, A. Fedorova, O.I. Korablev, E. Marcq, Y.L. Yung, $\mathrm{X}$. Zhang, Vertical profiling of $\mathrm{SO}_{2}$ and $\mathrm{SO}$ above Venus' clouds by SPICAV/SOIR solar occultations. Icarus 217, 740-751 (2012). doi:10.1016/j.icarus.2011.09.025

J.-L. Bertaux, T. Widemann, A. Hauchecorne, V.I. Moroz, A.P. Ekonomov, VEGA 1 and VEGA 2 entry probes: an investigation of local UV absorption $(220-400 \mathrm{~nm})$ in the atmosphere of Venus $\left(\mathrm{SO}_{2}\right.$, aerosols, cloud structure). J. Geophys. Res. 101, 12709-12746 (1996). doi:10.1029/96JE00466

J.-L. Bertaux, A.-C. Vandaele, O. Korablev, E. Villard, A. Fedorova, D. Fussen, E. Quémerais, D. Belyaev, A. Mahieux, F. Montmessin, C. Muller, E. Neefs, D. Nevejans, V. Wilquet, J.P. Dubois, A. Hauchecorne, A. Stepanov, I. Vinogradov, A. Rodin, J.-L. Bertaux, D. Nevejans, O. Korablev, F. Montmessin, A.C. Vandaele, A. Fedorova, M. Cabane, E. Chassefière, J.Y. Chaufray, E. Dimarellis, J.P. Dubois, A. Hauchecorne, F. Leblanc, F. Lefèvre, P. Rannou, E. Quémerais, E. Villard, D. Fussen, C. Muller, E. 
Neefs, E. van Ransbeeck, V. Wilquet, A. Rodin, A. Stepanov, I. Vinogradov, L. Zasova, F. Forget, S. Lebonnois, D. Titov, S. Rafkin, G. Durry, J.C. Gérard, B. Sandel, A warm layer in Venus' cryosphere and high-altitude measurements of $\mathrm{HF}, \mathrm{HCl}, \mathrm{H}_{2} \mathrm{O}$ and $\mathrm{HDO}$. Nature 450, 646-649 (2007a). doi:10.1038/ nature 05974

J.-L. Bertaux, D. Nevejans, O. Korablev, E. Villard, E. Quémerais, E. Neefs, F. Montmessin, F. Leblanc, J.P. Dubois, E. Dimarellis, A. Hauchecorne, F. Lefèvre, P. Rannou, J.Y. Chaufray, M. Cabane, G. Cernogora, G. Souchon, F. Semelin, A. Reberac, E. Van Ransbeek, S. Berkenbosch, R. Clairquin, C. Muller, F. Forget, F. Hourdin, O. Talagrand, A. Rodin, A. Fedorova, A. Stepanov, I. Vinogradov, A. Kiselev, Y. Kalinnikov, G. Durry, B. Sandel, A. Stern, J.C. Gérard, SPICAV on Venus Express: three spectrometers to study the global structure and composition of the Venus atmosphere. Planet. Space Sci. 55, 1673-1700 (2007b). doi:10.1016/j.pss.2007.01.016

B. Bézard, C. de Bergh, Composition of the atmosphere of Venus below the clouds. J. Geophys. Res., Planets 112, 4 (2007). doi:10.1029/2006JE002794

B. Bézard, C. de Bergh, D. Crisp, J.-P. Maillard, The deep atmosphere of Venus revealed by high-resolution nightside spectra. Nature 345, 508-511 (1990). doi:10.1038/345508a0

B. Bézard, C.C.C. Tsang, R.W. Carlson, G. Piccioni, E. Marcq, P. Drossart, Water vapor abundance near the surface of Venus from Venus Express/VIRTIS observations. J. Geophys. Res., Planets 114, E00B39 (2009). doi:10.1029/2008JE003251

B. Bézard, A. Fedorova, J.-L. Bertaux, A. Rodin, O. Korablev, The 1.10- and 1.18- $\mu$ m nightside windows of Venus observed by SPICAV-IR aboard Venus Express. Icarus 216, 173-183 (2011). doi:10.1016/j.icarus. 2011.08.025

G.L. Bjoraker, H.P. Larson, M.J. Mumma, R. Timmermann, J.L. Montani, Airborne observations of the gas composition of Venus above the cloud tops: measurements of $\mathrm{H}_{2} \mathrm{O}, \mathrm{HDO}, \mathrm{HF}$, and the $\mathrm{D} / \mathrm{H}$ and ${ }^{18} \mathrm{O} /{ }^{16} \mathrm{O}$ isotopic ratios, in AAS/Division for Planetary Sciences Meeting Abstracts \#24. Bulletin of the American Astronomical Society, vol. 24, 1992, p. 995

D. Blackie, R. Blackwell-Whitehead, G. Stark, J.C. Pickering, P.L. Smith, J. Rufus, A.P. Thorne, Highresolution photoabsorption cross-section measurements of $\mathrm{SO}_{2}$ at $198 \mathrm{~K}$ from 213 to $325 \mathrm{~nm}$. J. Geophys. Res., Planets 116, 3006 (2011). doi:10.1029/2010JE003707

K. Bogumil, J. Orphal, T. Homann, S. Voigt, P. Spietz, O.C. Fleischmann, A. Vogel, M. Hartmann, H. Kromminga, H. Bovensmann, J. Frerick, J.P. Burrows, Measurements of molecular absorption spectra with the SCIAMACHY pre-flight model: instrument characterization and reference data for atmospheric remotesensing in the 230-2380 nm region. J. Photochem. Photobiol. A, Chem. 157, 167-184 (2003)

S.W. Bougher, J.C. Gerard, A.I.F. Stewart, C.G. Fessen, The Venus nitric oxide night airglow-model calculations based on the Venus Thermospheric General Circulation Model. J. Geophys. Res. 95, 6271-6284 (1990). doi:10.1029/JA095iA05p06271

S.W. Bougher, A.S. Brecht, R. Schulte, J. Fischer, C.D. Parkinson, A. Mahieux, V. Wilquet, A. Vandaele, Upper atmosphere temperature structure at the Venusian terminators: a comparison of SOIR and VTGCM results. Planet. Space Sci. 113, 336-346 (2015). doi:10.1016/j.pss.2015.01.012

A.S. Brecht, S.W. Bougher, J.-C. Gérard, C.D. Parkinson, S. Rafkin, B. Foster, Understanding the variability of nightside temperatures, NO UV and $\mathrm{O}_{2}$ IR nightglow emissions in the Venus upper atmosphere. J. Geophys. Res., Planets 116, 8004 (2011). doi:10.1029/2010JE003770

J.B. Burkholder, S.P. Sander, J. Abbatt, J.R. Barker, R.E. Huie, C.E. Kolb, M.J. Kurylo, V.L. Orkin, D.M. Wilmouth, P.H. Wine, Chemical kinetics and photochemical data for use in atmospheric studies evaluation number 18, JPL Publication 15-10, Jet Propulsion Laboratory, California Institute of Technology, Pasadena CA, 2015

R.W. Carlson, L.W. Kamp, K.H. Baines, J.B. Pollack, D.H. Grinspoon, T. Encrenaz, P. Drossart, F.W. Taylor, Variations in Venus cloud particle properties: a new view of Venus's cloud morphology as observed by Galileo Near-Infrared Mapping Spectrometer. Planet. Space Sci. 41, 477-485 (1993). doi:10.1016/ 0032-0633(93)90030-6

S. Chamberlain, J. Bailey, D. Crisp, V. Meadows, Ground-based near-infrared observations of water vapour in the Venus troposphere. Icarus 222, 364-378 (2013). doi:10.1016/j.icarus.2012.11.014

S. Chamberlain, V. Wilquet, A. Mahieux, S. Robert, I. Thomas, A.C. Vandaele, J.-L. Bertaux, Venus water vapour profiles obtained by SOIR/VEx. Geophys. Res. Abs. 17 (2015)

E. Chassefière, R. Wieler, B. Marty, F. Leblanc, The evolution of Venus: present state of knowledge and future exploration. Planet. Space Sci. 63, 15-23 (2012). doi:10.1016/j.pss.2011.04.007

B.-M. Cheng, E.P. Chew, C.-P. Liu, M. Bahou, Y.-P. Lee, Y.L. Yung, M.F. Gerstell, Photo-induced fractionation of water isotopomers in the Martian atmosphere. Geophys. Res. Lett. 26, 3657-3660 (1999). doi:10. 1029/1999GL008367

R.T. Clancy, D.O. Muhleman, Diurnal CO variations in the Venus mesosphere from CO microwave spectra. Icarus 64, 157-182 (1985). doi:10.1016/0019-1035(85)90084-3 
R.T. Clancy, D.O. Muhleman, Long-term (1979-1990) changes in the thermal, dynamical, and compositional structure of the Venus mesosphere as inferred from microwave spectral line observations of ${ }^{12} \mathrm{CO}$, ${ }^{13} \mathrm{CO}$, and $\mathrm{C}^{18}$ O. Icarus 89, 129-146 (1991). doi:10.1016/0019-1035(91)90093-9

R.T. Clancy, B.J. Sandor, G.H. Moriarty-Schieven, Venus upper atmospheric CO, temperature, and winds across the afternoon/evening terminator from June 2007 JCMT sub-millimeter line observations. Planet. Space Sci. 56, 1344-1354 (2008). doi:10.1016/j.pss.2008.05.007

R.T. Clancy, B.J. Sandor, G. Moriarty-Schieven, Thermal structure and CO distribution for the Venus mesosphere/lower thermosphere: 2001-2009 inferior conjunction sub-millimeter CO absorption line observations. Icarus 217, 779-793 (2012). doi:10.1016/j.icarus.2011.05.032

A.D. Collard, F.W. Taylor, S.B. Calcutt, R.W. Carlson, L.W. Kamp, K.H. Baines, T. Encrenaz, P. Drossart, E. Lellouch, B. Bézard, Latitudinal distribution of carbon monoxide in the deep atmosphere of Venus. Planet. Space Sci. 41, 487-494 (1993). doi:10.1016/0032-0633(93)90033-X

P. Connes, J. Connes, W.S. Benedict, L.D. Kaplan, Traces of $\mathrm{HCl}$ and $\mathrm{HF}$ in the atmosphere of Venus. Astrophys. J. 147, 1230-1237 (1967). doi:10.1086/149124

P. Connes, J. Connes, L.D. Kaplan, W.S. Benedict, Carbon monoxide in the Venus atmosphere. Astrophys. J. 152, 731-743 (1968). doi:10.1086/149590

P. Connes, J.F. Noxon, W.A. Traub, N.P. Carleton, $\mathrm{O}_{2}{ }^{1} \Delta$ emission in the day and night airglow of Venus. Astrophys. J. Lett. 233, 29-32 (1979). doi:10.1086/183070

R.R. Conway, R.P. McCoy, C.A. Barth, A.L. Lane, IUE detection of sulfur dioxide in the atmosphere of Venus. Geophys. Res. Lett. 6, 629-631 (1979). doi:10.1029/GL006i007p00629

A. Coradini, F. Capaccioni, P. Drossart, A. Semery, G. Arnold, U. Schade, F. Angrilli, M.A. Barucci, G. Bellucci, G. Bianchini, J.P. Bibring, A. Blanco, M. Blecka, D. Bockelee-Morvan, R. Bonsignori, M. Bouye, E. Bussoletti, M.T. Capria, R. Carlson, U. Carsenty, P. Cerroni, L. Colangeli, M. Combes, M. Combi, J. Crovisier, M. Dami, M.C. DeSanctis, A.M. DiLellis, E. Dotto, T. Encrenaz, E. Epifani, S. Erard, S. Espinasse, A. Fave, C. Federico, U. Fink, S. Fonti, V. Formisano, Y. Hello, H. Hirsch, G. Huntzinger, R. Knoll, D. Kouach, W.H. Ip, P. Irwin, J. Kachlicki, Y. Langevin, G. Magni, T. McCord, V. Mennella, H. Michaelis, G. Mondello, S. Mottola, G. Neukum, V. Orofino, R. Orosei, P. Palumbo, G. Peter, B. Pforte, G. Piccioni, J.M. Reess, E. Ress, B. Saggin, B. Schmitt, D. Stefanovitch, A. Stern, F. Taylor, D. Tiphene, G. Tozzi, VIRTIS: an imaging spectrometer for the ROSETTA mission. Planet. Space Sci. 46, 1291-1304 (1998)

V. Cottini, N.I. Ignatiev, G. Piccioni, P. Drossart, D. Grassi, W.J. Markiewicz, Water vapor near the cloud tops of Venus from Venus Express/VIRTIS dayside data. Icarus 217, 561-569 (2012). doi:10.1016/j.icarus. 2011.06.018

V. Cottini, N.I. Ignatiev, G. Piccioni, P. Drossart, Water vapor near Venus cloud tops from VIRTIS-H/Venus express observations 2006-2011. Planet. Space Sci. (2015)

D.V. Cotton, J. Bailey, D. Crisp, V.S. Meadows, The distribution of carbon monoxide in the lower atmosphere of Venus. Icarus 217, 570-584 (2012). doi:10.1016/j.icarus.2011.05.020

C. de Bergh, B. Bézard, T. Owen, D. Crisp, J.-P. Maillard, B.L. Lutz, Deuterium on Venus-observations from Earth. Science 251, 547-549 (1991). doi:10.1126/science.251.4993.547

C. de Bergh, B. Bézard, D. Crisp, J.P. Maillard, T. Owen, J. Pollack, D. Grinspoon, Water in the deep atmosphere of Venus from high-resolution spectra of the night side. Adv. Space Res. 15, 79 (1995). doi:10. 1016/0273-1177(94)00067-B

C. de Bergh, V.I. Moroz, F.W. Taylor, D. Crisp, B. Bézard, L.V. Zasova, The composition of the atmosphere of Venus below 100 km altitude: an overview. Planet. Space Sci. 54, 1389-1397 (2006). doi:10. 1016/j.pss.2006.04.020

M.L. Delitsky, K.H. Baines, Storms on Venus: lightning-induced chemistry and predicted products. Planet. Space Sci. (2015). doi:10.1016/j.pss.2014.12.005

T.M. Donahue, New analysis of hydrogen and deuterium escape from Venus. Icarus 141, 226-235 (1999). doi:10.1006/icar.1999.6186

T.M. Donahue, C.T. Russell, The Venus atmosphere and ionosphere and their interaction with the solar wind: an overview, in Venus II: Geology, Geophysics, Atmosphere, and Solar Wind Environment, ed. by S.W. Bougher, D.M. Hunten, R.J. Phillips, 1997, p. 3

P. Drossart, G. Piccioni, A. Adriani, F. Angrilli, G. Arnold, K.H. Baines, G. Bellucci, J. Benkhoff, B. Bézard, J.-P. Bibring, A. Blanco, M.I. Blecka, R.W. Carlson, A. Coradini, A. Di Lellis, T. Encrenaz, S. Erard, S. Fonti, V. Formisano, T. Fouchet, R. Garcia, R. Haus, J. Helbert, N.I. Ignatiev, P.G.J. Irwin, Y. Langevin, S. Lebonnois, M.A. Lopez-Valverde, D. Luz, L. Marinangeli, V. Orofino, A.V. Rodin, M.C. Roos-Serote, B. Saggin, A. Sanchez-Lavega, D.M. Stam, F.W. Taylor, D. Titov, G. Visconti, M. Zambelli, R. Hueso, C.C.C. Tsang, C.F. Wilson, T.Z. Afanasenko, Scientific goals for the observation of Venus by VIRTIS on ESA/Venus express mission. Planet. Space Sci. 55, 1653-1672 (2007). doi:10.1016/j.pss.2007.01.003 
S. Du, J.S. Francisco, B.C. Shepler, K.A. Peterson, Determination of the rate constant for sulfur recombination by quasiclassical trajectory calculations. J. Chem. Phys. 128(20), 204306 (2008). doi:10.1063/ 1.2919569

T. Encrenaz, T.K. Greathouse, H. Roe, M. Richter, J. Lacy, B. Bézard, T. Fouchet, T. Widemann, HDO and $\mathrm{SO}_{2}$ thermal mapping on Venus: evidence for strong $\mathrm{SO}_{2}$ variability. Astron. Astrophys. 543, 153 (2012). doi:10.1051/0004-6361/201219419

T. Encrenaz, T.K. Greathouse, M.J. Richter, J. Lacy, T. Widemann, B. Bézard, T. Fouchet, C. deWitt, S.K. Atreya, $\mathrm{HDO}$ and $\mathrm{SO}_{2}$ thermal mapping on Venus. II. The $\mathrm{SO}_{2}$ spatial distribution above and within the clouds. Astron. Astrophys. 559, 65 (2013). doi:10.1051/0004-6361/201322264

T. Encrenaz, R. Moreno, A. Moullet, E. Lellouch, T. Fouchet, Submillimeter mapping of mesospheric minor species on Venus with ALMA. Planet. Space Sci. 113, 275-291 (2015). doi:10.1016/j.pss.2015.01.011

T. Encrenaz, T.K. Greathouse, M.J. Richter, C. DeWitt, T. Widemann, B. Bézard, T. Fouchet, S.K. Atreya, H. Sagawa, $\mathrm{HDO}$ and $\mathrm{SO}_{2}$ thermal mapping on Venus. III. Short-term and long-term variations between 2012 and 2016. Astron. Astrophys. 595, 74 (2016). doi:10.1051/0004-6361/201628999

L.W. Esposito, R.G. Knollenberg, M.I. Marov, O.B. Toon, R.P. Turco, The clouds are hazes of Venus, in Venus, ed. by D.M. Hunten, L. Colin, T.M. Donahue, V.I. Moroz (University of Arizona Press, Tucson, 1983), pp. 484-564

L.W. Esposito, M. Copley, R. Eckert, L. Gates, A.I.F. Stewart, H. Worden, Sulfur dioxide at the Venus cloud tops, 1978-1986. J. Geophys. Res. 93, 5267-5276 (1988). doi:10.1029/JD093iD05p05267

L.W. Esposito, J.-L. Bertaux, V. Krasnopolsky, V.I. Moroz, L.V. Zasova, Chemistry of lower atmosphere and clouds, in Venus II: Geology, Geophysics, Atmosphere, and Solar Wind Environment, ed. by S.W. Bougher, D.M. Hunten, R.J. Phillips, 1997, p. 415

A. Fedorova, O. Korablev, A.C. Vandaele, J.-L. Bertaux, D. Belyaev, A. Mahieux, E. Neefs, V. Wilquet, R. Drummond, F. Montmessin, E. Villard, HDO and $\mathrm{H}_{2} \mathrm{O}$ vertical distributions and isotopic ratio in the Venus mesosphere by solar occultation at infrared spectrometer on board Venus Express. J. Geophys. Res., Planets 113, E00B22 (2008). doi:10.1029/2008JE003146

A. Fedorova, B. Bézard, J.-L. Bertaux, O. Korablev, C. Wilson, The $\mathrm{CO}_{2}$ continuum absorption in the 1.10and 1.18- $\mu \mathrm{m}$ windows on Venus from Maxwell Montes transits by SPICAV IR onboard Venus Express. Planet. Space Sci. 113, 66-77 (2015). doi:10.1016/j.pss.2014.08.010

A. Fedorova, E. Marcq, M. Luginin, O. Korablev, J.-L. Bertaux, F. Montmessin, Variations of water vapor and cloud top altitude in the Venus' mesosphere from SPICAV/VEx observations. Icarus 275, 143-162 (2016). doi:10.1016/j.icarus.2016.04.010

B. Fegley Jr., A.H. Treiman, Chemistry of the surface and lower atmosphere of Venus. Sol. Syst. Res. 26, 97 (1992)

B. Fegley Jr., G. Klingelhöfer, K. Lodders, T. Widemann, Geochemistry of surface-atmosphere interactions on Venus, in Venus II: Geology, Geophysics, Atmosphere, and Solar Wind Environment, ed. by S.W. Bougher, D.M. Hunten, R.J. Phillips, 1997, p. 591

V. Formisano, F. Angrilli, G. Arnold, S. Atreya, K.H. Baines, G. Bellucci, B. Bézard, F. Billebaud, D. Biondi, M.I. Blecka, L. Colangeli, L. Comolli, D. Crisp, M. D’Amore, T. Encrenaz, A. Ekonomov, F. Esposito, C. Fiorenza, S. Fonti, M. Giuranna, D. Grassi, B. Grieger, A. Grigoriev, J. Helbert, H. Hirsch, N. Ignatiev, A. Jurewicz, I. Khatuntsev, S. Lebonnois, E. Lellouch, A. Mattana, A. Maturilli, E. Mencarelli, M. Michalska, J. Lopez Moreno, B. Moshkin, F. Nespoli, Y. Nikolsky, F. Nuccilli, P. Orleanski, E. Palomba, G. Piccioni, M. Rataj, G. Rinaldi, M. Rossi, B. Saggin, D. Stam, D. Titov, G. Visconti, L. Zasova, The Planetary Fourier Spectrometer (PFS) onboard the European Venus Express mission. Planet. Space Sci. 54, 1298-1314 (2006). doi:10.1016/j.pss.2006.04.033

J.-C. Gérard, S.W. Bougher, M.A. López-Valverde, M. Pätzold, P. Drossart, G. Piccioni, Space Sci. Rev. 212, $1617-1683$ (2017)

G. Gilli, Carbon monoxide and temperature in the upper atmosphere of Venus through the analysis of limb observations by VIRTIS/Venus Express, PhD thesis, Instituto de Astrofísica de Andalucía, 2012

G. Gilli, M.A. López-Valverde, J. Peralta, S. Bougher, A. Brecht, P. Drossart, G. Piccioni, Carbon monoxide and temperature in the upper atmosphere of Venus from VIRTIS/Venus Express non-LTE limb measurements. Icarus 248, 478-498 (2015). doi:10.1016/j.icarus.2014.10.047

C. Gillmann, E. Chassefière, P. Lognonné, A consistent picture of early hydrodynamic escape of Venus atmosphere explaining present $\mathrm{Ne}$ and $\mathrm{Ar}$ isotopic ratios and low oxygen atmospheric content. Earth Planet. Sci. Lett. 286, 503-513 (2009). doi:10.1016/j.eps1.2009.07.016

D. Grassi, R. Politi, N.I. Ignatiev, C. Plainaki, S. Lebonnois, P. Wolkenberg, L. Montabone, A. Migliorini, G. Piccioni, P. Drossart, The Venus nighttime atmosphere as observed by the VIRTIS-M instrument. Average fields from the complete infrared data set. J. Geophys. Res., Planets 119, 837-849 (2014). doi:10. 1002/2013JE004586

D.H. Grinspoon, Implications of the high D/H ratio for the sources of water in Venus' atmosphere. Nature 363, 428-431 (1993). doi:10.1038/363428a0 
D. Grinspoon, The surface and atmosphere of Venus: evolution and present state, in Towards Understanding the Climate of Venus (Springer, Berlin, 2013), pp. 17-22

D.A. Gurnett, P. Zarka, R. Manning, W.S. Kurth, G.B. Hospodarsky, T.F. Averkamp, M.L. Kaiser, W.M. Farrell, Non-detection at Venus of high-frequency radio signals characteristic of terrestrial lightning. Nature 409, 313-315 (2001)

M.A. Gurwell, D.O. Muhleman, K.P. Shah, G.L. Berge, D.J. Rudy, A.W. Grossman, Observations of the CO bulge on Venus and implications for mesospheric winds. Icarus 115, 141-158 (1995). doi:10.1006/ icar.1995.1085

M.A. Gurwell, G.J. Melnick, V. Tolls, E.A. Bergin, B.M. Patten, SWAS observations of water vapor in the Venus mesosphere. Icarus 188, 288-304 (2007). doi:10.1016/j.icarus.2006.12.004

G.L. Hashimoto, Y. Abe, Climate control on Venus: comparison of the carbonate and pyrite models. Planet. Space Sci. 53, 839-848 (2005). doi:10.1016/j.pss.2005.01.005

G.L. Hashimoto, Y. Abe, S. Sasaki, $\mathrm{CO}_{2}$ amount on Venus constrained by a criterion of topographicgreenhouse instability. Geophys. Res. Lett. 24, 289-292 (1997). doi:10.1029/96GL04006

R. Haus, D. Kappel, G. Arnold, Lower atmosphere minor gas abundances as retrieved from Venus Express VIRTIS-M-IR data at $2.3 \mu \mathrm{m}$. Planet. Space Sci. 105, 159-174 (2015)

H.-J. Hoffmann, K. Pelka, U. von Zahn, D. Krankowsky, D. Linkert, The Pioneer Venus Bus neutral gas mass spectrometer. IEEE Trans. Geosci. Remote Sens. 18, 122-126 (1980). doi:10.1109/TGRS.1980.350294

Y. Hong, B. Fegley, Formation of carbonyl sulfide (OCS) from carbon monoxide and sulfur vapor and applications to Venus. Icarus 130, 495-504 (1997). doi:10.1006/icar.1997.5824

O.I. Iakovlev, S.S. Matiugov, V.N. Gubenko, Venera-15 and -16 middle atmosphere profiles from radio occultations_-polar and near-polar atmosphere of Venus. Icarus 94, 493-510 (1991). doi:10.1016/00191035(91)90243-M

N.I. Ignatiev, V.I. Moroz, B.E. Moshkin, A.P. Ekonomov, V.I. Gnedykh, A.V. Grigoriev, I.V. Khatuntsev, Water vapour in the lower atmosphere of Venus: a new analysis of optical spectra measured by entry probes. Planet. Space Sci. 45, 427-438 (1997). doi:10.1016/S0032-0633(96)00143-2

P.G.J. Irwin, R. de Kok, A. Negrão, C.C.C. Tsang, C.F. Wilson, P. Drossart, G. Piccioni, D. Grassi, F.W. Taylor, Spatial variability of carbon monoxide in Venus' mesosphere from Venus Express/Visible and Infrared Thermal Imaging Spectrometer measurements. J. Geophys. Res., Planets 113, E00B01 (2008). doi:10.1029/2008JE003093

V.G. Istomin, K.V. Grechnev, V.A. Kochnev, L.N. Ozerov, Composition of Venus lower atmosphere from mass-spectrometer data. Cosm. Res. 17, 581-584 (1980)

N. Iwagami, S. Ohtsuki, K. Tokuda, N. Ohira, Y. Kasaba, T. Imamura, H. Sagawa, G.L. Hashimoto, S. Takeuchi, M. Ueno, S. Okumura, Hemispheric distributions of $\mathrm{HCl}$ above and below the Venus' clouds by ground-based $1.7 \mu \mathrm{m}$ spectroscopy. Planet. Space Sci. 56, 1424-1434 (2008). doi:10.1016/j.pss. 2008.05.009

N. Iwagami, T. Yamaji, S. Ohtsuki, G.L. Hashimoto, Hemispherical distribution of CO above the Venus' clouds by ground-based $2.3 \mu \mathrm{m}$ spectroscopy. Icarus 207, 558-563 (2010). doi:10.1016/j.icarus.2009. 12.019

J.M. Jenkins, P.G. Steffes, D.P. Hinson, J.D. Twicken, G.L. Tyler, Radio occultation studies of the Venus atmosphere with the Magellan spacecraft. 2: Results from the October 1991 experiments. Icarus 110, 79-94 (1994). doi:10.1006/icar.1994.1108

K.L. Jessup, E. Marcq, F. Mills, A. Mahieux, S. Limaye, M. Allen, J.-L. Bertaux, W. Markiewicz, T. Roman, A.C. Vandaele, W. Wilquet, Y.L. Yung, Coordinated Hubble Space Telescope and Venus Express observations of Venus' upper cloud deck. Icarus 258, 309-336 (2015)

R.K. Kakar, J.W. Waters, W.J. Wilson, Venus—microwave detection of carbon monoxide. Science 191, 379 (1976). doi:10.1126/science.191.4225.379

J.F. Kasting, J.B. Pollack, Loss of water from Venus. I-Hydrodynamic escape of hydrogen. Icarus 53, 479508 (1983). doi:10.1016/0019-1035(83)90212-9

W.M. Kaula, Constraints on Venus evolution from radiogenic argon. Icarus 139, 32-39 (1999). doi:10.1006/ icar.1999.6082

R.B. Klemm, D.D. Davis, A flash photolysis-resonance fluorescence kinetics study of the reaction $\mathrm{S}\left({ }^{3} \mathrm{P}\right)+$ OCS. J. Phys. Chem. 78, 1137-1140 (1974)

A.J. Kliore, V.I. Moroz, G.M. Keating, The Venus International Reference Atmosphere. Advances in Space Research, vol. 5(11) (1985)

M.A. Kolodner, P.G. Steffes, The microwave absorption and abundance of sulfuric acid vapor in the Venus atmosphere based on new laboratory measurements. Icarus 132, 151-169 (1998). doi:10.1006/icar. 1997.5887

V.A. Krasnopolsky, Lightnings and nitric oxide on Venus. Planet. Space Sci. 31, 1363-1369 (1983). doi:10. 1016/0032-0633(83)90072-7

V.A. Krasnopolsky, Photochemistry of the Atmospheres of Mars and Venus (Springer, Berlin, 1986) 
V.A. Krasnopolsky, Uniqueness of a solution of a steady state photochemical problem: applications to Mars. J. Geophys. Res. 100, 3263-3276 (1995). doi:10.1029/94JE03283

V.A. Krasnopolsky, A sensitive search for nitric oxide in the lower atmospheres of Venus and Mars: detection on Venus and upper limit for Mars. Icarus 182, 80-91 (2006a). doi:10.1016/j.icarus.2005.12.003

V.A. Krasnopolsky, Chemical composition of Venus atmosphere and clouds: some unsolved problems. Planet. Space Sci. 54, 1352-1359 (2006b). doi:10.1016/j.pss.2006.04.019

V.A. Krasnopolsky, Chemical kinetic model for the lower atmosphere of Venus. Icarus 191, 25-37 (2007). doi:10.1016/j.icarus.2007.04.028

V.A. Krasnopolsky, High-resolution spectroscopy of Venus: detection of OCS, upper limit to $\mathrm{H}_{2} \mathrm{~S}$, and latitudinal variations of CO and HF in the upper cloud layer. Icarus 197, 377-385 (2008). doi:10.1016/ j.icarus.2008.05.020

V.A. Krasnopolsky, Spatially-resolved high-resolution spectroscopy of Venus 1. Variations of $\mathrm{CO}_{2}, \mathrm{CO}, \mathrm{HF}$, and $\mathrm{HCl}$ at the cloud tops. Icarus 208, 539-547 (2010a). doi:10.1016/j.icarus.2010.02.012

V.A. Krasnopolsky, Spatially-resolved high-resolution spectroscopy of Venus 2. Variations of HDO, OCS, and $\mathrm{SO}_{2}$ at the cloud tops. Icarus 209, 314-322 (2010b). doi:10.1016/j.icarus.2010.05.008

V.A. Krasnopolsky, Venus night airglow: ground-based detection of $\mathrm{OH}$, observations of $\mathrm{O}_{2}$ emissions, and photochemical model. Icarus 207, 17-27 (2010c). doi:10.1016/j.icarus.2009.10.019

V.A. Krasnopolsky, Atmospheric chemistry on Venus, Earth, and Mars: main features and comparison. Planet. Space Sci. 59, 952-964 (2011). doi:10.1016/j.pss.2010.02.011

V.A. Krasnopolsky, A photochemical model for the Venus atmosphere at 47-112 km. Icarus 218, 230-246 (2012a). doi:10.1016/j.icarus.2011.11.012

V.A. Krasnopolsky, Observation of DCl and upper limit to $\mathrm{NH}_{3}$ on Venus. Icarus 219, 244-249 (2012b). doi:10.1016/j.icarus.2012.02.036

V.A. Krasnopolsky, Nighttime photochemical model and night airglow on Venus. Planet. Space Sci. 85, 7888 (2013a). doi:10.1016/j.pss.2013.05.022

V.A. Krasnopolsky, $\mathrm{S}_{3}$ and $\mathrm{S}_{4}$ abundances and improved chemical kinetic model for the lower atmosphere of Venus. Icarus 225, 570-580 (2013b). doi:10.1016/j.icarus.2013.04.026

V.A. Krasnopolsky, Observations of CO dayglow at $4.7 \mu \mathrm{m}, \mathrm{CO}$ mixing ratios, and temperatures at 74 and 104-111 km on Venus. Icarus 237, 340-349 (2014). doi:10.1016/j.icarus.2014.04.043

V.A. Krasnopolsky, Vertical profiles of $\mathrm{H}_{2} \mathrm{O}, \mathrm{H}_{2} \mathrm{SO}_{4}$, and sulfuric acid concentration at $45-75 \mathrm{~km}$ on Venus. Icarus 252, 327-333 (2015). doi:10.1016/j.icarus.2015.01.024

V.A. Krasnopolsky, Sulfur aerosol in the clouds of Venus. Icarus 274, 33-36 (2016). doi:10.1016/j.icarus. 2016.03.010

V.A. Krasnopolsky, V.A. Parshev, Chemical composition of the atmosphere of Venus. Nature 292, 610-613 (1981a). doi:10.1038/292610a0

V.A. Krasnopolsky, V.A. Parshev, Photochemistry of Venus' atmosphere at altitudes over $50 \mathrm{~km}$. I-Initial calculation data. Cosm. Res. 19, 61-74 (1981b)

V.A. Krasnopolsky, V.A. Parshev, Photochemistry of the Venus atmosphere, in Venus, ed. by D.M. Hunten, L. Colin, T.M. Donahue, V.I. Moroz (University of Arizona Press, Tucson, 1983), pp. 431-458

V.A. Krasnopolsky, J.B. Pollack, $\mathrm{H}_{2} \mathrm{O}-\mathrm{H}_{2} \mathrm{SO}_{4}$ system in Venus' clouds and OCS, CO, and $\mathrm{H}_{2} \mathrm{SO}_{4}$ profiles in Venus' troposphere. Icarus 109, 58-78 (1994). doi:10.1006/icar.1994.1077

V.A. Krasnopolsky, D.A. Belyaev, I.E. Gordon, G. Li, L.S. Rothman, Observations of D/H ratios in $\mathrm{H}_{2} \mathrm{O}$, $\mathrm{HCl}$, and $\mathrm{HF}$ on Venus and new DCl and DF line strengths. Icarus 224, 57-65 (2013). doi:10.1016/ j.icarus.2013.02.010

C. Lee, S.R. Lewis, P.L. Read, Superrotation in a Venus general circulation model. J. Geophys. Res., Planets 112, 4 (2007). doi:10.1029/2006JE002874

J.S. Lewis, Venus: atmospheric and lithospheric composition. Earth Planet. Sci. Lett. 10, 73-80 (1970). doi:10.1016/0012-821X(70)90066-X

M.-C. Liang, Y.L. Yung, Sources of the oxygen isotopic anomaly in atmospheric $\mathrm{N}_{2} \mathrm{O}$. J. Geophys. Res., Atmos. 112, 13307 (2007). doi:10.1029/2006JD007876

M.-C. Liang, Y.L. Yung, Modeling the distribution of $\mathrm{H}_{2} \mathrm{O}$ and $\mathrm{HDO}$ in the upper atmosphere of Venus. J. Geophys. Res., Planets 114, E00B28 (2009). doi:10.1029/2008JE003095

M.-C. Liang, R.-L. Shia, A.Y.-T. Lee, M. Allen, A.J. Friedson, Y.L. Yung, Meridional transport in the stratosphere of Jupiter. Astrophys. J. Lett. 635, 177-180 (2005). doi:10.1086/499624

S. Limaye et al., Space Sci. Rev. (2017 submitted for publication)

V.M. Linkin, V.V. Kerzhanovich, A.N. Lipatov, A.A. Shurupov, A. Seiff, B. Ragent, R.E. Young, A.P. Ingersoll, D. Crisp, L.S. Elson, R.A. Preston, J.E. Blamont, Thermal structure of the Venus atmosphere in the middle cloud layer. Science 231, 1420-1422 (1986). doi:10.1126/science.231.4744.1420

C.-W. Lu, Y.-J. Wu, Y.-P. Lee, R.S. Zhu, M.C. Lin, Experimental and theoretical investigation of rate coefficients of the reaction $\mathrm{S}\left({ }^{3} \mathrm{P}\right)+$ OCS in the temperature range of 298-985 K. J. Chem. Phys. 125(16), 164329 (2006). doi:10.1063/1.2357739 
A. Mahieux, A.C. Vandaele, E. Neefs, S. Robert, V. Wilquet, R. Drummond, A. Federova, J.L. Bertaux, Densities and temperatures in the Venus mesosphere and lower thermosphere retrieved from SOIR on board Venus Express: retrieval technique. J. Geophys. Res., Planets 115, 12014 (2010). doi:10.1029/ 2010JE003589

A. Mahieux, A.C. Vandaele, S. Robert, V. Wilquet, R. Drummond, F. Montmessin, J.L. Bertaux, Densities and temperatures in the Venus mesosphere and lower thermosphere retrieved from SOIR on board Venus Express: carbon dioxide measurements at the Venus terminator. J. Geophys. Res., Planets 117, 7001 (2012). doi:10.1029/2012JE004058

A. Mahieux, V. Wilquet, A.C. Vandaele, S. Robert, R. Drummond, S. Chamberlain, A. Grau Ribes, J.L. Bertaux, Hydrogen halides measurements in the Venus mesosphere retrieved from SOIR on board Venus Express. Planet. Space Sci. 113, 264-274 (2015a). doi:10.1016/j.pss.2014.12.014

A. Mahieux, A.C. Vandaele, S.W. Bougher, R. Drummond, S. Robert, V. Wilquet, S. Chamberlain, A. Piccialli, F. Montmessin, S. Tellmann, M. Pätzold, B. Häusler, J.L. Bertaux, Update of the Venus density and temperature profiles at high altitude measured by SOIR on board Venus Express. Planet. Space Sci. 113, 309-320 (2015b). doi:10.1016/j.pss.2015.02.002

A. Mahieux, A.C. Vandaele, S. Robert, V. Wilquet, R. Drummond, S. Chamberlain, D. Belyaev, J.L. Bertaux, Venus mesospheric sulfur dioxide measurement retrieved from SOIR on board Venus Express. Planet. Space Sci. 113, 193-204 (2015c). doi:10.1016/j.pss.2014.12.011

B.S. Maiorov, N.I. Ignat'ev, V.I. Moroz, L.V. Zasova, B.E. Moshkin, I.V. Khatuntsev, A.P. Ekonomov, A new analysis of the spectra obtained by the Venera missions in the Venusian atmosphere. I. The analysis of the data received from the Venera- 11 probe at altitudes below $37 \mathrm{~km}$ in the $0.44-0.66 \mu \mathrm{m}$ wavelength range. Sol. Syst. Res. 39, 267-282 (2005). doi:10.1007/s11208-005-0042-1

E. Marcq, Prelude to the Venus Express mission: a study of the atmosphere using infrared spectral imaging. Theses, Université Paris-Diderot - Paris VII, 2006. https://tel.archives-ouvertes.fr/tel-00126105

E. Marcq, S. Lebonnois, Simulations of the latitudinal variability of CO-like and OCS-like passive tracers below the clouds of Venus using the Laboratoire de Météorologie Dynamique GCM. J. Geophys. Res., Planets 118, 1983-1990 (2013). doi:10.1002/jgre.20146

E. Marcq, B. Bézard, T. Encrenaz, M. Birlan, Latitudinal variations of CO and OCS in the lower atmosphere of Venus from near-infrared nightside spectro-imaging. Icarus 179, 375-386 (2005). doi:10.1016/ j.icarus.2005.06.018

E. Marcq, T. Encrenaz, B. Bézard, M. Birlan, Remote sensing of Venus' lower atmosphere from ground-based IR spectroscopy: latitudinal and vertical distribution of minor species. Planet. Space Sci. 54, 1360-1370 (2006). doi:10.1016/j.pss.2006.04.024

E. Marcq, B. Bézard, P. Drossart, G. Piccioni, J.M. Reess, F. Henry, A latitudinal survey of CO, OCS, $\mathrm{H}_{2} \mathrm{O}$, and $\mathrm{SO}_{2}$ in the lower atmosphere of Venus: spectroscopic studies using VIRTIS-H. J. Geophys. Res., Planets 113, E00B07 (2008). doi:10.1029/2008JE003074

E. Marcq, D. Belyaev, F. Montmessin, A. Fedorova, J.-L. Bertaux, A.C. Vandaele, E. Neefs, An investigation of the $\mathrm{SO}_{2}$ content of the venusian mesosphere using SPICAV-UV in nadir mode. Icarus 211, 58-69 (2011). doi:10.1016/j.icarus.2010.08.021

E. Marcq, J.-L. Bertaux, F. Montmessin, D. Belyaev, Variations of sulphur dioxide at the cloud top of Venus's dynamic atmosphere. Nat. Geosci. 6(1), 25-28 (2013)

E. Marcq, E. Lellouch, T. Encrenaz, T. Widemann, M. Birlan, J.-L. Bertaux, Search for horizontal and vertical variations of $\mathrm{CO}$ in the day and night side lower mesosphere of Venus from CSHELL/IRTF $4.53 \mu \mathrm{m}$ observations. Planet. Space Sci. 113, 256-263 (2015). doi:10.1016/j.pss.2014.12.013

H. Matsui, N. Iwagami, M. Hosouchi, S. Ohtsuki, G.L. Hashimoto, Latitudinal distribution of HDO abundance above Venus' clouds by ground-based $2.3 \mu \mathrm{m}$ spectroscopy. Icarus 217, 610-614 (2012). doi: 10. 1016/j.icarus.2011.07.026

M.B. McElroy, N. Dak Sze, Y.L. Yung, Photochemistry of the Venus atmosphere. J. Atmos. Sci. 30, 14371447 (1973). doi:10.1175/1520-0469(1973)030<1437:POTVA >2.0.CO;2

F.P. Mills, A spectroscopic search for molecular oxygen in the Venus middle atmosphere. J. Geophys. Res. 104, 30757-30764 (1999). doi:10.1029/1999JE001085

F.P. Mills, I. Observations and Photochemical Modeling of the Venus Middle Atmosphere. II. Thermal Infrared Spectroscopy of Europa and Callisto, PhD thesis, California Institute of Technology, 1998

F.P. Mills, M. Allen, A review of selected issues concerning the chemistry in Venus' middle atmosphere. Planet. Space Sci. 55, 1729-1740 (2007). doi:10.1016/j.pss.2007.01.012

F.P. Mills, M. Shunmuga Sundaram, T.G. Slanger, M. Allen, Y.L. Yung, Oxygen chemistry in the Venus middle atmosphere, in Advances in Geosciences, Volume 3: Planetary Science (PS) (World Scientific, Singapore, 2006), p. 109

F.P. Mills, L.W. Esposito, Y.L. Yung, Atmospheric Composition, Chemistry, and Clouds. Geophysical Monograph Series, vol. 176 (American Geophysical Union, Washington DC, 2007), pp. 73-100. doi:10.1029/ 176GM06 
F. Montmessin, J.-L. Bertaux, F. Lefèvre, E. Marcq, D. Belyaev, J.-C. Gérard, O. Korablev, A. Fedorova, V. Sarago, A.C. Vandaele, A layer of ozone detected in the nightside upper atmosphere of Venus. Icarus 216, 82-85 (2011). doi:10.1016/j.icarus.2011.08.010

C.G. Morgan, M. Allen, M.C. Liang, R.L. Shia, G.A. Blake, Y.L. Yung, Isotopic fractionation of nitrous oxide in the stratosphere: comparison between model and observations. J. Geophys. Res., Atmos. 109, 4305 (2004). doi:10.1029/2003JD003402

V.I. Moroz, L.V. Zasova, VIRA-2: a review of inputs for updating the Venus International Reference Atmosphere. Adv. Space Res. 19, 1191-1201 (1997). doi:10.1016/S0273-1177(97)00270-6

V.I. Moroz, V.M. Linkin, I.A. Matsygorin, D. Spaenkuch, W. Doehler, Venus spacecraft infrared radiance spectra and some aspects of their interpretation. Appl. Opt. 25, 1710-1719 (1986). doi:10.1364/AO.25. 001710

V.I. Moroz, D. Spankuch, D.V. Titov, K. Schafer, A.V. Dyachkov, W. Dohler, L.V. Zasova, D. Oertel, V.M. Linkin, J. Nopirakowski, Water vapor and sulfur dioxide abundances at the Venus cloud tops from the Venera-15 infrared spectrometry data. Adv. Space Res. 10, 77-81 (1990). doi:10.1016/0273-1177(90) 90168-Y

J.I. Moses, M.Y. Zolotov, B. Fegley, Alkali and chlorine photochemistry in a volcanically driven atmosphere on Io. Icarus 156, 107-135 (2002). doi:10.1006/icar.2001.6759

C.Y. Na, L.W. Esposito, UV observation of Venus with HST, in AAS/Division for Planetary Sciences Meeting Abstracts \#27. Bulletin of the American Astronomical Society, vol. 27, 1995, p. 1071

C.Y. Na, L.W. Esposito, T.E. Skinner, International Ultraviolet Explorer observations of Venus $\mathrm{SO}_{2}$ and $\mathrm{SO}$ J. Geophys. Res. 95, 7485-7491 (1990). doi:10.1029/JD095iD06p07485

H. Nair, M. Allen, A.D. Anbar, Y.L. Yung, R.T. Clancy, A photochemical model of the martian atmosphere. Icarus 111, 124-150 (1994). doi:10.1006/icar.1994.1137

D. Nevejans, E. Neefs, E. van Ransbeeck, S. Berkenbosch, R. Clairquin, L. de Vos, W. Moelans, S. Glorieux, A. Baeke, O. Korablev, I. Vinogradov, Y. Kalinnikov, B. Bach, J.-P. Dubois, E. Villard, Compact highresolution spaceborne echelle grating spectrometer with acousto-optical tunable filter based order sorting for the infrared domain from 2.2 to $4.3 \mu \mathrm{m}$. Appl. Opt. 45, 5191-5206 (2006). doi:10.1364/AO.45. 005191

J.M. Nicovich, K.D. Kreutter, P.H. Wine, Kinetics and thermochemistry of $\mathrm{ClCO}$ formation from the $\mathrm{Cl}+$ CO association reaction. J. Chem. Phys. 92, 3539-3544 (1990). doi:10.1063/1.457862

D. Oertel, D. Spankuch, H. Jahn, H. Becker-Ross, W. Stadthaus, J. Nopirakowski, W. Dohler, K. Schafer, J. Guldner, R. Dubois, V.I. Moroz, V.M. Linkin, V.V. Kerzhanovich, I.A. Matsgorin, A.N. Lipatov, A.A. Shurupov, L.V. Zasova, E.A. Ustinov, Infrared spectrometry of Venus from 'Venera-15' and 'Venera16'. Adv. Space Res. 5, 25-36 (1985). doi:10.1016/0273-1177(85)90267-4

J. Oschlisniok, B. Häusler, M. Pätzold, G.L. Tyler, M.K. Bird, S. Tellmann, S. Remus, T. Andert, Microwave absorptivity by sulfuric acid in the Venus atmosphere: first results from the Venus Express Radio Science experiment VeRa. Icarus 221, 940-948 (2012). doi:10.1016/j.icarus.2012.09.029

C.D. Parkinson, F. Mills, A. Brecht, S.W. Bougher, Y.L. Yung, Photochemical distribution of Venusian sulfur and halogen species, in AAS/Division for Planetary Sciences Meeting Abstracts \#42. Bulletin of the American Astronomical Society, vol. 42, 2010, p. 994

C.D. Parkinson, P. Gao, R. Schulte, S.W. Bougher, Y.L. Yung, C.G. Bardeen, V. Wilquet, A.C. Vandaele, A. Mahieux, S. Tellmann, M. Pätzold, Distribution of sulphuric acid aerosols in the clouds and upper haze of Venus using Venus Express VAST and VeRa temperature profiles. Planet. Space Sci. (2015a)

C.D. Parkinson, P. Gao, L.W. Esposito, Y.L. Yung, S.W. Bougher, M. Hirtzig, Photochemical control of the distribution of Venusian water. Planet. Space Sci. (2015b). doi:10.1016/j.pss.2015.02.015

R.O. Pepin, D. Porcelli, Origin of noble gases in the terrestrial planets. Rev. Mineral. Geochem. 47(1), 191246 (2002)

H. Pernice, P. Garcia, H. Willner, J.S. Francisco, F.P. Mills, M. Allen, Y.L. Yung, Laboratory evidence for a key intermediate in the Venus atmosphere: peroxychloroformyl radical. Proc. Natl. Acad. Sci. 101, 14007-14010 (2004). doi:10.1073/pnas.0405501101

J.B. Pollack, J.B. Dalton, D. Grinspoon, R.B. Wattson, R. Freedman, D. Crisp, D.A. Allen, B. Bézard, C. De Bergh, L.P. Giver, Q. Ma, R. Tipping, Near-infrared light from Venus' nightside—a spectroscopic analysis. Icarus 103, 1-42 (1993). doi:10.1006/icar.1993.1055

R.G. Prinn, Photochemistry of $\mathrm{HCl}$ and other minor constituents in the atmosphere of Venus. J. Atmos. Sci. 28, 1058-1068 (1971). doi:10.1175/1520-0469(1971)028<1058:POHAOM>2.0.CO;2

R.G. Prinn, Venus - chemical and dynamical processes in the stratosphere and mesosphere. J. Atmos. Sci. 32, 1237-1247 (1975). doi:10.1175/1520-0469(1975)032<1237:VCADPI >2.0.CO;2

R.G. Prinn, Venus - chemistry of the lower atmosphere prior to the Pioneer Venus mission. Geophys. Res. Lett. 5, 973-976 (1978). doi:10.1029/GL005i011p00973

R.G. Prinn, On the possible roles of gaseous sulfur and sulfanes in the atmosphere of Venus. Geophys. Res. Lett. 6, 807-810 (1979). doi:10.1029/GL006i010p00807 
R.G. Prinn, The photochemistry of the atmosphere of Venus, ed. by J.S. Levine 1985, pp. 281-336

M. Roos, P. Drossart, T. Encrenaz, E. Lellouch, B. Bézard, R.W. Carlson, K.H. Baines, L.W. Kamp, F.W. Taylor, A.D. Collard, The upper clouds of Venus: determination of the scale height from NIMS-Galileo infrared data. Planet. Space Sci. 41, 505-514 (1993). doi:10.1016/0032-0633(93)90033-X

L.S. Rothman, I.E. Gordon, Y. Babikov, A. Barbe, D. Chris Benner, P.F. Bernath, M. Birk, L. Bizzocchi, V. Boudon, L.R. Brown, A. Campargue, K. Chance, E.A. Cohen, L.H. Coudert, V.M. Devi, B.J. Drouin, A. Fayt, J.-M. Flaud, R.R. Gamache, J.J. Harrison, J.-M. Hartmann, C. Hill, J.T. Hodges, D. Jacquemart, A. Jolly, J. Lamouroux, R.J. Le Roy, G. Li, D.A. Long, O.M. Lyulin, C.J. Mackie, S.T. Massie, S. Mikhailenko, H.S.P. Müller, O.V. Naumenko, A.V. Nikitin, J. Orphal, V. Perevalov, A. Perrin, E.R. Polovtseva, C. Richard, M.A.H. Smith, E. Starikova, K. Sung, S. Tashkun, J. Tennyson, G.C. Toon, V.G. Tyuterev, G. Wagner, The HITRAN2012 molecular spectroscopic database. J. Quant. Spectrosc. Radiat. Transf. 130, 4-50 (2013). doi:10.1016/j.jqsrt.2013.07.002

C.T. Russell, T.L. Zhang, H.Y. Wei, Whistler mode waves from lightning on Venus: magnetic control of ionospheric access. J. Geophys. Res. Space Phys. 113, E00B05 (2008). doi:10.1029/2008JE003137

A. Sánchez-Lavega, S. Lebonnois, T. Imamura, P. Read, D. Luz, Space Sci. Rev. 212, 1541-1616 (2017)

S.P. Sander, D.M. Golden, M.J. Kurylo, R.E. Huie, V.L. Orkin, G.K. Moortgat, A.R. Ravishankara, C.E. Kolb, M.J. Molina, B.J. Finlayson-Pitts, Chemical kinetics and photochemical data for use in atmospheric studies-evaluation number 14. JPL Publication 02-25 (2003)

B.J. Sandor, R.T. Clancy, Water vapor variations in the Venus mesosphere from microwave spectra. Icarus 177, 129-143 (2005). doi:10.1016/j.icarus.2005.03.020

B.J. Sandor, R.T. Clancy, Observations of $\mathrm{HCl}$ altitude dependence and temporal variation in the $70-100 \mathrm{~km}$ mesosphere of Venus. Icarus 220, 618-626 (2012). doi:10.1016/j.icarus.2012.05.016

B.J. Sandor, R. Todd Clancy, G. Moriarty-Schieven, F.P. Mills, Sulfur chemistry in the Venus mesosphere from $\mathrm{SO}_{2}$ and $\mathrm{SO}$ microwave spectra. Icarus 208, 49-60 (2010). doi:10.1016/j.icarus.2010.02.013

B.J. Sandor, R.T. Clancy, G. Moriarty-Schieven, Upper limits for $\mathrm{H}_{2} \mathrm{SO}_{4}$ in the mesosphere of Venus. Icarus 217, 839-844 (2012). doi:10.1016/j.icarus.2011.03.032

A. Seiff, Thermal structure of the atmosphere of Venus, in Venus, ed. by S.W. Bougher, D.M. Hunten, R.S. Phillips (University of Arizona Press, Tucson, 1983), pp. 215-279

A. Seiff, J.T. Schofield, A.J. Kliore, F.W. Taylor, S.S. Limaye, Models of the structure of the atmosphere of Venus from the surface to 100 kilometers altitude. Adv. Space Res. 5, 3-58 (1985). doi:10.1016/ 0273-1177(85)90197-8

H. Shiina, M. Oya, K. Yamashita, A. Miyoshi, H. Matsui, Kinetic studies on the pyrolysis $\mathrm{H}_{2}$ S. J. Phys. Chem. 100, 2136-2140 (1996)

M. Shunmuga Sundaram, F.P. Mills, M. Allen, Y.L. Yung, An initial model assessment of $\mathrm{NO}_{x}$ photochemistry on Venus with heterogenous oxidation of CO, in Proceedings of the 10th Australian Space Science Conference, 2011, pp. 119-132

M. Snels, S. Stefani, D. Grassi, G. Piccioni, A. Adriani, Carbon dioxide opacity of the Venus' atmosphere. Planet. Space Sci. 103, 347-354 (2014). doi:10.1016/j.pss.2014.08.002

A.I. Stewart, D.E. Anderson, L.W. Esposito, C.A. Barth, Ultraviolet spectroscopy of Venus-initial results from the Pioneer Venus orbiter. Science 203, 777-779 (1979). doi:10.1126/science.203.4382.777

F.W. Taylor, Carbon monoxide in the deep atmospheres of Venus. Adv. Space Res. 16, 81 (1995). doi:10.1016/ 0273-1177(95)00253-B

F.W. Taylor, D. Crisp, B. Bézard, Near-infrared sounding of the lower atmosphere of Venus, in Venus II: Geology, Geophysics, Atmosphere, and Solar Wind Environment, ed. by S.W. Bougher, D.M. Hunten, R.J. Phillips, 1997, p. 325

D.V. Titov et al., Space Sci. Rev. (2017 submitted for publication)

M.V. Tonkov, N.N. Filippov, V.V. Bertsev, J.P. Bouanich, N. van-Thanh, C. Brodbeck, J.M. Hartmann, C. Boulet, F. Thibault, R. Le Doucen, Measurements and empirical modeling of pure $\mathrm{CO}_{2}$ absorption in the 2.3- $\mu \mathrm{m}$ region at room temperature: far wings, allowed and collision-induced bands. Appl. Opt. 35, 4863-4870 (1996). doi:10.1364/AO.35.004863

W.A. Traub, N.P. Carleton, Observations of $\mathrm{O}_{2}, \mathrm{H}_{2} \mathrm{O}$ and $\mathrm{HD}$ in planetary atmospheres, in Exploration of the Planetary System, ed. by A. Woszczyk, C. Iwaniszewska IAU Symposium, vol. 65, 1974, pp. 223-228

J.T. Trauger, J.I. Lunine, Spectroscopy of molecular oxygen in the atmospheres of Venus and Mars. Icarus 55, 272-281 (1983). doi:10.1016/0019-1035(83)90082-9

A.H. Treiman, M.A. Bullock, Mineral reaction buffering of Venus' atmosphere: a thermochemical constraint and implications for Venus-like planets. Icarus 217, 534-541 (2012). doi:10.1016/j.icarus.2011.08.019

C.C.C. Tsang, P.G.J. Irwin, C.F. Wilson, F.W. Taylor, C. Lee, R. de Kok, P. Drossart, G. Piccioni, B. Bézard, S. Calcutt, Tropospheric carbon monoxide concentrations and variability on Venus from Venus Express/VIRTIS-M observations. J. Geophys. Res., Planets 113, E00B08 (2008). doi:10.1029/ 2008JE003089 
C.C.C. Tsang, F.W. Taylor, C.F. Wilson, S.J. Liddell, P.G.J. Irwin, G. Piccioni, P. Drossart, S.B. Calcutt, Variability of $\mathrm{CO}$ concentrations in the Venus troposphere from Venus Express/VIRTIS using a Band Ratio Technique. Icarus 201, 432-443 (2009). doi:10.1016/j.icarus.2009.01.001

C.C.C. Tsang, C.F. Wilson, J.K. Barstow, P.G.J. Irwin, F.W. Taylor, K. McGouldrick, G. Piccioni, P. Drossart, H. Svedhem, Correlations between cloud thickness and sub-cloud water abundance on Venus. Geophys. Res. Lett. 37, 2202 (2010). doi:10.1029/2009GL041770

A.C. Vandaele, C. Hermans, S. Fally, Fourier transform measurements of $\mathrm{SO}_{2}$ absorption cross sections: II. Temperature dependence in the $29000-44000 \mathrm{~cm}^{-1}(227-345 \mathrm{~nm})$ region. J. Quant. Spectrosc. Radiat. Transf. 110, 2115-2126 (2009). doi:10.1016/j.jqsrt.2009.05.006

A.C. Vandaele, A. Mahieux, D. Belyaev, J.-L. Bertaux, A. Fedorova, A. Piccialli, R. Drummond, S. Robert, F. Montmessin, O. Korablev, V. Wilquet, I. Thomas, Composition of the Venus mesosphere: a synthesis of SOIR/VEX observations, in 40th COSPAR Scientific Assembly. COSPAR Meeting, vol. 40, 2014, p. 3469

A.C. Vandaele, A. Mahieux, S. Chamberlain, S. Robert, I. Thomas, L. Trompet, V. Wilquet, J.-L. Bertaux, Carbon monoxide observed on Venus with SOIR/VEx. Planet. Space Sci. (2015a)

A.C. Vandaele, A. Mahieux, S. Robert, R. Drummond, V. Wilquet, J.L. Bertaux, Carbon monoxide short term variability observed on Venus with SOIR/VEX. Planet. Space Sci. 113, 237-255 (2015b). doi:10.1016/ j.pss.2014.12.012

A.C. Vandaele, O. Korablev, D. Belyaev, S. Chamberlain, T. Encrenaz, L.W. Esposito, K.L. Jessup, F. Lefèvre, S. Limaye, A. Mahieux, E. Marcq, F. Mills, C.D. Parkinson, S. Robert, B. Sandor, A. Stolzenbach, C.F. Wilson, V. Wilquet, Sulphur dioxide variability in the Venus atmosphere. Planet. Space Sci. (2017)

U. von Zahn, V.I. Moroz, Composition of the Venus atmosphere below $100 \mathrm{~km}$ altitude. Adv. Space Res. 5, 173-195 (1985). doi:10.1016/0273-1177(85)90201-7

U. von Zahn, S. Kumar, H. Niemann, R. Prinn, Composition of the Venus atmosphere, in Venus, ed. by D.M. Hunten, L. Colin, T.M. Donahue, V.I. Moroz (University of Arizona Press, Tucson, 1983), p. 299

B.A. Voronin, J. Tennyson, R.N. Tolchenov, A.A. Lugovskoy, S.N. Yurchenko, A high accuracy computed line list for the HDO molecule. Mon. Not. R. Astron. Soc. 402, 492-496 (2010). doi:10.1111/j.13652966.2009.15904.x

J.R. Winick, A.I.F. Stewart, Photochemistry of $\mathrm{SO}_{2}$ in Venus' upper cloud layers. J. Geophys. Res. 85, 78497860 (1980). doi:10.1029/JA085iA13p07849

L.D.G. Young, High resolution spectra of Venus—a review. Icarus 17, 632-658 (1972). doi:10.1016/00191035(72)90029-2

Y.L. Yung, W.B. DeMore, Photochemistry of the stratosphere of Venus-implications for atmospheric evolution. Icarus 51, 199-247 (1982). doi:10.1016/0019-1035(82)90080-X

Y.L. Yung, W.B. Demore, Photochemistry of Planetary Atmospheres (Oxford University Press, New York, 1999)

Y.L. Yung, M.C. Liang, X. Jiang, R.L. Shia, C. Lee, B. Bézard, E. Marcq, Evidence for carbonyl sulfide (OCS) conversion to CO in the lower atmosphere of Venus. J. Geophys. Res., Planets 114, E00B34 (2009). doi:10.1029/2008JE003094

L.V. Zasova, The structure of the Venusian atmosphere at high latitudes. Adv. Space Res. 16, 89 (1995). doi:10.1016/0273-1177(95)00254-C

L.V. Zasova, V.I. Moroz, L.W. Esposito, C.Y. Na, $\mathrm{SO}_{2}$ in the middle atmosphere of Venus: IR measurements from Venera-15 and comparison to UV data. Icarus 105, 92-109 (1993). doi:10.1006/icar.1993.1113

L.V. Zasova, V.I. Moroz, V.M. Linkin, Venera-15, 16 and VEGA mission results as sources for improvements of the Venus reference atmosphere. Adv. Space Res. 17, 171-180 (1996). doi:10.1016/02731177(95)00747-3

L.V. Zasova, V.I. Moroz, V.M. Linkin, I.V. Khatuntsev, B.S. Maiorov, Structure of the Venusian atmosphere from surface up to $100 \mathrm{~km}$. Cosm. Res. 44, 364-383 (2006). doi:10.1134/S0010952506040095

$\mathrm{X}$. Zhang, On the decadal variation of sulfur dioxide at the cloud top of Venus, in 40th COSPAR Scientific Assembly. COSPAR Meeting, vol. 40, 2014, p. 3800. Held 2-10 August 2014, in Moscow, Russia, Abstract B0.7-9-14

X. Zhang, M.-C. Liang, F. Montmessin, J.-L. Bertaux, C. Parkinson, Y.L. Yung, Photolysis of sulphuric acid as the source of sulphur oxides in the mesosphere of Venus. Nat. Geosci. 3, 834-837 (2010). doi:10.1038/ngeo989

X. Zhang, M.C. Liang, F.P. Mills, D.A. Belyaev, Y.L. Yung, Sulfur chemistry in the middle atmosphere of Venus. Icarus 217, 714-739 (2012). doi:10.1016/j.icarus.2011.06.016 